\title{
Maglemose
}

\section{Ein steinzeitlicher Wohnplatz im Moor bei Mullerup auf Seeland, verglichen mit verwandten Funden}

\author{
Beitrag zur Beleuchtung der frühneolithischen Steinzeit im Norden \\ Von Georg F. L. Sarauw, Kopenhagen \\ Aus dem Dänischen ${ }^{1}$ ) übertragen von IIse II u l I
}

\section{Ein le it ung:}

\section{Lage der Fundstelle und Geschichte der Untersuchung}

An der Westküste Seelands, am Grossen Belt, auf halbem Wege zwischen Kallundborg und Korsör liegt der kleine Hafenort Mullerup Havn.

Vom Meeresufer erhebt sich das Land zu einem Höhenzug, der der Küste folgend bei Drösselbjerg bis zu $45 \mathrm{~m}$ über dem Meeresspiegel ansteigt. Auf der Strecke zwischen dieser höchsten Erhebung und dem nördlicher. ungefähr $19 \mathrm{~m}$ über dem Meere gelegenen Dorf Mullerup ist der Höhenrücken nur $2,5 \mathrm{~km}$ breit, indem er hier im Osten von einem grossen, tief gelegenen Moorstrich, einem ,Niedermoor", begrenzt ist, das von der Böstrup-Au ${ }^{2}$ ) durchflossen wird.

Wegen seiner Grösse wird das Moor Mag le mos e genannt. Das ostdänische Wort $\mathrm{magle}$, wie das jütländische $\mathrm{mögel}$, entspricht dem altnordischen mikill, althochdeutschen $\mathrm{michil}$ und bedeutet ,gross“; es ist aber heute nur noch in Ortsnamen erhalten. Im Namen Me ckle nb u rg begegnet uns dasselbe Wort. Dänisch m ose heisst Moor.

Maglemose ${ }^{3}$ ) ist geteilt zwischen dem Rittergute Böstrup und den Dörfern Mullerup und Löve, wonach die einzelnen Teile benannt sind. Die beigefügte Karte (Abb. 1) gibt einen Ùberblick über das Flussgebiet, zu dem das Moor gehört. Es ist in dessen südlichem Abschnitt gelegen.

1) Die in den ,Aarböger for nordisk Oldkyndighed og Historie“ 1903 erschienene Original. abhandlung liegt hier in einer vom Verfasser revidierten Gestalt vor. Die darin verwendeten Klischees wurden von der $\mathrm{Kgl}$. nordiske Oldskrift-Selskab gütigst zur Verfügung gestellt. An diese Gesellschaft und an die Verwaltungen der vielen Museen in Dänemark, Schweden, Deutschland, Belgien und Frankreich sowie an Privatpersonen, die mir das Studien- und das sonstige Abbildungsmaterial geliefert haben, sei auch an dieser Stelle mein ergebenster Dank gerichtet.

G. S.

2) Nicht ohne Vorbehalt wird hier, dem schleswigschen Sprachgebrauch folgend, das dänische $A a$ „Bach“ durch $A u$ wiedergegeben. Eigentlich entspricht deutsch $A u$ dem

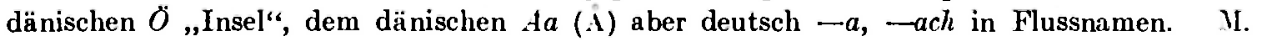

3) Vgl. Generalstabskarte „Slagelse“ nebst Trap: Beskrivelse af Danmark. 3. Ausg. Bd. 2, Köbenhavn 1898, S. 465, 471 und hierzu Klingseys Atlas, wo der Name angeführt ist. 
Auf einer der Parzellen in dem zu Mullerup gehörenden westlichen Teile (les Moores ${ }^{1}$ ) hatte man beim Torfstechen in den letzten zehn Jahren beständig Altertümer aus Knochen und Horn und eine Menge Flintabfälle gefunden, deren Vorhandensein namentlich deshalb bemerkt worden war, weil sie das Kneten der Torfmasse beschwerlich machten, indem sie die Hände und Füsse der Arbeiter zerschnitten.

Der Fund war jedoch unbeachtet geblieben und nur eine ganz geringe Anzahl von Gegenständen aufbewahrt worden bis zum letzten Mai 1900,

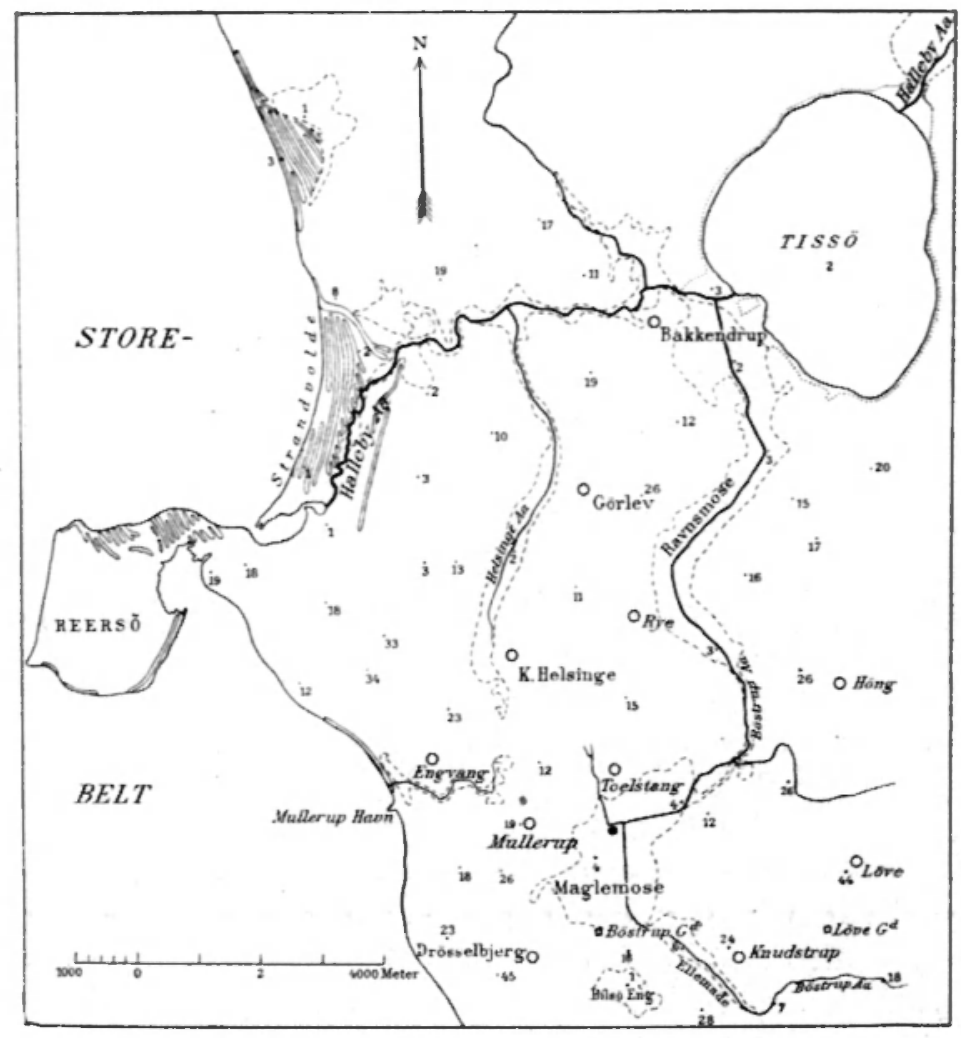

Abb. 1. Übersichtskarte.

Das Zuflussgebiet der Halleby-Au von dem Tissö bis zum Grossen Belt (Store-Belt). Südlich liegt II a g le mose, von der Böstrup-Au durchflossen. Die Moorränder sind durch Strichlinien, die alten Uferwälle (Strandvolde) durch volle Linien angedeutet. (Nach der geologischen Karte „Kaiundborg“: Danmarks geologiske Undersögelse. I. Række Nr. 8, Köbenhavn 1900). Die Zahlen (Höhenziffern) geben die Höhen in Metern über dem Meere an. Ein • in Maglemose bezeichnet die Lage des steinzeitlichen Wohnplatzes.

an welchem Tage der Lehrer M. J. Mathiassen in Mullerup von einem Torfgräber einige kurz vorher gefundene Knochengeräte erhielt. Mathiassen untersuchte unmittelbar danach die Stelle und fand zahlreiche zum Zweck der Markgewinnung gespaltene Knochen, den Zapfen eines Urstierhornes,

4) Zugehörig dem Hofe Kataster Nr. 7 vom Dorf Mullerup, Kirchspiel Drösselbjerg. Harde Löve, Amt Holbrek. 
verkohltes Holz, Flintabfälle, Knochenspitzen u. a. m., was ihn vermuten liess, dass hier ein steinzeitlicher Kökkenmödding (Abfallhaufen) von besonderer Art vorläge. Noch am selben Tage verständigte er das Nationalmuseum zu Kopenhagen, und da seine Beschreibung, welche die Fundverhältnisse vortrefflich klarlegte, einen Fund von seltener Art und Bedeutung erwarten liess, traf das Museum sofort Anstalten zu einer umfassenden Untersuchung, deren Ausbeute im folgenden rorgeführt werden soll. An der Untersuchung, die vom 8. bis 29. Juni 1900 währte, beteiligten sich ausser dem Verfasser dieser Abhandlung der norwegische Archäologe cand. philol. Theodor Petersen aus Drontheim und der Konservator des Nationalmuseums G. A. Rosenberg.

\section{I e r P l a t z}

\section{Beschaffenheit des Moores}

Das Moor Maglemose ist gegen 300 ha gross; seine Oberfläche. welche ungefähr $4 m$ über dem Meeresspiegel liegt, ist jetzt so fest, dass es mit Wagen und Lasten befahren wird; dieser Zustand ist aber erst in der letzten Zeit eingetreten. nachdem Arbeiten für eine verbesserte Wasserableitung ausgeführt sind.

Durch die Böstrup-Au, die das Moor durchfliesst, wird das Wasser in nördlicher Richtung auf einem $9 \mathrm{~km}$ langen Weg in die Halleby-Au abgeleitet, nahe bei ihrem Ausfluss aus dem Tissö, ${ }^{1}$ ) dessen Wasserspiegel nur $2 m$ über dem Meere liegt. Der See wird von der Halleby-Au durchströmt, die für das ganze Flussgebiet den Ablauf gegen Westen zum Grossen Belt auf einer $10 \mathrm{~km}$ langen Strecke bildet. Das Wasser aus dem Maglemose hat somit einen langen Weg bis zum Meer, und das Gefälle ist nur gering (Abb. 1).

Die obere Schicht besteht überall im Moor aus Torf; dieser wird als Brennmaterial benutzt, das in der Regel durch Kneten des Torfes hergestellt wird; das angewandte Verfahren ist von deutschen Torfstechern gelernt. weshalb dieser Streichtorf ,Tyskertörv", d. h. „Deutschen-Torf", genannt wird. Nur seltener eignet sich der Torf zur Gewinnung von Stichtorf.

Die Tiefe des Moorgrundes und damit die Dicke der'Torfschicht ist sehr verschieden; so war der Torf nahe dem Rand gegen Osten zu sehr tief, aber weiter hinaus fanden sich Strecken, wo die Schicht nur $1 / 2$ bis $1 m$ dick oder sogar noch dünner war. Wo an solchen Stellen der Torf weggeschnitten war, trat darunter die Oberfläche einer Schicht Wiesenmergel oder Schneckenmudde zutage, die im wesentlichen aus Schalen von kleinen Schnecken und Muscheln bestand, die man allgemein in unsern Süsswasserseen antrifft. Dass die so blossgelegte Fläche, aus zahllosen weissen Schneckenschalen bestehend, auf die man nun hier mit Füssen trat, der Grund eines ehemaligen Sees sein musste, in dessen Wasser der Torf abgesetzt war, konnte für

1) Die "Auen“ fliessen in einer Entfernung ron ungefähr $300 \mathrm{~m}$ vom westlichen Ufer des Sees zusammen. Ursprünglich hat der See sicher bis hierher und sogar weiter nach Westen gereicht; aber ein von dem See angeschwemmter schmaler Sandstreifen trennt jetzt den Tissö von der Böstrup-Au. 
den Beobachter von Anfang an nicht zweifelhaft sein und ist auch durch die spätere genauere Untersuchung bestätigt worden.

I)ie Ausfüllung des Sees mit Torf oder richtiger der Teil der Torfbildung, der ron Sumpfpflanzen herrührt, muss vom Rande des Niedermoores, vom Seeufer und von Inselchen ausgehend und sich in den verschlammten See fortsetzend gedacht werden, ${ }^{1}$ ) während der Wald allmählich auf dem trockengelegten Ufergürtel vorrückte. Das Vorkommen von Baumstubben, die an verschiedenen Stellen aus dem Torf gegraben werden, gibt Zeugnis dafür, dass es auf jeden Fall zu einer bestimmten Zeit an diesen Stellen hinreichend trocken gewesen ist, dass hier Bäume haben wachsen können, während sich später über dem Waldboden jüngerer Torf gebildet hat, wohl weil das Wasser durch das fortgesetzte Verwachsen des Sees wieder gestaut wurde.

Auf einer Strecke gegen Nordwesten im Moor standen die Stubben, von denen durch das Zusammensinken dieser Torfschicht und durch das Torfstechen der umgebende und deckende Torf entfernt worden war, so dicht, dass sie, falls sie aus gleicher Zeit stammten, einmal einen Wald gebildet haben mussten. Auch weiter nach Nordosten und Osten im Moor waren Baumstrünke zu bemerken; sie standen alle in der Torfschicht, etwas über der Schneckenmudde. Nach der Beschaffenheit sowohl des Holzes als auch der Rinde war die. Holzart leicht zu bestimmen. Alles, was ich an jenen Stellen zu sehen Gelegenheit fand, war Kiefer (Pinus silvestris L.). Die Strünke waren oben nicht verkohlt, die Bäume also nicht durch Feuer gefällt, wie man es sonst in unseren Mooren oft beobachten kann.

Ausser den erwähnten, vom Verfasser angetroffenen Stellen können im Maglemose noch eine Reihe anderer nachgewiesen werden, wo die Strünke sich noch finden oder nachweisbar in der letzten Zeit erst entfernt worden sind.

Auf mein Ersuchen ist Lehrer Mathiassen mit grosser Sorgfalt dieser Sache nachgegangen. Es hat sich gezeigt, dass sich in Wurzeln stehende Stubben, ganz wie zu vermuten war, in einem Gürtel längs dem Rande des Moores fanden, namentlich in dessen westlichem Teil, während sie weiter drinnen fehlten. Im ganzen liessen sich 253 Baumstrünke nachweisen, davon 152 in einem Gürtel nördlich von der Wohnstätte und in nur 100 bis $300 \mathrm{~m}$ Abstand von ihr. Ausserdem wusste man bestimmt, dass viele andere Strünke aufgepflügt worden waren. Die Holzart war fast ausschliesslich Kiefer, nur ein einziger Birkenstrunk fand sich. (Proben des Holzes habe ich anatomisch untersucht). Die untere Dicke der Stämme schwankte zwischen ungefähr 5 und $40 \mathrm{~cm}$; am häufigsten betrug sie ungefähr 15 bis $20 \mathrm{~cm}$. Ǔber den Wald wird im übrigen weiter unten eingehender gesprochen werden.

1) Uber dänische Niedermoore, die sich in flachen Süsswasserseen oder um Wasserläufe herum bilden, siehe J. H. C. Dau: Die Torfmoore Seelands. Kopenhagen 1829, S. 8. Jap. Steenstrup: Skovmoserne Vidnesdam- og Lillemose. Köbenhavn 1841, 4 ${ }^{\circ}$, S. 99, 111 und K. Rördam in Danmarks geologiske Undersögelse. I. Reihe, Nr. 1, S. 66; I. Reihe, Nr. 8, S. 127; II. Reihe, Nr. 2, S. 67. 
Im Maglemose ist wenigstens während der letzten zwei Jahrhunderte. wahrscheinlich jedoch viel länger, Torf gestochen worden. Bestimmte Aufklärungen hierüber hat Mathiassen beim Untersuchen von Urkunden im Böstrupper Gutsarchiv gefunden.

Das dort erwähnte Torfstechen hat hiernach wahrscheinlich in der Nähe des Wohnplatzes stattgefunden; die Grundparzelle, auf der dieser liegt. hat früher zum Gut Böstrup gehört; möglicherweise ist sogar damals schon auch auf der Wohnstätte selbst Torf gestochen worden. Böstrup hat wohl seit der Errichtung des Rittergutes (um 1660) seinen Torfstich namentlich im südlichen Teil des Moores gehabt. Das Moor wird schon auf Karten von 1771 und 1772 als Magle Mo e s e bezeichnet.

In älterer Zeit hat man beim Torfstechen nicht so tief zu graben vermocht wie jetzt. Erst 1892 fand die Veränderung im Zustand des Moores statt, die die Ausnützung tieferer Lagen möglich gemacht hat. Die Au, die ihre Quelle im SO. hat und die zuerst die Moore Ellem ade und K nudstrup Mose durchströmt (Abb. 1), hat man damals tiefer gelegt, den Hauptgraben gereinigt und mehrere ntue Gräben ausgehoben. Hierdurch sank das Grundwasser um etwa $0,6 \mathrm{~m}$. Während das Wasser im Hauptgraben und in den nahegelegenen Torfstichen im Juni 1900 bei 3,10 bis $3,20 \mathrm{~m}$ stand und im November 1901 im Graben $3,16 \mathrm{~m}$ über dem Meeresspiegel erreichte, betrug also der Stand des Grundwassers vor 1892 ungefähr 3,70 bis $3,80 m$ über dem Meeresspiegel. Da aber die Oberfläche des Moores durchschnittlich $4 \mathrm{~m}$ über dem Meeresspiegel liegt (vgl. unten S. 59), so ist der Abstand zwischen der Oberfläche und dem Grundwasser früher nur gering gewesen. Die Senkung des. Wasserstandes machte die Oberfläche trocken und fest. Früher konnte man in dem nördlichen Teil des Moores nicht mit Wagen fahren und musste sogar das geerntete Heu mehrere hundert Meter weit zum festen „Holm" südlich im Moore in den Armen tragen. In älterer Zeit geriet das Vieh oft in den Morast hier draussen und kam um, wenn es nicht von den durch ein Horn herbeigerufenen Frohnbauern gerettet wurde. Für die Wahrheit dieses Berichtes, der von einem alten Manne stammt, der die Tage des Frohndienstes auf Böstrup-Hof erlebt hat, zeugen wohl einige, zum Teil zusammengehörige Skeletteile von Kälbern, die sich bei der vom Museum unternommenen Grabung in der obersten Torfschicht fanden, und die schon durch ihr Äusseres von den Knochen in der Altertümerschichte abwichen.

Bis zur letzten Zeit stand das Moor im Winter in der Regel unter Wasser und war der Versammlungsort grosser Entenschwärme. Bei plötzlichem Tauwetter im Frühjahr soll das Wasser verschiedene Male so hoch gestiegen sein, dass es in die Häuser am Rande des Moores drang, also eine Höhe von mindestens $5 m$ über dem Meeresspiegel erreicht haben. ${ }^{1}$ )

1) Nachdem der Wasserspiegel gesenkt worden, wird eine solche Höhe jetzt nicht mehr erreicht. Bei der Frühjahrsschmelze im Februar 1903 fand Mathiassen, dass der Wasserstand $3,47 m(3,46$ bis 3,48 $m$ ) über dem Meeresspiegel betrug, ein Unterschied also von $0,30 m$ gegen den Sommer. 


\section{Der Wohnplatz}

Nach der ganzen Art des Fundes, nach den Altertümern und den verschiedenen Abfällen ist die Fundstelle als ein steinzeitlicher Wohnplatz aufzufassen.

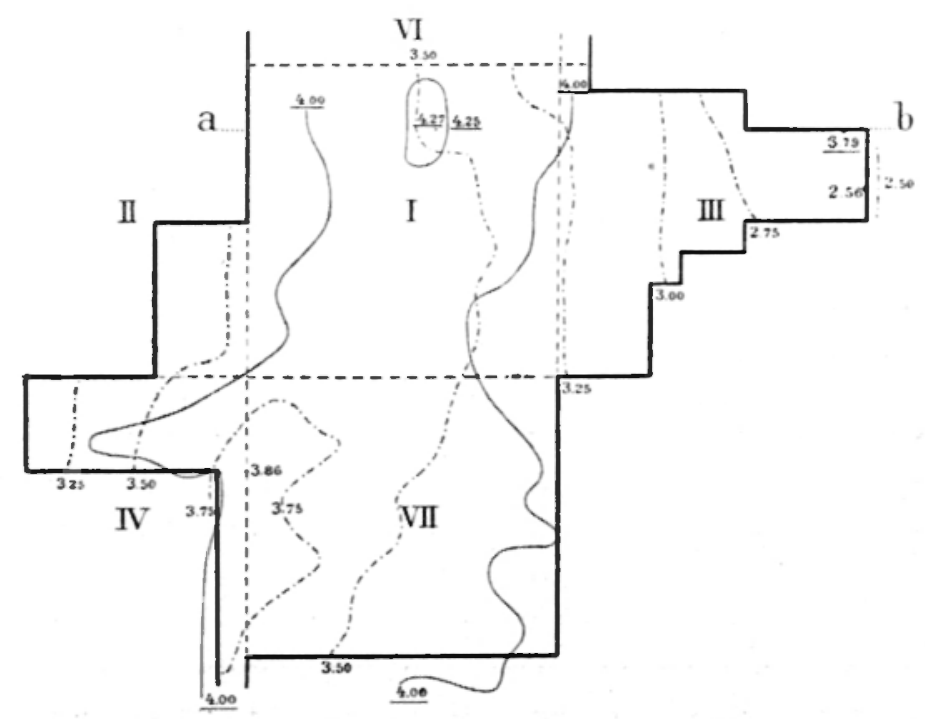

Abb. 2. Die Höhenverhältnisse des Mooresauf dem Wohnplatze.

Die vollen Kurven und die unterstrichenen Zahlen (Höhen über dem Meere) bezeichnen die Oberfläche; die Strichlinien-Kurven mit zugehörigen Zahlen beziehen sich auf die Unterfläche des Torfes (bezw: die Oberfläche der Schneckenmudde). Der dunkle Rand gibt die Grenze der untersuchten Fläche an.

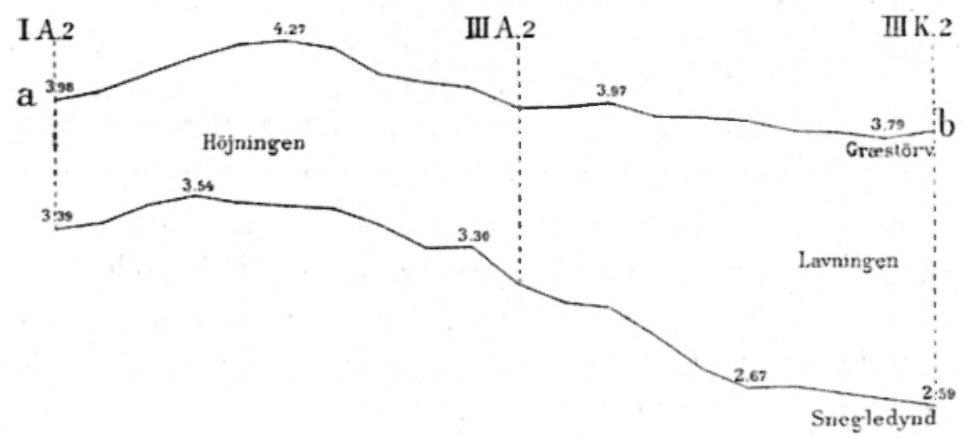

Abb. 3. Profil.

Schnitt durch den höchsten Punkt des Wohnplatzes in der Richtung W.-O. nach der Linie $a-b$ (siehe $A b b .2)$. Die Länge von $a-b=19 m$. Das Verhältnis der Höhen zu den Längen ist im Masstab wie 5 zu 1. „Höjningen“ heisst: Erhebung, Anhöhe, „Lavningen“: Niederung, „Græstörv": Grasnarbe, Rasen, „Snegledynd“: Schneckenmudde.

Die Lage des Wohnplatzes kann nun auf folgende Weise näher bezeichnet werden.

Die Grenze des Kirchspiels Drösselbjerg folgt auf einer langen Strecke durch das Moor einem Hauptgraben, der von Norden kommt und darauf 
gegen Ostnordost zur Böstrup-Au abbiegt, welche die weitere Grenze in südlicher Richtung bildet.

Der Wohnplatz stiess unmittelbar an die Kirchspielgrenze, ungefähr in der Mitte und südlich von dem kurzen Stück des Grenzgrabens, das die Richtung WSW.-ONO. zeigt. Die Stelle ist hiernach leicht auf der Karte zu finden und ist auf unseren Abb. 1 und 12 angegeben.

Bis zum Rand des Moores war ziemlich weit; das nächste „feste Land“ traf man in der Richtung gegen Nordwesten. Von dem nächsten Punkt der 5 \% Höhenkurve nach dieser Seite zu betrug der Abstand zum Wohnplatze ungefähr $350 \mathrm{~m}$.

Eine feste Verbindung mit dem Rande des Moores hat der Wohnplatz ursprünglich nach keiner Richtung gehabt. Jetzt führten Wegspuren bis dicht an die Stelle teils vom Norden, teils in einem

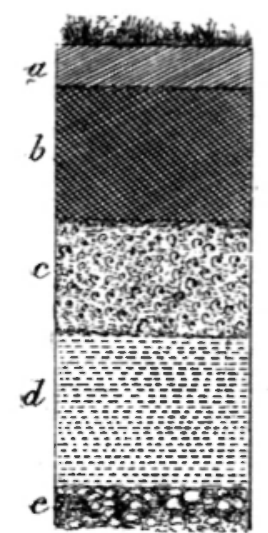

Abb. 4. Profil der Moorschiohten. $a$ Grasnarbe. $b$ Torf. $c$ Sohneckenmudde. $d$ Mudde. $e$ Ton und Sand mit grösserem oder kleinerem Gerölle. 1 . nat. Gr. (Raum VII E 2; vgl. Tab. I) grösseren Bogen von Nordwesten quer über das Moor.

Auf dem Platze selbst trat eine schwache Erhöhung in der grasbewachsenen Oberfläche des Moores zutage. Die Erhöhung hatte in der Länge eine Richtung von N.-S. und hob sich 15 bis $25 \mathrm{~cm}$ innerhalb eines Gürtels von ungefähr $10 \mathrm{~m}$ Breite; ausserhalb desselben verlor sie sich unmerklich in der Oberfläche.

Ihr entsprach, wie die umfassenden Nivellierungen ergaben, eine Erhöhung auf dem Grunde des Torfmoores. Der Rücken des Grundes lag etwas westlicher, sein höchster Punkt etwas südlicher als der der Oberfläche, und seine Seiten neigten sich bedeutend stärker, mit $1 m$ Gefälle auf 10 bis $15 m$, gegen Osten und Westen (Abb. 2).

An der höchsten Stelle des Grundes war die Torfschicht nur $17 \mathrm{~cm}$ dick; $20 \mathrm{~m}$ weiter nach Osten erreichte man den Grund hingegen erst unter einer Torfschicht von 1,24 $m$ Dicke (die Grasnarbe mit eingerechnet; vgl. umstehende Tabelle I). Der Sachverhalt ist aus vorstehendem Profil. Querdurchschnitt von Osten nach Westen durch den Platz an dem

höchsten Punkt der Oberfläche, ersichtlich (Abb. 3).

Der Seeboden hatte an dieser Stelle eine von Norden nach Süden sich ziehende Erhöhung gebildet, sicher eine der höchsten Bodenstellen, die sich im See fanden, ehe dieser zuwuchs.

Die oberste Schicht des Torfes war mit Graswurzeln durchwachsen und stark vermodert. An dieser Umwandlung war sicher die grosse Menge von Regenwürmern, die in der Schicht vorkamen, in erster Linie schuld.

Unter dem Torf folgte Schneckenmudde, darauf Mudde ohne zutage tretende Schalenreste und darunter endlich Gerölle, feiner blauer Ton oder Sand, welcher die oberste Eiszeitablagerung bildete. Obenstehendes Profil, Abb. 4, gibt Aufschluss hierüber. 
Die Schichtenfolge ist deutlich auf der Photographie Abb. j ersichtlich, die einen senkrechten Schnitt durch den östlichen Teil der Wohnstätte zeigt. In der Schneckenmudde eingebettet liegen in der Wand unten zwei deutlich erkennbare Knochenstücke.

\section{Die Schichtenfolge und Mächtigkeit der Schichten}

erhellt aus nachstehender $\mathrm{C}^{\mathrm{b}}$ bersicht über eine kleine Auswahl der gemessenen Profile (Tabelle I). Die Bezeichnung der Messpunkte bezieht sich auf die Einteilung der Fläche, die weiter unten erklärt werden wird.

Die Höhe über dem Meeresspiegel ron der Oberfläche und dem Grunde des Moores, wie auch die Mächtigkeit der Schichten ist in Metern ange-

Tabelle I. 'Schichtenfolge

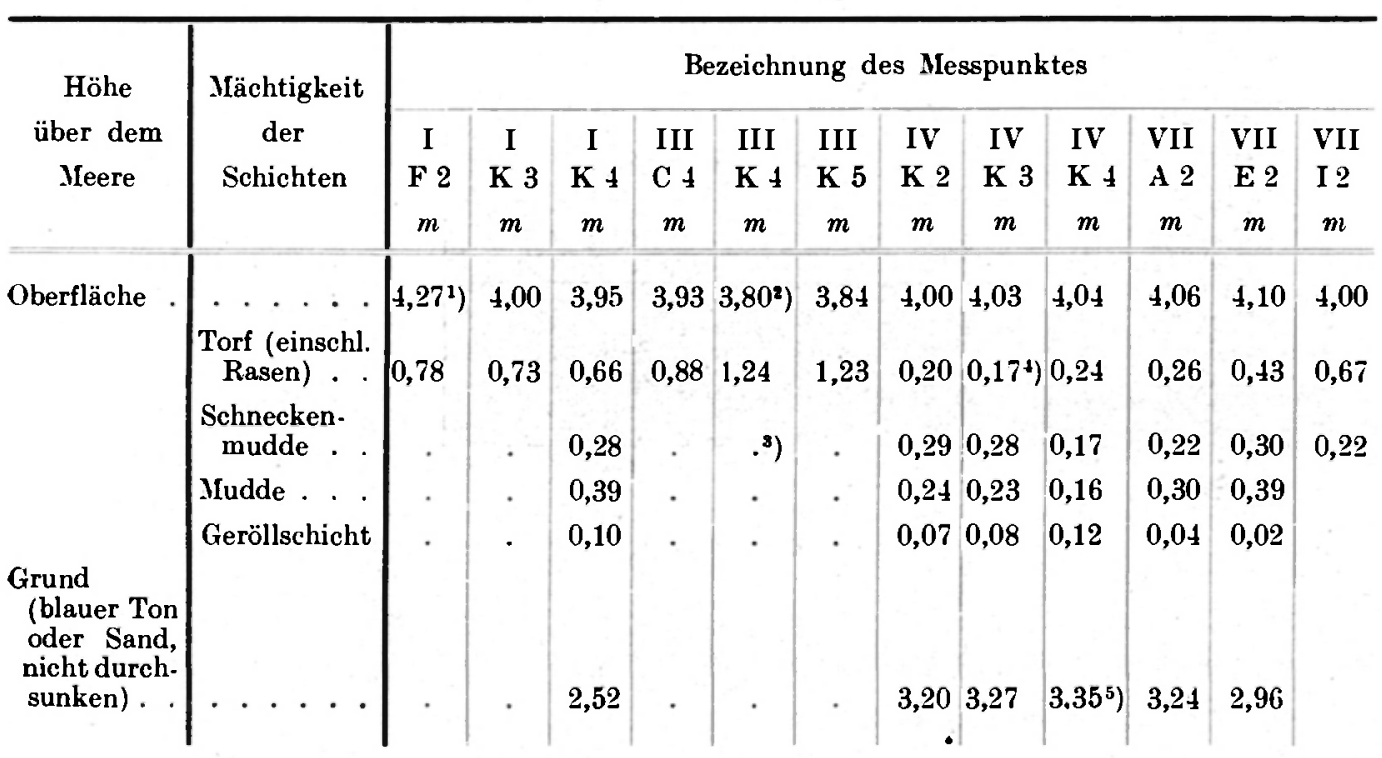

geben. Die Zahlen für die Höhe stehen in richtigem Verhältnis zueinander, sind aber mit einem ,systematischen" Fehler behaftet, da keine Gelegenheit gewesen ist, die Höhe des Ausgangspunktes über Normal-Null genau zu bestimmen.

Auf der Generalstabsmesstischkarte $c 4$ ist die Höhe der Oberfläche nur an fünf Punkten im Moore angegeben, und diese Kotenpunkte sind allę auf $4 \mathrm{~m}$ festgesetzt. Hiernach habe ich denn auch die mittlere Höhe inner-

1) Höchster Punkt in der Oberfläche des Wohnplatzes.

2) Der niedrigste Punkt in der Oberfläche des Wohnplatzes, 3,79 $\mathrm{m}$ über dem Meere, ist dicht dabei.

3) Hier war der Torf am dicksten, die Oberfläche der Schneckenmudde am tiefsten gelegen, indem sie nur bis 2,56 $m$ über dem Meere reichte (vgl. Abb. 2).

4) Hier war die Torfschicht am dünnsten, die Oberfläche der Schneckenmudde am hochsten gelegen, indem sie bis $3,86 \mathrm{~m}$ über dem Meere reichte.

j) Der höchste Punkt des Grundes unter der Mudde. 
halb des Wohnplatzes bewertet. Der hierbei begangene Fehler kann nicht gross sein; aus einer Nivellierung von mehreren Punkten am Rande des Moores, von denen anzunehmen ist, dass sie in der $5 \mathrm{~m}$-Kurve liegen, schien hervorzugehen, dass alle Höhenzahlen um ungefähr $0,40 m$ zu erhöhen wären. Es ist selbstverständlich, dass alle Höhenangaben für Punkte i n n e r hal b des Moores von dem gleichen Ausgangspunkt gerechnet sind.

Der Boden des Beckens, in dem die Ablagerungen des Sees, bzw. Mudde und Torf, ausgefällt waren, bestand aus feinem, steinfreiem, blauem Ton, der stellenweise auf Sand oder Schotter lagerte. Dieser Ton war entweder Glazialton oder gefällte Tonmudde, Binnenseelehm ${ }^{1}$ ) und dann vielleicht am ehesten spätglazialer Süsswasserton. In letzterem Falle könnte er

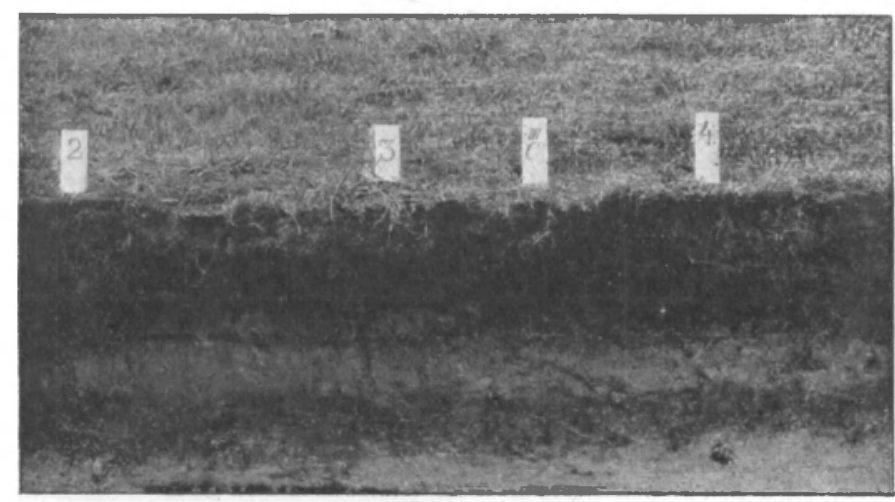

Abb. 5. Profil in der Niederung.

Westwand von Bank III C 2 bis 5. Unter dem Gras dunkler Torf mit einem helleren Streifen nach unten zu. Darunter braune Torfmudde über heller Schneckenmudde. Zu oberst in der Schneckenmudde sieht man unter Pfahl 4 eine Knochengelenkrolle, unter Pfahl 2 noch ein Knochenstück. Die Entfernung zwischen 2 und 3 sowie zwischen 3 und 4 beträgt je $1 \mathrm{~m}$. möglicherweise U̇berbleibsel arktischer Pflanzen enthalten; doch liessen sich solche beim Schlemmen kleinerer, dem Boden entnommener Proben von Lehm und Schotter, was freundlichst durch Herrn Dr. N. Hartz ausgeführt wurde, nicht nachweisen.

Auf dem höchsten Teil des Grundes war derTon mit einer einfachen Schicht von St e i n e n (Gerölle) bedeckt, die dicht beieinander lagen, von Lehm rein geschlemmt waren und ein natürliches Pflaster bildeten, wie man solches häufig an See- oder Meeresufern sieht. Die Steine waren von sehr verschiedener Grösse, von 2 bis $80 \mathrm{~cm}$, am häufigsten jedoch 5 bis $30 \mathrm{~cm}$ im Durchmesser. Von Gesteinsarten war dabei Flint vorherrschend; auch in den Schotter- oder Sandschichten, die dem Torf am Rande des Moores unterteuften, ${ }^{2}$ ) kam er in Menge vor.

Die alluvialen Bildungen, die den Glazialton deckten, bestanden aus M udde und Torf. ${ }^{3}$ ) Eine genauere Untersuchung derselben mag dazu

1) In derselben Bedeutung wie „,insjölera“ bei Gunnar Andersson im Bulletin de la Commission geologique de Finlande. Nr. 8. Helsingfors 1898, S. 9.

2) Beobachtet in einer Sandgrube am Moorrand gegen Nordnordwest, 350-400 $m$ von dem Wohnplatze entfernt.

3) Wegen dieser Ausdrücke und ihrer Bedeutung siehe C. A. Weber: Aufbau und Vegetation der Moore Norddeutschlands. Englers Botan. Jahrbücher, Bd. 40, Beiblatt 90, 1907, S. 21; C. A. Weber: (UUber die Entstehung der Moore. Zeitschr. f. angew. Chemie, Jg. 18 H. 42,1905 . 
dienen, über die ursprünglichen Naturverhältnisse, besonders über die ehemalige Wassertiefe an Ort und Stelle zu belehren.

Die II ud de schicht, die den blauen Ton und die Steinschicht deckte, war hellgrau, seltener etwas bräunlich gefärbt und enthielt viel kohlensauren Kalk (bei Zusatz von Säure stark brausend). Dr. C. Wesenberg-Lund hat freundlichst einige kleinere Proben dieser Iudde untersucht und dabei gefunden, dass sie am ehesten den Charakter von "Strandgyttja" hat, worunter eine Schlammbildung in flacherem Wasser am Seeufer oder an Untiefen zu verstehen ist, die im wesentlichen aus den Exkrementen von Schnecken. Muscheln und Wasserinsekten besteht (schwedisch als Gyttja bezeichnet). ${ }^{1}$ )

Die äussere Grenze der Strandgyttja läuft in unseren Seen in etwa 9 bis $11 \mathrm{~m}$ Wassertiefe; am reichlichsten findet sich die Ablagerung zwischen 3 bis $4 m$ Wassertiefe und dem Strande.

Der obere Teil der Mudde enthielt so viel Schalen von Weichtieren, dass diese stark ins Auge fielen, weshalb die Arbeiter die Schicht kurzweg S n e g l, ,Schnecken“, nannten.

Mudde und Schneckenmudde zusammen hatten an dem höchsten Punkt des Grundes eine Mächtigkeit von nur $0,33 m$ (siehe Tabelle I bei IV K 4), aber gegen Osten zu, wo der Grund tief gelegen war (bei III K 2-5), betrug sie über $2,50 \mathrm{~m}$.

Die Sch ne ckenm ud d e war hell, erhielt durch Trocknen eine grauweisse Farbe und fühlte sich beim Schneiden hornartig an. Zwei Proben davon (aus I D 5, 3. Schicht und II H 7, 3. Schicht) sind von Dr. V. Nordmann untersucht worden. der in beiden Proben Schalen folgender Weichtiere fand:

Limnaea ovata f. peregra Müll., Planorbis nautileus L., Valvata cristata Müll., V. piscinalis Müll., Bythinia tentaculata L., Sphaerium sp., Pisidium sp.

In der einen Probe kam ausserdem die Abart Valvata piscinalis var. ambigua Westerlund vor, was auf das Vorhandensein von in der Nähe befindlichem fliessendem Wasser hindeutet ( $\mathrm{Zu}$ - oder Abfluss vom See).

Alle diese Schaltiere leben allgemein in unsern süssen Gewässern in der Nähe des Ufers; die Schneckengehäuse $m$ üssen in geringer Tiefe (a m ehesten von $1 \mathrm{~b}$ is $2 m$ ) im See abgelager $\mathrm{t}$ sein und sind nicht von weit her gekommen; die Schalen der Bythinia haben nämlich, worauf Nordmann aufmerksam macht, den Deckel nicht verloren, sind also nicht weit geschwemmt. Die erwähnten Schnecken könne n zwar auch in geringerer Wassertiefe als $1 m$ vorkommen, ausnahmsweise sogar sehr nahe dem Strand; sie können andererseits auch über $2 m \mathrm{hin}$ a u s g e he n, aber Formen, die für das tiefere Wasser eigentümlich sind, wie Maler- und Teichmuscheln (Unio, Anodonta) und Valvata piscinalis var. antiqua fehlen in der Ablagerung: diese wird also in seichtem Wasser statt-

1) Siehe hierüber C. Wesenberg-Lund: Studier over Sökalk, Bönnemalm og Sögytje i danske Indsöer. Meddelelser fra Dansk geologisk Forening, Nr. 7, Köbenharn 1901, S. $99,137$. 
gefunden haben, womit es auch übereinstimmt, dass Lungenschnecken etwas häufiger zu sein scheinen als Kiemenschnecken. ${ }^{1}$ )

Andrerseits bildet sich die Schneckenmudde, der Wellenbewegung wegen, nicht ganz nahe am Ufer. Der Kalk der Mudde ist zum grossen Teil ron Pflanzen (Characeen u. a.) abgeschieden; die stete Bewegung des Wassers am Ufer lässt eine tblagerung des Kalkes nicht zu, sondern er wird transportiert in die stilleren Gebiete jenseit der Schilf- und Rohrz o $\mathrm{n}$ e, so dass er in 3 bis $7 \mathrm{~m}$ Wassertiefe am reichlichsten vorhanden ist. ${ }^{2}$ )

Verschiedene am Seeboden wachsende Pflanzen inkrustieren sich mit Kalk; die Mollusken fressen die faulenden Pflanzen und wandeln sie in Kot, wobei die Schnecken geradezu die Kalkkrusten abweiden. Die Schalen der abgestorbenen Weichtiere sinken zu Boden oder werden wieder aufgelöst. So entsteht die Schneckenmudde. ${ }^{3}$ )

Auf dem Wohnplatze hatte die Schneckenmudde für gewöhnlich eine Dicke von 20 bis $30 \mathrm{~cm}$ und erstreckte sich fast über den ganzen Wohnplatz; nur gegen Südosten wurde sie dünner und verschwand zuletzt, indem eine hellbraune, auf der Mudde lagernde Torfmudde hier an ihre Stelle trat. Die Schneckenmudde senkte sich ron dem obersten Punkt des Grundes nach allen Seiten hin; die Untiefe war in keiner Richtung ,landfest", sondern ist überall von tieferem Wasser umgeben gewesen.

"Schneckenmudde" oder "Schneckenmergel" ist sowohl aus andern Mooren Nordseelands, unter Torf abgelagert, ${ }^{4}$ ) als auch vom Grunde der Seen bekannt. ${ }^{5}$ )

Der höchste Punkt der Oberfläche der Schneckenmudde (bei IV $\mathrm{K}$ 3) lag 3,86 $m$ über dem Meeresspiegel. ${ }^{6}$ ) Der Spiegel des Sees stand in der Zeit, da die Muddebildung ihren Abschluss erreichte, wohl zwischen 5

1) Vgl. A. C. Johansen: Om Aflejringen af Molluskernes Skaller i Indsöer og i Havet. Videnskab. Yedd. fra den naturhist. Foren. i Kjöbenharn, 1901, Sonderabdruck \$. 10. Schalen von Maler- und Teichmuscheln, die der Aufmerksamkeit nicht leicht entgehen konnten, fanden sich nirgends auf dem Platz. Vgl. auch Wesenberg-Lund a. a. O., S. 71.

2) U. Steusloff: Torf- und Wiesenkalk-Ablagerungen im Rederang- und Ioorsee-Becken. Inaug.-Diss. Rostock, Güstrow 1905, S. 40. Separatabdr. aus Archiv. des Ver. der Freunde d. Naturgesch. in Mecklenburg, Jg. 59, 1905.

3) S. Passarge: Die Kalkschlammablagerungen in den Seen von Lvchen, Uckermark. Jahrbuch der kgl. preuss. geolog. Landesanstalt für 1901, Bd. 22, H. 1. Berlin 1902, S. 114, $121,142$.

4) Jap. Steenstrup: Skovmoserne Vidnesdam- og Lillemose. 1842. S. 28, Fig. II n; S. 62. Jap. Steenstrup: Törvemosernes Bidrag etc. 1888. S. 41. K. Rördam: De geologiske Forhold i det nordostlige Sjielland. Danmarks geol. Unders. I. Rrkke, Nr. 1. Köbenharn 1893 . S. 68,84 .

5) Aus Anlass der (ungefähr $2 m$ betragenden) Tieferlegung des Wasserspiegels im Söndersö bei Jonstrup fand man dicke Schichten von Muschel- und Schneckenschalen, die in einem Ring um den ganzen See herum abgelagert waren. Auf dem Seegrunde verstreut, namentlich in der obersten Schicht der Mudde, fanden sich hier Flintgeräte, Knochen. Hirschgeweihe und Bruchstücke eines Menschenschädels. H. Mortensen: Söndersöens Vegetation. Botanisk Tidsskrift. Bd. 2. Köbenhavn 1868. S. 264 und schriftliche Mitteilungen des Verfassers.

6) Siehe Abb. 2 und Tabelle I. 
und $7 m$, am ehesten vielleicht um $6 m$ über dem jetzigen Stand des Meeresspiegels, also etwa $2 m$ höher als die jetzige Oberfläche des Moores an jener Stelle. ${ }^{1}$ )

Nach dem Aufhören der Schlamm- oder Muddebildung begann die T or f ablagerung. Auch dieser hat sich, auf jeden Fall in der Hauptsache, u $\mathrm{n}$ e $r$ Wasser gebildet.

Der untere Teil des Torfes, also die Schicht zunächst über der Schneckenmudde, bestand auf dem ganzen Platz im wesentlichen aus äusserst fein zerteilten organischen Abfallstoffen, war plastisch, etwas klebrig oder abfärbend wie Schlamm und von braunroter Farbe; hierin waren zahlreiche wohlerhaltene Pflanzensamen eingebettet. Schon diese Beschaffenheit der Lebermudde, des schlammigen Torfs oder der „Gyttja“ bewies mit Sicherheit, dass er auf dem Grund des Sees unter Wasser abgesetzt worden war.

Diesen im „offenen“ Wasser des Sees gebildeten unteren Torf oder Lebertorf wollen wir $W$ a s sertorf nennen.

Darin fand sich der weitaus grösste Teil der Altertümer, verkohltes Holz, Knochen usw., d. h. der grösste Teil der „Fund-“ oder „Kulturschicht“. ${ }^{2}$ )

Moos wurde an keiner einzigen Stelle im Torf beobachtet. Je nachdem die Tiefe des Wassers abnahm, indem der Grund durch das Anwachsen der Torfschicht sich erhöhte, oder weil der Wasserstand sank, änderte sich der Pflanzenwuchs. Die „Wasserpflanzen“, d. h. die g a nz unter dem Wasser, auf dem Seeboden wachsenden submersen Pflanzen, die entweder gar nicht über dem Wasser sichtbar sind, oder wie die Seerosen nur einige Blätter und Blüten an die Oberfläche senden, wurden durch Sumpfpflanzen abgelöst, deren t'berreste namentlich in dem mittleren Teil des Torfs angetroffen wurden. Dieser war durchwebt von Wurzeln und Wurzelstöcken monocotyler Pflanzen, wohl hauptsächlich des gemeinen Rohrs (Phragmites communis); dadurch wurde die Masse so zusammenhängend, dass sie als Stichtorf benutzt werden konnte. Der obere Teil des Torfes war durchwachsen von den Wurzeln von Halbgräsern und in Büscheln wachsenden Gräsern; ein dichter Rasen bedeckte die ganze Oberfläche des Moores.

Durch solche Sumpf- und später folgende Landpflanzenvegetation hatte sich oben das gebildet, was wir $S \mathrm{u}$ p f t orf bzw. Wiese $\mathrm{n}$ orf nennen möchten.

Diese Einteilung der Torfarten entspricht jener der torfbildenden Pflanzenvereine nach Wasser, Sumpf und Wiese. ${ }^{3}$ )

1) Die Gräben, die heute aus dem umgebenden Gelände das. Oberflächenwasser dem Moore zuführen, reichen ungefähr bis $6 \mathrm{~m}$ über dem Meere hinauf.

2) Diesen Sachverhalt habe ich schon bei der Vorlegung des Fundes in der Sitzung der Kgl. nordiske Oldskrift-Selskab vom 20. November 1900 geschildert. Siehe Zeitschrift für Ethnologie, Jg. 32. Berlin 1900. Verhandlungen S. (584) bis (585).

3) Eine ähnliche Darstellung der Moorbildung in Norwegen ist von Jens Holmboe gegeben worden: Planterester i norske torvmyrer. Videnskabsselskabets Skrifter. 1. Math.naturv. Klasse. 1903. Nr. 2. Kristiania 1903. S. 30 bis 33 mit Fig. 2. - Vgl. Grevillius: Zur Physiognomie der Wasservegetation. Berichte über die Versammlungen des botan. und des zool. Vereins für Rheinland-Westfalen. Jg. 1909. S. 43 bis 71. 
Der Sumpf oder Rohrsumpf (Scirpetum und Phragmitetum) ist jener Schilfgürtel, der einen See oder eine $A u$ nächst dem Ufer umkränzt. Im Schlamm unter dem Wasser, bis hinaus in eine Wassertiefe von 2 bis $3 m$, wächst hier das lange ,Schilf", d. h. Rohr und Binse oder Simse mit ihren Begleitern. die mit den Rispen hoch über die Oberfläche des Wassers hinausragen. In seichtem Wasser ist das gemeine Rohr vorherrschend.

Der Wiesentorf. der durch Riedgras und Gras gekennzeichnet ist, Pflanzen, die, im Moor oder auf Wiesen wachsend, es nicht vertragen, das ganze Jahr unter Wasser zu stehen, ist auf der Wohnstätte auf die oberste Schicht beschränkt und dürfte eine neuere Bildung sein, die nicht bis in die Vorzeit zurückreicht.

Es muss jedoch darauf aufmerksam gemacht werden, dass, so wenig man eine scharfe Grenze zwischen den Pflanzengürteln ziehen kann, so wenig auch bestimmte Grenzen zwischen den Torfarten feststellbar sind, nach denen sichere Schlüsse in Bezug auf die Entstehungsbedingungen gezogen werden könnten, wenn man von den äussersten Grenzen absieht, in denen die Schlüsse sicher oder immerhin sicher genug sind.

Was den Wassertorf und zum Teil den Sumpftorf betrifft, darf behauptet werden, dass deren Bildung in und unter dem Wasser vor sich gegangen ist. Hierauf ist das meiste Gewicht zu legen, da der grösste Teil der Altertümer in diesen Schichten, also bei einer Wassertiefe von etwa 4 bis $1 \mathrm{~m}$, abgelagert war. Dass sich auch der Wiesentorf in beständig feuchtem $\mathrm{Zu}$ stand bildete, ist ebenfalls gegeben, weil die Pflanzenreste sonst einfach nicht erhalten wären. Aber was hier die Wassermenge anbelangt, die doch nach den Jahreszeiten merkbar verschieden war, so ist es schwierig, irgend etwas Bestimmtes zu sagen. Bedeutung hat dieser Sachverhalt nur, weil ein geringer Teil der Altertümer und auch Abfälle sich in der obersten Schicht fanden, auf den höchsten Stellen sogar in grösserer Anzahl; aber die Bedeutung dieses Umstandes wird wieder in hohem Grade dadurch abgeschwächt, dass die Verhältnisse in dieser oberen Schicht nicht als ganz ungestört angesehen werden können.

In dem oberen Torf fanden sich (an der Südostecke des Hauptfeldes II und in Raum VII F 5, 1. Schicht) die schon früher erwähnten Skeletteile von Kälbern, die wohl an jener Stelle ertrunken sind, und ebenfalls im 'Torf, in einer Tiefe von 30 bis $50 \mathrm{~cm}$ unter der Oberfläche (im Raum III C 7) lag ein Tüderpfahl aus Buchenholz und von ziemlich neuem Aussehen. Dieser lag in wagrechter Richtung, war also nicht hineingeschlagen, und in der Torfschicht oberhalb desselben war trotz sorgfältiger Untersuchung keine Störung nachzuweisen. Am ehesten kann man annehmen, dass jener Tüderpfahl an dieser Stelle ins Wasser hineingefallen ist, und dass sich eine ungefähr $40 \mathrm{~cm}$ dicke Torfschicht seither darüber gebildet hat.

Gerade in der Nähe dieser Stellen, bei der Südwest- und Südostecke des Hauptfeldes I, schien es mir bei der Untersuchung, als ob sich hier Spuren alter Torfgruben fänden, die später verwachsen waren, namentlich durch Rhizome vom Rohr; aber sichere Grenzen für derartige Torfgruben liessen sich nicht nachweisen. Auch mit Hilfe historischer Quellen ist es mir nicht 
geglückt, darzutun, dass gerade an di e ser Stelle im Moor früher Torf gegraben worden ist; ich selbst zweifle jedoch nicht daran, dass die Sache sich wirklich so verhält. Einen Anhalt für diese Annahme finde ich darin, dass Dau im Jahre 1828 auf seiner Reise durch das nahegelegene Moor Store Aamose aus seinen Beobachtungen glaubte schliessen zu können, dass eine obere Deckschicht in älterer Zeit weggeschnitten worden sei. ${ }^{1}$ ) Das merkwürdige Vorkommen von Altertümern und Abfällen in der obersten Schicht des Moores, die zum Teil von der Hauptmenge durch dicke, von einem derartigen Inhalt freie Torfschichten getrennt waren, liesse sich dadurch erklären, dass in älterer Zeit der gegrabene Torf auf einem Stapelplatz hier ausgebreitet wurde, während die Torfgruben, denen das Material entstammte, später wieder verwachsen und nun schwer von der Umgebung zu unterscheiden wären. Das starke Zusammensinken der oberen Torfschicht nach der Entwässerung muss dabei auch in Betracht gezogen werden.

Man wird jedoch sicher zugeben, dass es fast undenkbar ist, dass die Altertümer in den unteren Schichten im Wasser abgelagert sein sollten, in der oberen hingegen nicht, wo sie ganz gleichartig sind.

In der unteren Schicht is t der Torf entschieden $W$ a s s e r t orf. Diese untere Torfschicht und die Schneckenmudde, die die Hauptmenge der Altert ümer enthalten, sind im of f e n e n Süsswasser gebildet, das eine Höhe von mindestens $4 \mathrm{~m}$, wahrscheinlicher noch u $\mathrm{gef}$ äh r $6 \mathrm{~m}$ üb e r de m he utigen Meeresspiegel erreicht haben dürfte. Dass auch die Altertümer in dem oberen Wiesentorf ursprünglich unter dem Wasser in einem See oder Sumpf abgelagert sind, muss ich annehmen, doch lässt sich der Beweis hierfür nicht sicher führen.

Wichtig ist, dass der Wassertorf mit seinem Inhalt an Altertümern den Grund auf dem ganzen Platz bedeckt; von Anfang an is t a u ch nicht das geringste Fleckchen vorhandengewesen, das trocken gelegen hätte, selbst nicht auf dem höchsten St rich.

Die Wasserpflanzen sind hier in einem S e gewachsen, der nicht austrocknete.

An mehreren Stellen auf dem Platz sind Torfproben entnommen worden, die aufgehoben wurden, um später einer besonderen, pflanzenkundigen Untersuchung unterworfen zu werden. In dieser Beziehung am wichtigsten waren zwei ,,Torfpfeiler", zwei vierseitig prismenförmige Ausschnitte von 1,25 m Höhe, die von der Oberfläche bis auf den Grund reichten. Úber die Schichtenfolge und den Inhalt der Schichten an jenen Stellen, wo diese grösseren, zusammenhängenden Proben entnommen waren, soll hier nur folgendes bemerkt werden:

Der eine Pfeiler wurde aus Raum III D 4 (dessen Oberfläche $1 \mathrm{qm}$ gross war) in der $\mathrm{Ni}$ ederung gegen Osten nahe dem Rand des Wohnplatzes herausgeschnitten. Die Oberfläche des Rasens lag hier in den vier

1) J. H. C. Dau: Die Torfmoore Seelands. Kopenhagen und Leipzig 1829, S. 181, 186. 193. Vgl. Holmboe a. a. O., S. 38.

Praebistorische Zeitschrift III Heft 1/2. 1911 
Ecken des Raumes bei 3,92 bis $3,93 \mathrm{~m}$, die Oberfläche der Schneckenmudde bei 2,90 bis $3,05 m$ über dem Meeresspiegel. Der Torf in diesem Raum war also um 90 bis $100 \mathrm{~cm}$ dick, den Rasen eingerechnet.

In der Grasnarbe des Raumes fanden sich 3 Stück Flintabfall, die vermutlich bei früherem Torfstechen dort hingekommen waren; die ganze darunter liegende Torfmasse, die im wesentlichen aus Sumpftorf bestand, bis hinunter zu einer Tiefe von ungefähr $70 \mathrm{~cm}$ unter der Oberfläche, enthielt weder Altertümer, noch Flintabfälle, noch Knochen. Diese zeigten sich erst in dem unteren Teil des Wassertorfes über der Schneckenmudde; zwischen 70 und $100 \mathrm{~cm}$ tief unter der Oberfläche fanden sich hier 5 Stück Altertümer, 36 Stück Flintabfall und 14 Knochenstücke, im ganzen 55 St ück. An der Grenze zwischen der Schneckenmudde und dem braunen Lebertorf enthielt der Torfpfeiler selbst zwei Stücke aus Flint aus der „Altertümerschicht", von denen das eine behauen (ein Flintknorren), das andere ein Abfallstück war.

Der andere Torfpfeiler war mitten auf der Erhe bung der Oberfläche in Raum VII E 2 entnommen. Sein Profil ist aus Abb. 4, Seite 58, zu ersehen.

Die Höhe der Oberfläche der Grasnarbe über dem Meeresspiegel betrug hier, wie ebenfalls durch Nivellierung festgestellt wurde. 4,04 bis $4,14 \mathrm{~m}$, die der Schneckenmudde gleichfalls 3,67 bis $3,72 \mathrm{~m}$. Die Dicke des Torfs an den vier Ecken des Raumes betrug zwischen 37 und 43 , also ungefähr $40 \mathrm{~cm}$, den Rasen eingerechnet. Auch beim unmittelbaren Messen der Schicht während der Arbeit zeigte es sich, dass die Dicke des Torfs nur $40 \mathrm{~cm}$ betrug. Die Grenze gegen die darunter liegende helle Schneckenmudde war hier, wie in der vorigen Torfprobe, scharf.

Nach unten zu war die Masse deutlich Wassertorf, nach oben hin, gegen den Rasen zu, war der Torf stark zersetzt, der ursprüngliche Charakter daher nicht mehr erkennbar.

In der Schneckenmudde und im Wassertorf fand Dr. N. Hartz durch Untersuchung der Proben hauptsächlich zahlreiche Samen von Nixkraut (Najas marina), einige Samen von der Seerose (Nymphaea alba) und Früchte rom Samkraut (Potamogeton sp.). Im Sumpftorf wurden nachgewiesen Früchte der Schneide (Cladium Mariscus) und Rhizome rom Rohr (Phragmites communis), in der Wiesentorfschicht Früchte ron der Simse (Scirpus Tabernaemontani) und der Segge (Carex sp.).

Die weit überwiegende Menge von Altertümern und Abfallstücken war auch in diesem Raum auf der Anhöhe im Wassertorf dicht über der Schneckenmudde enthalten, wie es aus untenstehender Zusammenstellung (Tabelle II) hervorgeht. Dagegen wurde in der Schneckenmudde und den unterteufenden Schichten hier nichts gefunden. Das Profil in den vier Ecken des Raumes zeigte durchschnittlich: zu oberst $40 \mathrm{~cm}$ Torf, darunter $27 \mathrm{~cm}$ Schneckenmudde, dann $32 \mathrm{~cm}$ graue Mudde, $5 \mathrm{~cm}$ Geröle und Kies über Ton und Sand (nicht durchsunken; vgl. Tabelle I, Seite 59). Von der Art und Weise, in der die Altertümer in Torf und Mudde eingebettet waren, soll übrigens weiter unten die Rede sein. 
Tabelle II. Raun mit Torlpleiler

\begin{tabular}{|c|c|c|c|c|}
\hline \multirow{2}{*}{$\begin{array}{c}\text { Tiefe der Schicht unter der } \\
\text { Oberfläche des Moores }\end{array}$} & \multicolumn{4}{|c|}{ Raum VII E 2. Inhalt } \\
\hline & $\begin{array}{c}\text { Altertümer } \\
\text { Stück }\end{array}$ & $\begin{array}{c}\text { Flintabfälle } \\
\text { Stück }\end{array}$ & $\begin{array}{l}\text { Knochen- } \\
\text { stücke }\end{array}$ & $\begin{array}{l}\text { Zusammen } \\
\text { Stück }\end{array}$ \\
\hline $0-10 \mathrm{~cm}$ Rasen........ & 0 & 3 & 3 & 6 \\
\hline $10-30$, 1. Torfschicht . . . . . & 0 & 5 & 3 & 8 \\
\hline $30-40,, 2 . \quad$, & 2 & 25 & 4 & 31 \\
\hline
\end{tabular}

Dass indessen der Wasserstand im Moor nicht immer eine solche Höhe erreicht hat, wie es zur Bildung der Mudde und der unteren Torfschichten erforderlich war, zeigt die Untersuchung des Niveaus, in dem der schon obenerwähnte nahegelegene $\mathrm{K}$ i ef e $\mathbf{r} \mathbf{n}$ ald gewachsen ist, eine Untersuchung, die nachher mit grosser Sorgfalt von Mathiassen ausgeführt worden ist, und deren Ergebnis in entgegenkommender Weise uns zur Verfügung gestellt wurde.

Durch Nivellierung wurde die Lage jener Moorfläche, auf welcher die Strünke gewachsen waren, bestimmt, und zwar für jeden einzelnen von 125 Strünken im nordwestlichen Teil des Moores nächst dem Wohnplatze. Die gemessenen Punkte des ehemaligen Waldbodens, nach Höhenklassen geordnet, gruppieren sich hiernach zwischen 2,99 und 4,25 $m$ über dem Meeresspiegel, wie die obenstehende Tabelle III zeigt.

Tabelle III. Kiefernstrünke

\begin{tabular}{|c|c|c|c|c|}
\hline $\begin{array}{l}\text { Stand der Str } \\
\text { Höhe über dem }\end{array}$ & $\begin{array}{l}\text { ünke. } \\
\text { Meere }\end{array}$ & $\begin{array}{l}\text { Zahl der } \\
\text { Strünke }\end{array}$ & $\begin{array}{c}\text { Stand der Strünke. } \\
\text { Höhe über dem Meere }\end{array}$ & $\begin{array}{l}\text { Zahl der } \\
\text { Strünke }\end{array}$ \\
\hline $4,30-4,21 m$. . & . & 1 & $3.60-3,51 m$. & 34 \\
\hline $4,20-4,11, \ldots$. & . . . . & 1 & $3,50-3,41$, . . . . . . . . & 23 \\
\hline $4,10-4,01, \ldots$. & .... & 2 & $3,40-3,31$, . . . . . . . . & 13 \\
\hline $4,00-3,91, \ldots$. & . . . . & 8 & $3,30-3,21, \ldots . . . . . . .$. & 6 \\
\hline $3,90-3,81, \ldots$. & . . . . & 6 & $3,20-3,11$, . . . . . . . . & 2 \\
\hline $3,80-3,71, \ldots$. & . . . . & 8 & $3,10-3,01$, . . . . . . . . & 0 \\
\hline $3,70-3,61, \ldots$. & . . . & 20 & $3,00-2,91, \ldots . . . . . .$. & 1 \\
\hline Im ga & nzen . . & 46 & + & 79 \\
\hline
\end{tabular}

Bei der Nivellierung wurde die Messstange oben auf den wagrecht auslaufenden Wurzeln angebracht, gewöhnlich nahe dem Stamm oder, bei stärkeren Strünken, etwas weiter ausserhalb.

Die Höhenklassen sind in der Tabelle nur der Übersicht halber benutzt und künstlich gewählt; eine natürliche Verteilung der Strünke in ver- 
schiedene, bestimmt abgegrenzte Horizonte konnte nicht beobachtet werden. Von den 125 Strünken standen 90 Stück oder $72 \%$ in einer Höhe von 3,31 bis $3,70 \mathrm{~m}$. Noch unter dem Niveau von $3,50 \mathrm{~m}$ über dem Meeresspiegel sind, wie man sieht, 45 Strünke gemessen, von denen der am tiefsten stehende 2,99 $\mathrm{m}$ über dem Meeresspiegel gewachsen ist, also in derselben Tiefe wie die Altertümerschicht im Sumpf- und Wassertorf des Wohnplatzes.

Der Kiefernwald hier kann somit $n$ i cht gleich zeitig mit den im Wasser abgesetzten Schichten auf dem Wohnplatze sein; der Wald muss ja auf einigermassen trockenem Boden gewachsen sein. ${ }^{1}$ )

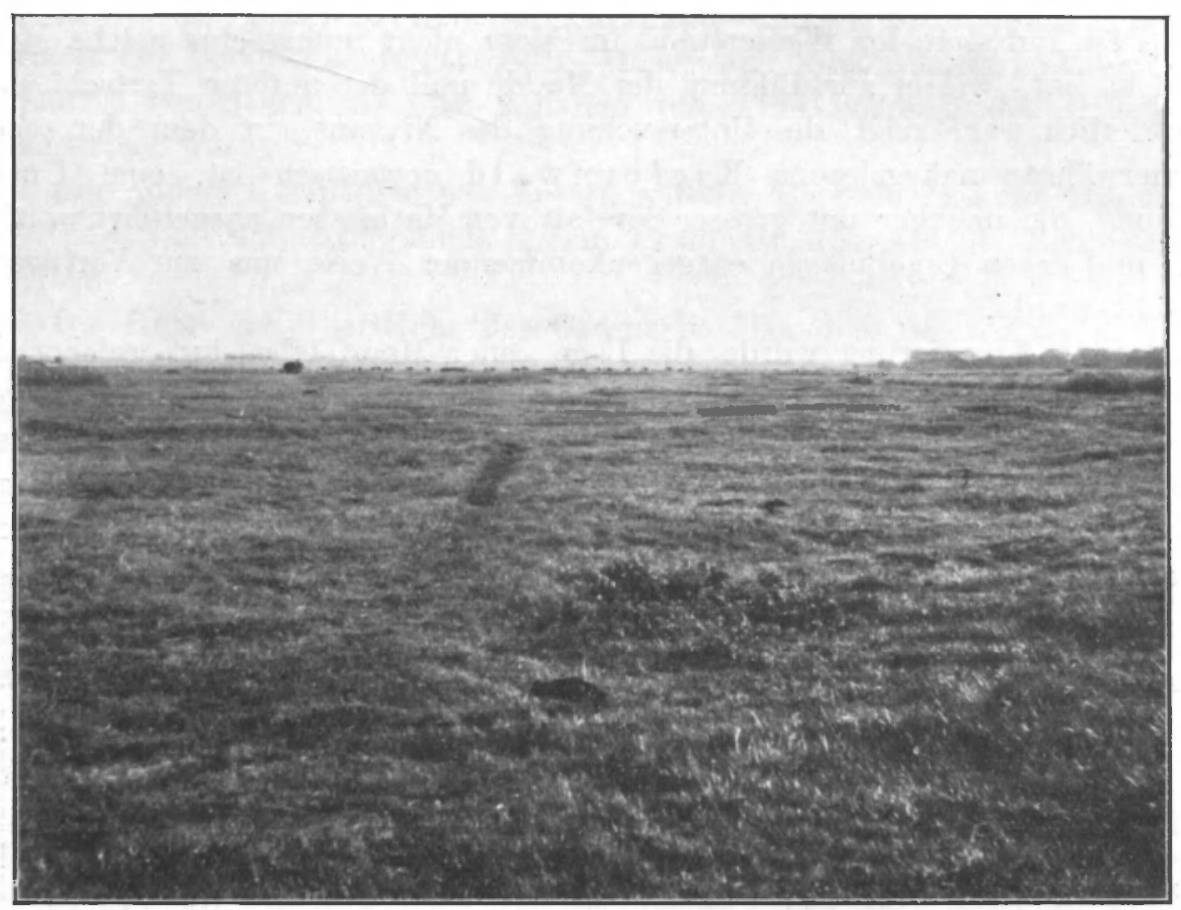

Abb. 6. Aussicht gegen Süden.

Das Altersverhältnis kann nur aus der Beschaffenheit und Mächtigkeit der darunter liegenden Torfschicht oberhalb der Schneckenmudde bestimmt werden. Die Bildung der Schneckenmudde dürfte an gleich tiefen Stellen wohl ungefähr gleichzeitig aufgehört haben, sie scheint sich ohne Unterbrechung mit welliger Oberfläche von dem Wohnplatze bis hin unter die Kiefernstrünke zu erstrecken, die alle durch eine dünnere oder dickere Torfschicht von der Schneckenmudde, dem alten Seegrund, getrennt waren.

1) Utber das Vorkommen von Strunkschichten in Torfmooren und die Ursachen des. selben siehe Holmboe, a. a. O. S. 35 bis 42 mit Fig. 3 und 4, und die Arbeiten von R. Sernander, Gunnar Andersson, A. Gavelin und L. von Post. Diskussion der Frage und Literatur im Werke: Die Veränderungen des Klimas seit dem Maximum der letzten Eiszeit. Herausgegeben von dem Exekutivkomitee des 11. internationalen Geologenkongresses. Stockholm 1910. 
Unter dem obersten Strunk, der gegen Nordwesten dem Ufer des Moores am nächsten war und 4,25 $\mathrm{m}$ über dem Meeresspiegel stand, befand sich die Oberfläche der Schneckenmudde in einer Höhe von $3,63 \mathrm{~m}$; der Torf war hier also $0,62 m$ dick.

Proben des Torfes unter diesem Kiefernstrunk, die ungefähr 0,15 m über der Oberfläche der Schneckenmudde oder ungefähr 3,78 $\mathrm{m}$ über dem Meeresspiegel entnommen waren, sind bereitwilligst von Dr. N. Hartz untersucht worden; der Torf enthielt hiernach eine Menge Früchte von der Schneide (Cladium Mariscus), ganz vereinzelte Früchte von der Segge oder dem Riedgras (Carex Pseudocyperus) und von der Birke (Betula sp.), sowie

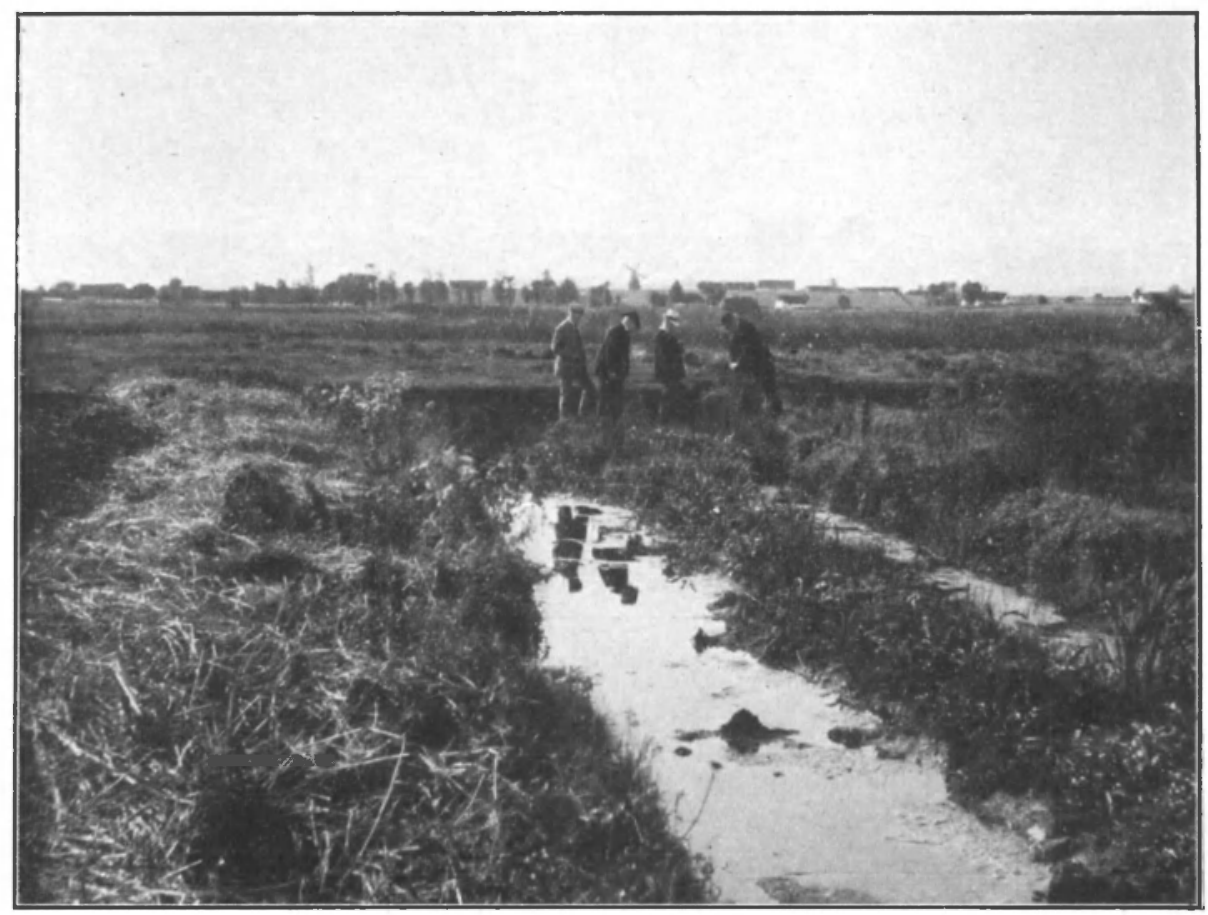

Abb. 7. Aussicht gegen Osten.

einzelne Samen der Kiefer (Pinus silvestris). Ausserdem hat Mathiassen darin verkohlte Pflanzenreste bemerkt.

Verkohltes Holz ist ausserdem noch unter mehreren Strünken und anderwärts im Torf gefunden worden, bis zur Schneckenmudde herunter, und unter zwei Strünken fand Mathiassen behauene Flintstücke. Die letzteren, ebenso wie die Kohle, gehören gewiss der Zeit des Bewohntseins an; folglich müssen die $\mathrm{R}$ este des $\mathrm{K}$ i ef e r $\mathrm{nwaldes}$, die jetzt noch vorhanden sind, aber in wenigen Jahren verschwunden sein werden, aus einer j ü n g e r e n, vielleicht sogar v i e l jüngeren Zeit als der Wohnplatz stammen.

Innerhalb der Grenzen des. Wohnplatzes selbst fand sich nur ein einziger kleiner Strunk mit Wurzeln von einer Kiefer; dieser wurde losgerissen auf dem zerstörten Teil des Platzes in einer Torfgrube angetroffen 
und war von einem ganz kleinen Baum, nicht grösser, als dass er leicht von Menschen dort hingebracht sein konnte. Dies war augenscheinlich der Fall bei der grossen Menge von Holzresten, die der Torf sonst überall auf dem Wohnplatze enthielt. Es fanden sich hier keine Stämme, sondern nur Äste und Zweige, von denen kaum welche mehr als Armdicke hatten; die meisten waren weit dünner und kein einziger länger als einen halben Meter.

Ein grosser Teil dieser Zweige war ganz oder doch teilweise verkohlt, wodurch in Verbindung mit dem übrigen Sachverhalt deutlich ersichtlich war, dass sie in menschlichen Händen gewesen waren. Es waren hauptsächlich Kiefernzweige, die einem Walde entnommen sein mögen, der damals

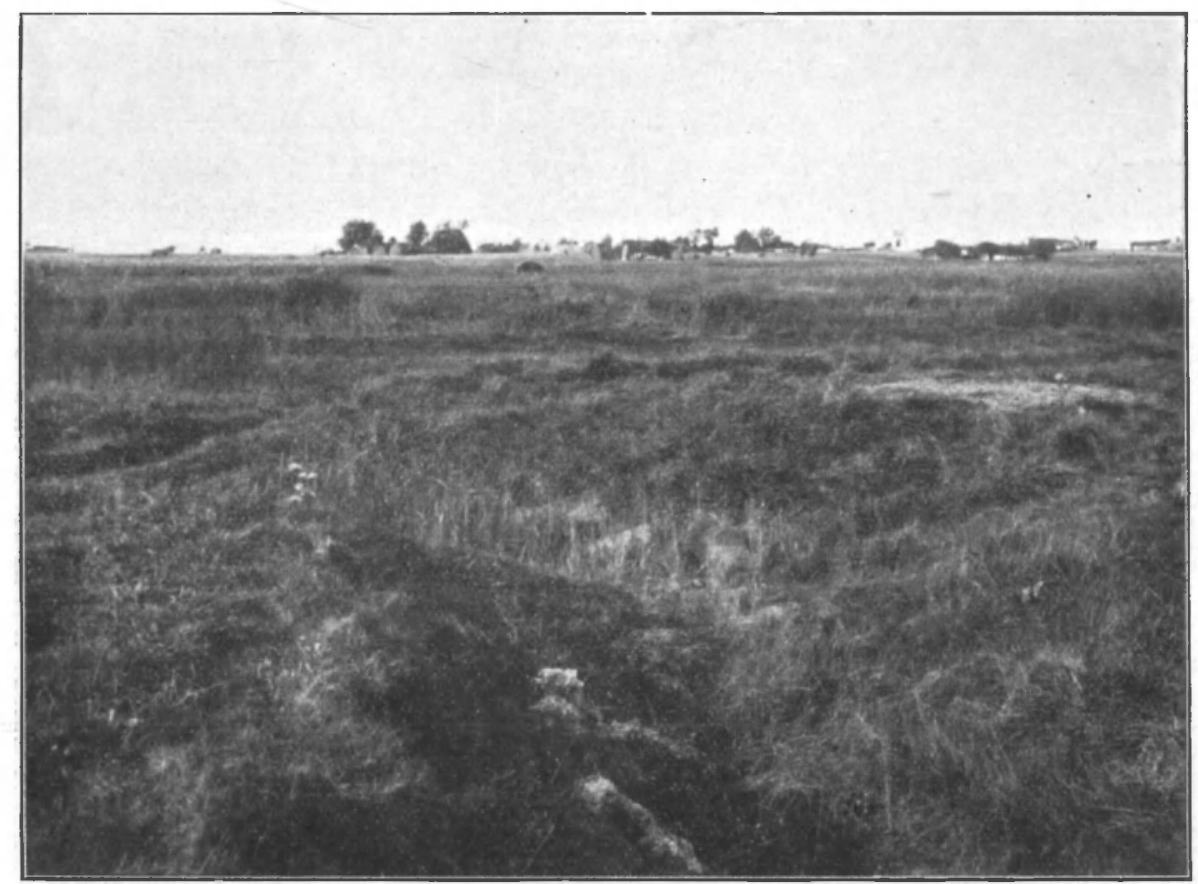

Abb. 8. Aussicht gegen Norden.

am Ufer des Sees wuchs und einer viel älte ren Zeit angehörte als der eben genannte im Moor verborgene Wald.

Einige Holz- oder Kohlenstücke hatten eine abgenutzte Oberfläche, wie sie für Stücke kennzeichnend ist, die vom Wasser gerollt und umhergeworfen worden sind. Dieselbe Beobachtung liess sich bei einigen $\mathrm{K} \mathrm{n}$ o chen machen; deren Oberfläche war sonst durchgehends so vorzüglich erhalten, häufig sogar mit Resten der Knorpelhaut, dass sie $\mathrm{nicht}$ lange der Luft ausgesetzt gelegen haben können, ehe sie ins Wasser gelangten und einsanken, während sie seither mit einer feuchten Torfschicht bedeckt gewesen sein müssen.

Nirgends fand man hinzugeführte „Erde“; weder Lehm noch Sand fand sich zwischen dem Torf.

Über die Naturverhältnisse in dem ehemaligen „Maglesee“, ehe er sich 
durch Anfüllen mit Torf in das gegenwärtige „Maglemose“ (d. h. Grossmoor) umwandelte, kann man sich vielleicht am leichtesten eine Vorstellung machen, wenn man ihn mit dem nahegelegenen Soröer See vergleicht, der ungefähr dieselbe Form hat, allerdings etwas geringere Ausdehnung ( $220 h a$ ), dafür aber wohl eine grössere Tiefe besitzt. Auf dem Grunde des Soröer Sees finden sich entsprechende Ablagerungen von Mudde und Schneckennudde, ${ }^{1}$ ) während der Moorstrich „Flommen“ im Osten des Sees den Vorgang des Verwachsens und die Veränderungen der Pflanzenwelt bei Torfbildung und Austrocknen zeigt. ${ }^{2}$ )

Den eintönigen Charakter der Moorlandschaft gibt die Abb. 6 wieder.

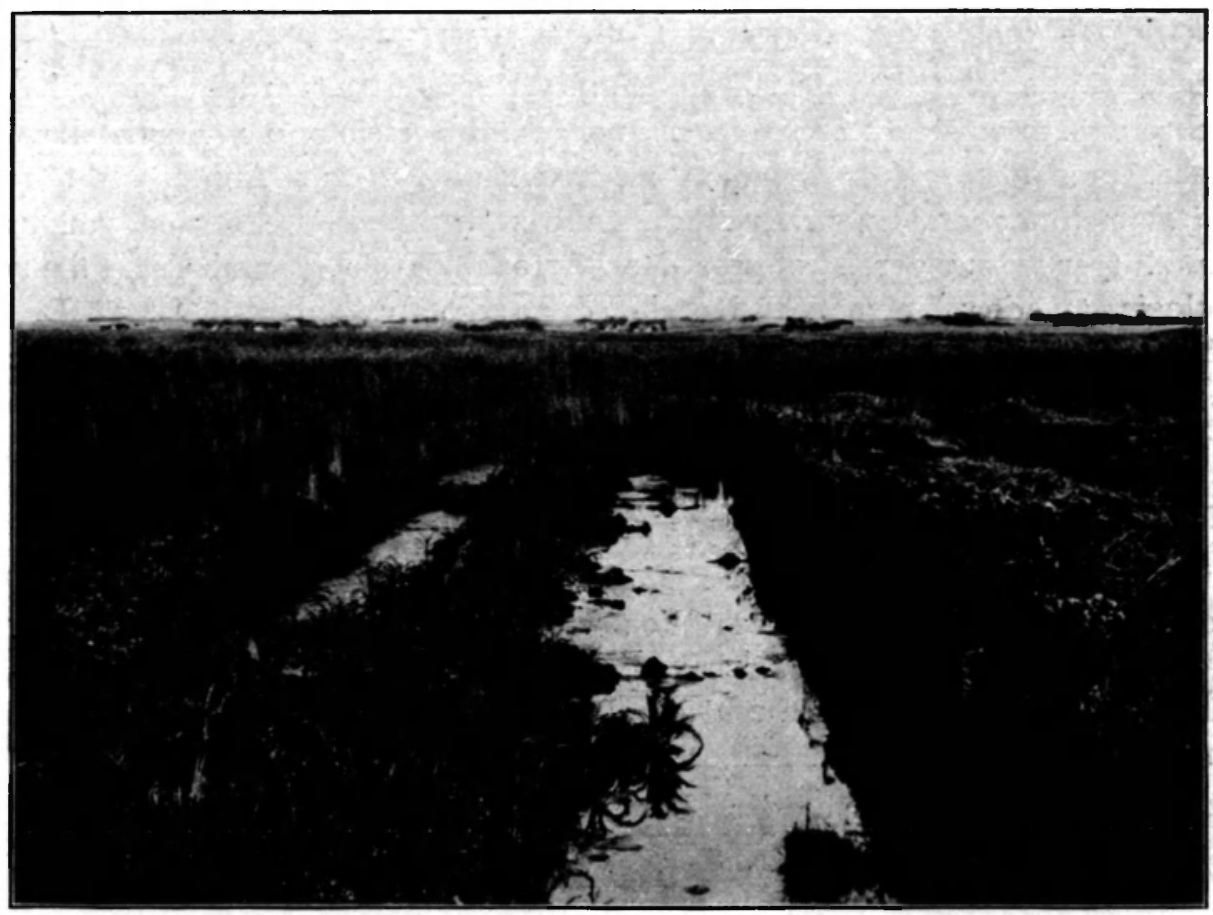

Abb. 9. Aussicht gegen Westen.

Sie zeigt die Aussicht über M a g le mos e von dem Wohnplatze aus gegen Süden. Im Park im Hintergrunde rechts liegt Böstrup; links davon auf dem Höhenrücken am Horizont' ein grosser Grabhügel „Topshöj". Ein Wagen auf dem Moore ladet Heu.

Die Abb. 7 zeigt den Blick vom Wohnplatze aus gegen Osten über eine in dessen unmittelbarer Nähe neu ausgeschachtete Torfgrube. Im Hintergrunde liegt das Dorf Höng. In der Torfgrube tritt das Grundwasser zutage. Dahinter reiche Rohrvegetation (,Schilf").

1) C. Wesenberg-Lund in Oversigt over det Kgl. Danske Videnskabernes Selskabs Forhandlinger. 1903. S. 172 bis 173 . In der Bucht bei der Soröer Akademie (Gymnasium) findet sich in einer Wassertiefe von 1 bis $3 \mathrm{~m}$ graue Schneckenmudde, zum Teil mit Schalen derselben Molluskenarten wie auf dem Wobnplatze im Maglemose.

2) P. Nielsen in Botanisk Tidsskrift. Bd. 1. Kjöbenhavn 1866. S. 225. 
Den Vordergrund in der Abb. 8 nimmt der 1900 untersuchte Wohnplatz ein. In der Mitte liegen, vom Grase halb verdeckt, die grösseren Steine des Untergrundes sichtbar, weil über ihnen Torf und Mudde abgegraben ist. Reste von der weissen Schneckenmudde sieht man im Vordergrunde. Links führt der Moorweg über den Wohnplatz nach den am Nordrande des Moores liegenden Häusern von Toelstang im Hintergrunde. Das rechts auf dem Wohnplatze liegende Stroh hat als Decke für einen Torfstapel gedient. Einen solchen sieht man hinten im Zwischengrunde, links vom nächsten Hause, dicht am Wege stehen. Hier ungefähr lag der in den Jahren 1902 bis 1904 untersuchte nördliche Wohnplatz.

Die drei Bilder sind, wie auch Abb. 9, gelegentlich einer am 6. Oktober 1908 erfolgten Exkursion vom Verfasser aufgenommen worden. Nachdem der hier besprochene Fund bekannt geworden war, haben mehrere schwedische Archäologen und Naturforscher die Fundstelle besucht, um dort weitere Studien zu machen. Auf der Abb. 9 sieht man die Teilnehmer an jenem Ausfluge, und zwar als zweite Person von links Dr. Rutger Sernander, Professor der Phytopaläontologie und der Pflanzenbiologie an der Universität Upsala, dann die Archäologen Dozent Dr. 0. Almgren, Upsala, als erste Person von links, und Dr. O. Frödin vom Nationalmuseum in Stockholm, dann rechts Herrn Lehrer M. J. Mathiassen, Mullerup, den Entdecker des Wohnplatzes. Letzterer liegt im Vordergrunde des Bildes, links von der neuen Torfgrube; auf dessen Oberfläche Stroh vom Torfstapel. Im Hintergrunde (westlich) erblickt man das Dorf Mullerup mit seiner Mühle. Die Bilder zeigen die Aussicht nach den vier Himmelsrichtungen über das Moor vom Wohnplatze aus.

Professor Sernander, der bekannte Torfmoorforscher, besuchte dreimal die Lokalität, um den Torf und die Baumstrünke an verschiedenen Stellen zu untersuchen. Darnach hat er für Maglemose folgendes Profil mitgeteilt ${ }^{1}$ ):

Oberfläche des Moores

\begin{tabular}{l}
\hline $35 \mathrm{~cm}$ Phragmitestorf \\
$\begin{array}{c}\text { Kiefernstrünke } \\
35 \mathrm{~cm} \text { Amblystegium-Moostorf } \\
\text { Laubholzstrünke }\end{array}$ \\
\hline $35 \mathrm{~cm}$ Cladium-Phragmitestorf $\}$ Z o n e mi t K u l t u r res t e \\
\hline $10 \mathrm{~cm}$ braune Mudde \\
\hline $20 \mathrm{~cm}$ Schneckenmudde \\
\hline $80 \mathrm{~cm}$ grüne Myriophyllummudde \\
\hline $10 \mathrm{~cm}$ glazialer Süsswasserton \\
Moräne
\end{tabular}

Hierzu möchte ich nur die Bemerkung machen, dass auf dem Wohnplatze selbst $k$ eine Strünke vorhanden waren. Entweder stammt das Profil aus einem anderen, vermutlich dem nordwestlichen Teile des Moores,

1) R. Sernander: Om Ancylustidens människa och tallperioden i södra Skandinavien. Geologiska Fören. i Stock holm Förhandlingar. Bd. 30. 1908. S. 390. 
oder es ist kein einfaches, unmittelbares, sondern ein aus mehreren Profilen theoretisch zusammengestelltes. Dass die Zusammenstellung das Richtige trifft, bezweifle ich übrigens nicht. Auf die Deutung jener Schichten und ihrer Bildungszeit durch Sernander werde ich später zurückkommen.

Proben des Lebertorfs wurden auf Ersuchen des schwedischen Landesgeologen Dr. N. O. Holst von Mathiassen direkt bei der Wohnstätte entnommen und von Professor G. Lagerheim in Stockholm mikroskopisch untersucht. Das Resultat dieser Untersuchung wird ebenfalls weiter unten besprochen werden.

\section{Die Altertiimerschicht}

Die Altertümerschicht-d. h. die viel Holz, Kohle, Knochen, Geräte und Abfälle von deren Herstellung auf dem Wohnplatz enthaltende Fund- oder Kulturschicht — folgte überall dem Seeboden, schmiegte sich demselben an. t'ber den Höhenrücken hin reichte sie an gewissen Stellen durch den Torf und Rasen bis ganz hinauf an die Oberfläche des Moores; aber auf dem Abhang gegen Osten zu, wo die Schneckenmudde tief lag, bestand die obere Schicht aus fast reinem Torf ohne Altertümer und Abfälle. Allerdings fand man auch wohl hier hin und wieder einige Flintabfälle zu oberst im Torf; es ist jedoch leicht denkbar, dass diese aus dem beim Stechen und Aufsetzen des Torfs auf der Oberfläche in älterer Zeit abgefallenen Bruch herstammen, wie auch das Vorkommen von Altertümern und Abfällen in der oberen Schicht der Anhöhe möglicherweise dieselbe Ursache hat. Vgl. Abb. 8 und 9.

Die Altertümerschicht war 0,2 bis $1 m$ mächtig; die Gegenstände lagen zumeist zu unterst im Torf, oft an der Grenze zwischen diesem und der Schneckenmudde, derart, dass das Gerät, der Knochen oder das Holzstück zur Hälfte in der Mudde eingebettet war. Nur selten waren sie ganz mit Schneckenmudde bedeckt, und zwar dann nur mit einer dünneren Schicht, höchstens etwa $5 \mathrm{~cm}$ dick. Die Knochensachen waren hier durch die Berührung mit dem Kalk von heller Farbe, nicht braun wie in dem dunklen Torf, und gleichzeitig ganz rein. Gegenstände von grösserer Längenausdehnung lagen gewöhnlich ungefähr wagerecht; nur wenige Geräte wurden in einer Stellung gefunden, die darauf deuten konnte, dass sie in die Mudde hineingesteckt waren; ${ }^{1}$ ) wahrscheinlich war dies zumeist nicht geschehen.

Die Sachen waren durch die ganze Altertümerschicht verteilt, ohne Rücksicht auf ihr spezifisches Gewicht, so dass leichte Holzkohle, Holz und Knochen häufig auf dem Grunde, manche Steinsachen dagegen hoch oben, nahe der Oberfläche des Moores lagen.

Ein Herabsinken durch den Torf im Laufe der Zeit liess sich nicht nachweisen und erscheint aus genannten Gründen ausgeschlossen.

1) In Raum I E 9, 2. Schicht steckte eine $12,4 \mathrm{~cm}$ lange, hübsche Knochenspitze nach abwärts gerichtet in der Schneckenmudde, während sie oben abgebrochen war und nur ungefähr $1 \mathrm{~cm}$ vom Stumpf des Schaftendes über die Oberfläche der Mudde hinausragte (Nr. 251). 
Wo nicht besondere Verhältnisse sich geltend machen, mögen in der Regel die Sachen in den Torfmooren in jener Schicht gefunden werden, die im Moment der Einlagerung sich zu bilden im Begriffe war. Allerdings gehen die Ansichten der Forscher über diesen Punkt noch auseinander, ohne dass jedoch Beweise angeführt werden. Meiner Auffassung schliesst sich u. a. der schwedische Landesgeologe Dr. N. O. Holst an. ${ }^{1}$ )

Wenn der Torf zusammensinkt, sinken zugleich die in ihm enthalteren Fremdkörper, verändern aber dabei ihre relative Lage nicht. Dass auf Mooren aufgeschüttete Wege und Eisenbahndämme einsinken können, indem die Torfmassen seitwärts verschoben werden, ist eine wohlbekannte Tatsache. Auch sind mehrere Forscher, wie Weber und Deecke ${ }^{2}$ ) der Ansicht,

\section{Menge und Verteilung der Altertümer}

Tabelle IV. Anhöhe aul dem Wohnplatze

$G=$ Geräte. $\quad A=$ Abfälle aus Flint

\begin{tabular}{|c|c|c|c|c|c|c|c|c|c|c|c|c|}
\hline \multirow{3}{*}{$\begin{array}{c}\text { Raum } \\
\text { mit } \\
1 \text { qm } \\
\text { Ober- } \\
\text { fläche } \\
\text { Feld } \\
\text { I }\end{array}$} & \multicolumn{2}{|c|}{$\begin{array}{c}\text { Höhe über } \\
\text { dem Meere }{ }^{1} \text { ) }\end{array}$} & \multirow{3}{*}{$\begin{array}{c}\text { Mäch- } \\
\text { tig- } \\
\text { keit } \\
\text { des } \\
\text { Torfs } \\
\\
m\end{array}$} & \multicolumn{8}{|c|}{ Schichten } & \multirow{3}{*}{$\begin{array}{c}\text { Im } \\
\text { ganzen }\end{array}$} \\
\hline & 总 & 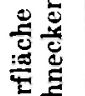 & & \multicolumn{2}{|c|}{$0-10 \mathrm{~cm}$} & \multicolumn{2}{|c|}{$10-30 \mathrm{~cm}$} & \multicolumn{2}{|c|}{$30-50 \mathrm{~cm}$} & \multicolumn{2}{|c|}{$50-70 \mathrm{~cm}$} & \\
\hline & $m$ & $m$ & & $G$ & $A$ & G & A & $\mathbf{G}$ & $A$ & G & A & \\
\hline E 1 & 4,25 & 3,53 & 0,72 & * & * & 1 & 42 & 9 & 73 & 7 & 189 & 321 \\
\hline $\mathrm{E} 2$ & 4,25 & 3,51 & 0,74 & 1 & 80 & 1 & 50 & 5 & 34 & 2 & 270 & 443 \\
\hline E 3 & 4,26 & 3,54 & 0,72 & 2 & 25 & 0 & 7 & 1 & 9 & 6 & 99 & 149 \\
\hline E 4 & 4,23 & 3,60 & 0,63 & 5 & 137 & 1 & 37 & 1 & 15 & 4 & 93 & 293 \\
\hline F 2 & 4,27 & 3,49 & 0,78 & 1 & 89 & 0 & 44 & 0 & 30 & 3 & 151 & 318 \\
\hline F 3 & 4,25 & 3,52 & 0,73 & 4 & 55 & 0 & 13 & 5 & 39 & 4 & 55 & 175 \\
\hline F 4 & 4,19 & 3,59 & 0,60 & 0 & 35 & 1 & 19 & 2 & 24 & 5 & 49 & 135 \\
\hline G 2 & 4,23 & 3,48 & 0,75 & 4 & 113 & 0 & 3 & 2 & 76 & 8 & 254 & 460 \\
\hline G 3 & 4,19 & 3,51 & 0,68 & 6 & 79 & 0 & 6 & 9 & 78 & 6 & 160 & 344 \\
\hline G 4 & 4,14 & 3,53 & 0.61 & 2 & 54 & 2 & 26 & 1 & 220 & 0 & 20 & 325 \\
\hline & ga & Stu & $\cdot \cdot$ & 25 & 667 & 6 & 247 & 35 & 598 & 45 & 1340 & 2963 \\
\hline
\end{tabular}

*) Bei der Aufzählung nicht für diese Schicht des Raumes getrennt gehalten.

1) N. O. Holst: Postglaciala tidsbestämningar. Sveriges geologiska Undersökning. Àrsbok 2 (1908), Nr. 8 . Stockholm 1909, S. 8.

2) C. A. Weber: Augstumalmoor, Berlin 1902, S. 180. Weber in Englers Botan. Jahrbüchern, Bd. 35, 1904. Sonderabdruck S. 54. - W. Deecke: Säugethiere aus dem Diluvium und Alluvium der Provinz Pommern. Mitt. d. naturw. Vereins Greifswald. Sonderabdruck. Greifswald 1904, S. 12. 
Tabelle V. Niederung aul dem Wohnplatze

$\mathbf{G}=$ Geräte. $\quad \mathrm{A}=\mathrm{A}$ bfälle aus Flint

\begin{tabular}{|c|c|c|c|c|c|c|c|c|c|c|c|c|c|c|c|c|c|c|}
\hline \multirow[t]{2}{*}{$\begin{array}{l}\text { Raum } \\
\text { mit } \\
1 \mathrm{qm} \\
\text { Ober- } \\
\text { fläche } \\
\text { Feld } \\
\text { III }\end{array}$} & $\begin{array}{c}\text { Höhe } \\
\text { dem } .\end{array}$ & 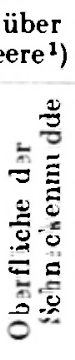 & \multirow[t]{2}{*}{$\begin{array}{c}\text { Mäch- } \\
\text { tig- } \\
\text { keit } \\
\text { des } \\
\text { Torfs }\end{array}$} & $\stackrel{5}{\stackrel{5}{0}}$ & \multicolumn{11}{|c|}{ S } & & & \multirow[t]{2}{*}{$\begin{array}{c}\text { Im } \\
\text { ganzen } \\
\text { Stück }\end{array}$} \\
\hline & $m$ & $m$ & & G & A & G & A & G & A & G & A & G & $A$ & r: & $A$ & G & A & \\
\hline$C 4$ & 3,93 & 3,05 & 0,88 & 0 & 5 & 0 & 4 & 0 & 0 & 1 & 19 & 5 & 40 & - & - & - & - & 74 \\
\hline D 4 & 3,93 & 2,92 & 1,01 & 0 & 3 & 0 & 0 & 0 & 0 & 0 & 0 & 4 & 35 & 1 & 1 & - & - & 44 \\
\hline E 4 & 3,89 & 2,83 & 1,06 & 0 & 0 & 0 & 1 & 0 & 0 & 0 & 1 & 4 & 35 & 0 & 0 & - & - & 41 \\
\hline $\mathbf{F} 4$ & 3,86 & 2,74 & 1,12 & 0 & 0 & 0 & 0 & 0 & 0 & 0 & 0 & 0 & 1 & 3 & 26 & - & - & 30 \\
\hline F 5 & 3,86 & 2,79 & 1,07 & 0 & 0 & 0 & 0 & 0 & 0 & 0 & 0 & 0 & 3 & 2 & 34 & - & - & 39 \\
\hline F 6 & 3,86 & 2,82 & 1,04 & 0 & 0 & 0 & 0 & 0 & 0 & 0 & 0 & 0 & 0 & 5 & 6 & - & - & 11 \\
\hline G 4 & 3,82 & 2,69 & 1,13 & 0 & 0 & 0 & 0 & 0 & 0 & 0 & 0 & 0 & 0 & 0 & 0 & 2 & 13 & 15 \\
\hline H 3 & 3,82 & 2,64 & 1,18 & 0 & 0 & 0 & 0 & 0 & 0 & 0 & 0 & 0 & 0 & 0 & 0 & 1 & 14 & 15 \\
\hline $\mathrm{H} 4$ & 3,83 & 2,65 & 1,18 & 0 & 0 & 0 & 0 & 0 & 0 & 0 & 0 & 0 & 0 & 0 & 0 & 1 & 16 & 17 \\
\hline H $\tilde{5}$ & 3,86 & 2,64 & 1,22 & 0 & 0 & 0 & 0 & 0 & 0 & 0 & 0 & 0 & 0 & 0 & 0 & 2 & 18 & 20 \\
\hline & & & & 0 & 8 & 0 & b & 0 & 0 & 1 & 20 & 13 & 114 & 11 & 67 & 6 & 61 & 306 \\
\hline
\end{tabular}

dass schwere oder spezifisch schwere Gegenstände im Laufe der Zeit durch den Torf hinuntersinken können. Am krassesten äusserte sich wohl in dieser Richtung Henri Breuil mit folgenden Worten: ${ }^{2}$ ), La tourbe se laisse penètrer très facilement par des objets de toute date; la présence d'un objet à l'interieur de ce dépót est done insuffisant pour en indiquer l'âge. Cela résulte des observations prolongèes de M. d'Ault du Mesnil, si compétent pour les ètudes picardes."

Hiergegen wandte jedoch Marcel Baudouin gleich ein, dass für die Moore des westlichen Küstenlandes Frankreichs, z. B. in Vendée, dies nicht zutreffe. ${ }^{3}$ )

Die beigefügten Tabellen IV und $\mathrm{V}$ sollen zur Aufklärung über die Menge der in den verschiedenen Torfschichten innerhalb zweier je $10 \mathrm{qm}$ grossen Flächen enthaltenen Altertümer dienen. Die Flächen sind so gewählt, dass die eine (Tab. IV) den höchsten Teil des Platzes umfasst,

1) Die Angaben der Meereshöhe beziehen sich auf die eine, und zwar die südöstliche Ecke des Raumes. Die Tiefen dagegen sind ungefähre Durchschnittszahlen für die ganze Schicht (weniger genau ermittelt).

2) Abbe Breuil in Congres prehistorique de France. 1 ere Session - Périgueux 1905. Paris 1906, S. 441.

3) Ebenda, S. 442. 
während die andere (Tab. V) sich über die östliche Niederung der Wohnstätte erstreckt. ${ }^{1}$ ) Zwischen den Flächen ist ein Abstand von $5 m$ (von I $\mathrm{G} 4$ bis III $\mathrm{C} 4$ ).

In der Aufzählung sind Geräte (G) und Flintabfälle (A) mit inbegriffen, während der aus Knochen bestehende Abfall und einzelne Vorarbeiten aus Knochen nicht mitgerechnet sind. Das Verhältnis würde sich nicht ändern, wenn diese auch miteinbezogen würden.

Man sieht, dass die tiefste Torfschicht auf der Anh öhe, 50 bis $70 \mathrm{~cm}$ unter der Oberfläche, in welcher sich schon an verschiedenen Stellen unten die Schneckenmudde zeigt, ${ }^{2}$ ) im ganzen $45+1340=1385$ Stück Altertümer enthält. Genau halb so viele $(692=25+667$ Stück) fanden sich in der obersten, in der Rasenschicht, die jedoch nur die halbe Dicke $(0$ bis $10 \mathrm{~cm}$ unter der Oberfläche) hatte, weshalb das Verhältnis zwischen oberer und unterer Schicht hier gleich ist. Die mittleren Schichten sind dagegen verhältnismässig arm an Altertümern, während die Menge unten am grössten ist; die untere Schicht enthielt im gewählten Beispiel gegen die Hälfte a lle r Sachen (1385 von 2963). An der höchsten Stelle des Grundes, in Raum IV K 3, lag der ga nze Inhalt: 25 Stück Flintabfall und 4 Knochen zu unterst im Torf dicht über der Schneckenmudde.

In der $\mathbf{N}$ iederung enthielten die oberen Schichten so gut wie gar nichts; die Altertümerschicht liegt hier. wie deutlich zu erkennen ist, tief und folgt dem Boden dicht über der Schneckenmudde.

Jedoch nicht nur hier, sondern auch auf der Anhöhe enthielten die unteren Torfschichten, also der Wassertorf, die weit überwiegende Menge der Alter$\mathrm{t} \ddot{\mathrm{u}} \mathrm{me} \mathrm{r}$; von mehreren, selbst auf dem hö chsten Teil des Platzes, ist festgestellt, dass sie sich auf oder dicht über der Schneckenmudde fanden, andre sogar in der Schneckenmudde selbst.

Unmittelbar auf der Oberfläche der Schneckenmudde, seltener dicht über oder unter derselben, fanden sich inner. $\mathrm{halb}$ der A nhöhe in Feld I unter anderem folgende Geräte: 17 Knochenspitzen (Nr. 217 in D 1, 62 in D 5, 218 und 221 in D 8,220 in D 9, 101 in E 7, 251 in $\mathrm{E} 9,252$ in $\mathrm{E} 10,120$ und 121 in $\mathrm{F} 3,277$ in $F 6.175$ in $\mathrm{G} 10,193$ in $\mathrm{H} \mathrm{3}, 524$ in $\mathrm{I} 4,556,563$ und 564 in $\mathrm{K} 5$ ), 8 Harpunen (Nr. 68 in D 7, 198 in $H$ 5, 794 bis 799 in $K 7$ ), 2 Hornäxte (Nr. 134 in $F 8,718$ in I 1), 2 Messer aus Eberhauern (Nr. 149 in G 5, 577 in K 9), 1 Knochenaxt mit Schafttülle (Nr. 559 in $\mathrm{K} 5$ ), 1 Netzknüpfer aus Knochen (Nr. 566 in $\mathrm{K} 4$ ), 3 Flintkratzer (Nr. 219 in D 9, 171 in G 3,177 in G 10), 5 Knorren und Kerne (Nr. 206 in C 7, 207 in $\mathrm{C} 7,222$ in $\mathrm{D} 8,578$ in $\mathrm{K} 9,580$ in $\mathrm{K} 10$ ). Ausserdem einige Flintklingen und Späne, wie auch viel Flintabfall und viele Knochen.

Alles dies ist i m Wasser a bge lage r t, wodurch vollständig die Möglichkeit ausgeschlossen ist, dass dort ursprünglich eine trockene Insel gewesen sei, die zum Bewohnen gewählt wurde. Es fand sich hier kein derartiges Inselchen.

1) Es wird erinnerlich sein, dass sich der höchste Punkt in der Oberfläche des Wohnplatzes (bei I F 2) 4,27 $m$ ü. d. M. befindet, der niedrigste (bei III I 2) 3,79 $\mathrm{m}$ ü. d. M. (Tab. I).

2) An der einen Ecke von I F 4, z. B. $60 \mathrm{~cm}$ unter der Oberfläche. 
Auf der Abb. 10, nahe der Mitte, sieht man in der Wand der durchschnittenen Anhöhe zu unterst im Torf, der $50 \mathrm{~cm}$ mächtig war (in Raum I B 3, 2. Schicht) die abgeschnittene Krone eines Hirschgeweihs. Diese lag hier zusammen mit 67 Stück Flintabfall dicht über der Schneckenmudde, die unterhalb als lichter Streifen im Bilde hervortritt.

Die Ablagerung muss im offenen Wasser begonnen und sich während der Bildung der Torfschicht im See fortgesetzt haben.

Entsprechende Ablagerungsverhältnisse sind keineswegs ungewöhnlich. Altertumsfunde aus der Steinzeit sind in Dänemark sicher recht oft unter ähnlichen Verhältnissen gemacht worden, aber nur sehr selten waren die Funde reichhaltiger oder sorgfältig genug aufgeklärt. Erwähnt seihier zum Vergleich nur der Fund aus dem Storemose im Kirchspiel Gentofte bei Kopenhagen, wo zwei hölzerne Stiele für Steinäxte, andre Geräte aus Holz und Knochen, ein behauenes Flintstück sowie ein kleines Stück von einem Fischnetz gefunden wurden, und zwar zusammen mit vielen

Holzstücken, die Spuren von Feuer trugen, auf einer Schicht Schneckenmudde am Moorgrund, ungefähr $3 \mathrm{~m}$ unter der Oberfläche

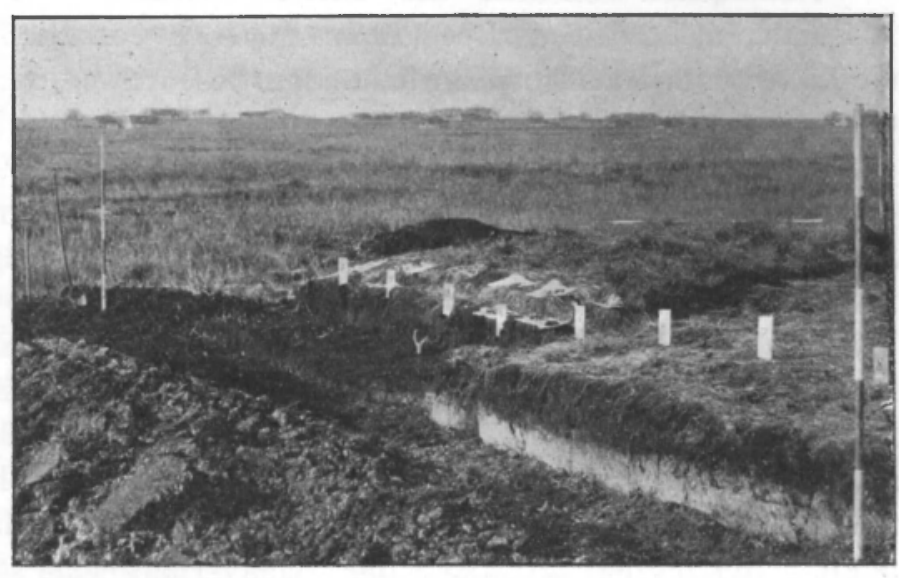

Abb. 10. Die Anhöhe in Feld I.

Am obersten Punkt des Platzes ist eine Vermessungsstange wagerecht auf das Gras gelegt, das das Moor bedeckt. Drei andere Stangen sind an den Ecken des Feldes aufgestellt in einem Seitenabstand von $10 \mathrm{~m}$ voneinander. Die numerierten Pfähle stehen in gegenseitigem Abstand von je $1 m$ an der Ostwand der Bank B 1 bis 8 entlang. Von 0 (links) bis 5 sind die Grasnarbe und zwei $20 \mathrm{~cm}$ mächtige Schichten Torf untersucht und bis auf die helle Schneckenmudde abgegraben, die am deutlichsten in der Wand rechts zutage tritt. Im Vordergrund (links) ist die untersuchte Torfmasse aufgeschichtet. Hinter jedem der untersuchten Räume sind die darin zuletzt gefundenen Sachen zur weiteren Behandlung vorläufig auf Säckchen ausgelegt.

lagernd. Diese Fund-

verhältnisse sind bisher rätselhaft erschienen, ${ }^{1}$ ) dürften jetzt jedoch ihre Erklärung finden.

An vielen Orten, überall in Europa, von Norditalien, Frankreich und der Schweiz, durch Deutschland und das westliche Russland bis an die Ostsee, z. B. bei Wismar, ${ }^{2}$ ) sind sowohl steinzeitliche als jüngere Funde in der gleichen Weise abgelagert getroffen worden, indem die Altertümer auch

1) Aarböger f. nord. Oldkyndighed. 1898. S. 136. Memoires des Antiquaires du Nord. 1896-1901. S. 177. Mus. Nr. A. 2659 bis 2670.

2) G. C. F. Lisch: Lagerungsverhältnisse des Pfahlbaues von Wismar. Jahrbücher des Vereins für meklenburg. Geschichte. Jg. 30. 1865. S. 17. 
hier in der unteren Torfschicht der Moore gefunden wurden, dicht über oder gerade auf der Grenze gegen die darunter liegende Schneckenmudde: fango con marna, blanc fond (in engerem Sinne), We is sergrund, Schneckenmergel, Seemergel, Wiesenkalk, Kalkmudde, Seekreide, Alb oder welche Namen man nun immer dieser Art von Grundschicht in den früheren Seen gegeben hat. Die Funde sind häufig aus grossen Wohnplätzen, über deren Natur man nicht im Zweifel gewesen ist; in fast allen Fällen sind es $P f a h l b$ a u te $n$, von denen man immer angenommen hat, dass sie in Seen errichtet wurden, die während des Bewohntseins und später mit Torf verwachsen sind. ${ }^{1}$ )

Namentlich scheinen die Naturverhältnisse bei dem steinzeitlichen Pfahlbau im Moosseedorfsee (10 $\mathrm{km}$ nördlich von Bern), die verhältnismässig sorgfältig vom Naturforscher Chlmann beschrieben sind, ziemlich genau mit denjenigen übereinzustimmen, die wir im Maglemose kennen gelernt haben, sowohl in Bezug auf die Anlage der Wohnstätte auf einer Erhöhung der Schneckenmudde weit draussen in dem ursprünglichen See, in die die Pfähle hineingerammt waren, als auch in Bezug auf die Lage und Verteilung der Altertümer im Torf ohne Abhängigkeit von ihrem spezifischen Gewicht. Gleiche t'bereinstimmung zeigen die beiden Funde betreffend die Mächtigkeit der Altertümerschicht im Torf. Obgleich alle auf dem Wohnplatze im Moosseedorfsee gefundenen Altertümer der kurzen Schlussperiode der Steinzeit angehören, war die Kulturschicht von der gleichen Dicke wie unsere, nämlich am Rand ungefähr $5^{\prime \prime}(13 \mathrm{~cm})$, in der Mitte des Platzes 2 bis 3 Fuss (63 bis $94 \mathrm{~cm}$ ); dass der Sachverhalt ein solcher war, mag befremdend sein; aber die Tatsache, dass sich diese dicke Schicht in ver$\mathrm{h}$ ält n ismässig kurzer Zeit bei diesem sowohl als auch wahrscheinlich bei anderen Pfahlbauten gebildet hat, lässt sich nicht abweisen. ${ }^{2}$ )

Ähnlich lagen die Verhältnisse beim Pfahlbau von Robenhausen, ${ }^{3}$ ) und im Bare Moor in Schonen hatte die steinzeitliche Kulturschicht ebenfalls eine bedeutende Mächtigkeit, etwa $70 \mathrm{~cm} .{ }^{4}$ )

Die Bildung des Torfs und damit die Vertorfung des Sees schreitet verhältnismässig schnell vorwärts, wohingegen die Bildung der Mudde sehr langsam vonstatten geht, weil in diesem Falle die abgelagerten Pflanzenreste ganz klein sind oder zunächst von den Wassertieren durchexkrementiert, in Kot rerwandelt werden müssen. ${ }^{5}$ )

1) Kellers Pfahlbauten. 6. Ber. 1866. S. ㄴ⒍ Jol n Lubbock: Pre historic Times. 2. edit. London 1869. S. 180.

2) 'J. Uhlmann: Geologisch-archäologische Verhältnisse am Moosseedorfsee. Berner Mitteilungen $\mathrm{N}_{\mathbf{r}}$.47. Bern 1860. S. 60, mit Profilen und Plan. Jahn und Uhlmann: Die Pfahlbau-Altertümer von Moosseedorf. Bern 1857. 12 ${ }^{\circ}$. S. 15. Uhlmann in Kellers Pfahl. bauten. 2. Ber. 1858. S. 119, 155, Taf. III, Fig. j6; 3. Ber. 1860. S. 97. Taf. VI, Fig. 2. Vgl. ebenda S. 73 samt Anm. 1, S. 75. Taf. I, Fig. 1 und Rob. Munro: Lake-Dwellings of Europe. 1890. S. 75.

3) Nach gütiger Mitteilung des Herrn Professor Dr. Jakob Heierli, Zürich. Vgl. Kellers Pfahlbauten. 6. Ber. 1866. S. 247, Profil.

4) R. Sernander: Om Ancylustidens människa och tallperioden i södra Skandinavien. Geol. Foren. i Stockholm Förhandlingar. Bd. 30. 1908. S. 391.

5) Vgl. Troyon: Habitations lacustres. Lausanne 1860. S. 413. 


\section{Ausdehnung des Wohnplatzes}

Es ist schon oben erwähnt, dass der Wohnplatz im Maglemose unmittelbar südlich von dem Hauptgraben lag, denı die Kirchspielsgrenze folgt. Nördlich vom Graben wurden einige Probelöcher ausgeschachtet, in denen sich jedoch nur ein einziges Stück Flintabfall fand; von früheren Funden in den hier befindlichen Torfgruben wusste man nichts.

Es ist also wahrscheinlich, dass der Graben ungefähr die Grenze für diesen Wohnplatz gegen Norden bildet.

Nach den anderen Himmelsrichtungen wurde die Untersuchung des Platzes so lange fortgesetzt, bis die Spärlichkeit des Abfalls und der Altertümer andeutete, dass die Grenze aller Wahrscheinlichkeit nach erreicht sei. Hiernach betrug die Ausdehnung der Wohnstätte von Norden nach Süden ungefähr $35 \mathrm{~m}$, von Osten nach Westen gegen $30 \mathrm{~m}$; der Platz war also rund 100 Fuss lang und breit.

Der Torfstich war am Graben begonnen und in der Richtung gegen Süden fortgesetzt worden; der Teil des Platzes, der dadurch zerstört worden war, ehe das Museum benachrichtigt wurde, dürfte zwischen einem Drittel und der Hälfte der Fläche ausgemacht haben.

Sowohl weiter im Norden als im Süden des Wohnplatzes sind jedoch im Moor auch gleichartige Sachen gefunden, ein Beweis, dass der Aufenthalt der Steinzeitmenschen nicht auf diesen Platz allein beschränkt war.

Am wichtigsten ist ein bedeutender Fund, der später im nördlichen Teil vom Maglemose gemacht wurde. Im Mai 1902 teilte Lehrer M. J. Mathiassen dem Verfasser mit, dass dort ein neuer Wohnplatz gefunden worden war, und in der Folge wurde Mathiassen vom Nationalmuseum beauftragt, daselbst weitere Nachforschungen zu machen. Nachdem seine erfolgreichen Grabungen in den Jahren 1902 und 1903 den Beweis geliefert hatten, dass man auf eine Wohnstätte von grösserer Ausdehnung gestossen war, wurde im Jahre 1904 vom Nationalmuseum selbst eine umfassendere Grabung an dieser Stelle vorgenommen. Der südlichste Punkt des neuen Wohnplatzes war ungefähr $75 \mathrm{~m}$, der nördlichste $125 \mathrm{~m}$ nördlich vom oben erwähnten Hauptgraben. Die Länge betrug somit etwa $50 \mathrm{~m}$ bei einer Breite in ostwestlicher Richtung von mindestens $33 \mathrm{~m}$. Der Platz gehörte der Flur von Böstrup Toëlstang im Kirchspiel Gjerslev (Kataster Nr. 1). Auch hier war in der Oberfläche des Moores und im alten Seegrund eine schwache Anhöhe vorhanden, die etwa die Mitte der Wohnstätte einnahm. Die Lage zeigt die Abb. 8.

Die beiden Plätze berührten sich nicht; das Verhalten von Torf und Schneckenmudde wie das Auftreten und die Art der gefundenen Altertümer war aber in beiden Fällen fast ganz gleich; die Mächtigkeit des Torfs betrug 20 bis 100, in der Regel 25 bis $35 \mathrm{~cm}$. Unten war der Torf Lebertorf; darunter folgte wieder Schneckenmudde.

Südlicher in Maglemose, in dem angrenzenden Moor Ellemade (s. Karte, Abb. 1) und in dem von der Halleby-Au durchströmten grossen, östlich gelegenen Moorgelände Store Aamose sind Altertümer gleicher Art aber nur vereinzelt gefunden worden. 


\section{Art des Wohnplatzes}

Da alle Beobachtungen an der Stelle zu dem Schluss führten, dass die ganze Masse von Altertümern und Abfall in einem $\mathrm{See}$ abgelagert war, in dem die Torfbildung vor sich ging, so war es bei der Untersuchung höchst überraschend, dass sich trotz genauesten Suchens auch nicht die geringste Spur eires Baues fand, der als Stand, als feste Unterlage für die Ansiedlung gedient haben könnte.

Wohnplätze wurden im Altertum sehr häufig in Seen angelegt. In Dänemark trifft man derartige Ansiedelungen oft auf kleinen, natürlichen Inseln, Holmen, wohin man sich wohl namentlich zurückgezogen hat, um in der Nacht vor den wilden Tieren sicher zu sein. Eine solche kleine Insel mit einem steinzeitlichen Wohnplatz ist z. B. Magleö bei Bodal in dem nahegelegenen grossen Aamose, ${ }^{1}$ ) ein Torfmcor, das von der Halleby-Au durchflossen wird, die gleich nachdem sie den Tissö verlässt, die aus dem Maglemose kommende Böstrup-Au aufnimmt (s. nordöstliche Ecke der Karte, Abb. 1).

Wo indessen eine solche. Insel nicht zur Verfügung stand, half man dem in anderen Ländern oft auf kürstliche Weise $a b$, indem man entweder eine künstliche Insel aufführte oder einen Pfahlbau.

$\mathrm{Zu}$ der letzteren Art waren gewöhnlich eine grosse Menge von Pfählen erforderlich - bis zu 50000 auf einem einzigen Platz -; für die erstere benötigte man weniger Pfähle, aber mehr Reisig, Erde und Steine. ${ }^{2}$ )

Etwas Derartiges fand sich nicht auf dem Wohnplatze im Maglemose. Nicht ein einziges Stück Holz zeigte sich, das durch seine Grösse oder Stellung hätte vermuten lassen können, dass es als Pfahl gedient hatte. Die Einwendung, dass die Pfähle weggefault oder beim Eisgang auf dem See im Frühling weggerissen und auf diese Weise verschwunden sein könnten, muss zurückgewiesen werden, da sich im Torf eine grosse Menge anderes Holz von der Wohnstätte wohlerhalten vorfand, und da Pfähle von wirklichen Pfahlbauten in den verschiedensten Seen, auf denen auch Eisgang ist, ihren Platz bewahrt haben. ${ }^{3}$ ) Ausserdem mussten, selbst wenn die Pfähle hier herausgerissen worden wären, die Löcher, die durch das Einrammen in die Schneckenmudde in dieser hervorgebracht waren, sich danach mit dunklem Torf gefüllt haben, und sich auf diese Weise leicht in der kalkweissen Grundschicht nachweisen lassen. Derartige runde, ausgefüllte Pfahllöcher liessen

1) Danmarks geolog. Cnders. I. Reihe, Nr. 8, S. 128. Kartenblatt „Holbæk“. S. Müller: Nordische Altertumskunde, Bd. 1, Strassburg 1897, S. 20.

2) t'ber die verschiedenen Formen siehe Rob. Munro: Prehistoric Scotland, Edinburgh 1899, S. 426. Vgl. Munro: Lake-Dwellings of Europe, London 1890.

3) S. photographische Wiedergaben in Keller: Pfahlbauten, 8. Bericht, Zürich 1879. Vignetten A u. B und Munro: Prehistoric Scotland, S. 429, Fig. 257 (Schweiz). M. Foule: Conferences de Paleontologie, Paris 1905, S. 140, Fig. 217. Der obenerwähnte Moosseedorfsee bei Bern und alle anderen kleinen Seen in der nördlichen Schweiz sind jeden Winter mit festem Eis überfroren. Keller: Ffahlbauten, 2. Ber., S. 119. 
sich indessen nirgends nachweisen. ${ }^{1}$ ) Dagegen sah man nicht selten ganz schmale Risse, Spalten in der Schneckenmudde, die mit Torf ausgefüllt waren, was sicher nur eine Folge des Austrocknens bei der Entwässerung des Moores war.

Von einem regelrechten Pfahlbau kann hier also durchaus nicht die Rede sein; aber ebensowenig hatte man in Maglemose eine künstliche Insel, einen cran nog angelegt.

Zweige kamen allerdings in Menge vor, aber nur in kurzen Stücken, nicht etwa in Schichten gesammelt oder auf irgendeine Weise zusammengehalten und ohne darauf geschüttete Erde. Ein grosser Teil der Zweige war ausserdem durch Feuer halb oder ganz verkohlt, konnte demnach nicht zu einem Unterbau im Wasser gedient haben. Wir folgern also, dass auf dem Seegrund kein Bau aufgeführt gewesen ist, und es muss versucht werden, die Frage nach der Art des Siedelns auf andere Weise zu beantworten.

Da man voraussetzen muss, dass der See schon während der Zeit der Besiedlung im Zuwachsen begriffen gewesen ist, und dass er sich auf diese Weise vom Ufer aus nach und nach verengte, so könnte man sich denken, dass dort in der Steinzeit ein kleiner, offener See war, ein Wasserloch im Moor, um welches herum man sich niedergelassen hatte. Dass aber diese Erklärung nicht die richtige ist, geht deutlich aus der Lagerung der Altertümer hervor. Diese müssten in einem solchen Fall am dichtesten am Rande des Wohnplatzes gelegen haben, während sie in Wirklichkeit von der Mitte nach aussen hin an Menge stark abnahmen.

Auch der Gedanke läge nicht fern, dass man in der Steinzeit nur im Winter hier gewohnt habe, wenn der See mit Eis bedeckt war, und dass die Sachen bei der Eisschmelze zu Boden gesunken seien. Wenn man versucht hat, sich die Bedeutung ähnlicher Funde im Ausland zu erklären, so hat man sich denn auch in der Regel bei der Hypothese einer bewohnten Eisfläche beruhigt. Ja, selbst in Dänemark ist man, um die Verhältnisse auf dem steinzeitlichen Wohnplatz im Brabrander See (in Jütland) zu erklären, in neuester Zeit auf jene alte „Eistheorie“ wieder verfallen und hat, meines Erachtens mit Unrecht, seine Zuflucht zu einer schmelzenden Eisscholle genommen. ${ }^{2}$ )

Es ist jedoch wenig wahrscheinlich, dass die Jäger und Fischer der Steinzeit, während sie sonst auf dem Lande wohnten, gerade in der strengsten Kälte des Winters und im schneidenden Wind auf das offene Eisfeld des Sees gezogen sein sollten, um dort sich niederzulassen, wenn ihnen am Ufer durch den Wald Schutz und Schirm geboten wurde. Gerade bei unserem Fund lässt es sich denn auch erweisen, dass diese Erklärung nicht stichhaltig ist.

1) Vgl. K. Schumacher: Untersuchung von Pfahlbauten des Bodensees. Veröffentlichungen der grossherzogl, badischen Sammlungen für Altertums- und Völkerkunde, Heft 2, Karlsruhe 1899, S. 28.

2) Thomsen et Jessen: La trouvaille de Brabrand. Mémoires des Antiquaires du Nor't, 1904. Copenhague, S. 227. Aarböger for nordisk Oldkynd. 1906, S. 70.

Praehistorische Zeitschrift III Heft 1/2. 1911. 
Es ist bekannt, dass die Tierreste unter dem Abfall in unseren Kökkenmöddingern (Abfallhaufen) ausgezeichnete Aufklärungen über die Jahreszeit während der Benutzung dieser Wohnstätten gegeben haben. Im Vertrauen darauf, dass die Knochen aus dem Maglemosefund ähnliche Belehrung bringen könnten, richtete ich eine Anfrage hierüber an den Zoologen Herluf Winge, der mit grösstem Entgegenkommen die Bestimmung der vielen zum Fund gehörigen Knochen ausgeführt hat (siehe unten). Die Antwort widersprach nicht meinen Erwartungen; sie lautete dahin, dass der Platz sicher im Sommer bewohnt gewesen war. da der Fund Knochen ron Hirschkälbern, jungen Elchen, jungen Enten, jungen Eichelhähern, ju ngen Gabelweihen und anderen jung en Vögeln (Schwänen?) enthielt, die nicht im Winter leben, und von denen mehrere auf der Stelle verspeist sein mussten, da man an den Knochen il von Geräten herrührende Schabund Schnittmarken oder Zeichen von der Benagung durch Hunde bemerken konnte. Mehrere auf natürliche Weise abgeworfene Hirschgeweihe könnten vielleicht am ehesten auf das Winterhalbjahr deuten. Auch das Vorkommen von Haselnüssen weist wohl in die gleiche Richtung. Auf einen Winteraufenthalt allein deuten aber keine bestimmten Tatsachen.

Ebenso verhält es sich mit dem genannten Fund aus dem Brabrander See. Eine Anzahl Knochen von junge n Rotwildkälbern (Cervus elaphus), die nicht im Winter getötet sein können, zeugen davon, dass man auch hier i m Som mer sich auf dem See aufhielt.

Nach alledem scheint also nur eine Erklärung möglich: Man muss in der Steinzeit im See auf einer s chwimmenden Unterlage gewohnt haben. I’ber deren Art können wir uns keine sichere Vorstellung machen, da keine Spur davon erhalten ist. Dass man sich ständig in Booten oder Einbäumen aufgehalten, also geradezu darin gewohnt haben sollte, ist wohl wenig wahrscheinlich; die Betätigung, die hier stattgefunden hat, scheint zu umfassend, als dass für sie in einem einzigen ausgehöhlten Baum Platz gewesen wäre. Dass eine grössere Anzahl von Booten hier ihren Versammlungsplatz gehabt und an dieser Stelle verankert gelegen hätte, würde die Anhäufung von Altertümern leichter erklären; aber natürlicher als ein Schiffspark dieser Art, eine Flottille, erscheint doch ein aus Baumstämmen zusammengebundenes $\mathrm{Holz}$ floss.

Ein solches war hier leicht zuwege zu bringen; Stämme der Kiefer, deren Zweige abgehauen waren, und die man mit Wieden zusammenband, konnten ein vortreffliches Holzfloss bilden, wie Tausende von gleichen Flössen, die in unserer Zeit auf den Flüssen des Kontinents hinabgetrieben werden, zur Genüge dartun.

Das spezifische Gewicht des Kiefernholzes beträgt in an der Luft getrocknetem Zustand ungefähr 0,5 , in frischem Zustand 0,8 . Der grösste Kiefernstamm, den man im Moor gesehen hat. war ungefähr $40 \mathrm{~cm}$ dick. Selbst wenn man mit einer so grossen Dicke der Stämme im Holzfloss rechnete, so würde dieses also nur 20 bis $30 \mathrm{~cm}$ tief im Wasser liegen; ein gewöhnliches, leichtes und einfaches Holz-

1) Ein Knochen von einem jungen Vogel aus Raum I H 2, 2. Schicht, ist z. B. geschabt und eingeschnitten vom Steinzeitvolk. 
floss hat wohl nur einen Tiefgang von ungefähr $15 \mathrm{~cm}$. Die Belastung mit etwa zehn Menschen und anderer Last von gleicher Grösse vermehrt den Tiefgang nicht merklich. Bei rationell betriebener Flösserei auf den Bächen und Flüssen wird eine Wassertiefe von 0,50 bis $0,70 \mathrm{~m}$ als hinreichend für die Fortbewegung mit Befrachtung befunden. ${ }^{1}$ )

Ein Holzfloss, das nur still liegen oder sich langsam in einem kleinen, ruhigen See fortbewegen soll, benötigt etwas geringere Wassertiefe.

Damit das Floss ungehindert schwimmen könnte, würden auf dem Wohnplatze in Maglemose nicht mehr als 30 bis $50 \mathrm{~cm}$ Wasser über den höchsten Stellen derjenigen Schicht erforderlich sein, die zu jeder gegebenen Zeit der Boden war, auf dem die Altertümer und der Abfall abgelagert wurden. Der Umstand, dass das Wasser zur Steinzeit hier verhältnismässig flach war, ist sicher gerade der Grund gewesen, warum die Stelle als Ankerplatz gewählt wurde, da das Wasser infolgedessen ruhig und still sein musste. Eine Wassertiefe von 30 bis $50 \mathrm{~cm}$ dürfte jedoch nur ein Mindestmass bezeichnen. Die obige Betrachtung der Naturverhältnisse führte uns zu dem Ergebnis, dass bei Beginn der Torfbildung die Wassertiefe an der höchsten Bodenstelle etwa $2 m$ betragen haben dürfte.

Dass nun das Floss, auf dem man, wie ich vermute, gewohnt hat, verschwunden ist, nimmt nicht weiter wunder. Es kann durch Strom und Wind oder durch Eisgang anderswo hingetrieben worden, verfault oder beim Abgraben der oberen Torfschicht in älterer Zeit vernichtet worden sein. Man möge sich hierbei nur daran erinnern, dass man bei den Pfahlbauten in der Regel ebenfalls keine anderen Teile der Unterlage als die untersten Pfahlenden erhalten findet. Beim Eisgang auf dem See bricht der obere Teil des Pfahls ab, der im Eis eingefroren ist, und wird fortgeführt. ${ }^{2}$ )

Wir kommen nun zu einer höchst wichtigen Frage, die oft vorgebracht worden, die aber bis jetzt noch unbeantwortet geblieben ist und ein Rätsel zu sein schien.

Warum hatte man, bis auf die neueste Zeit, in Dänemark und Schweden aus der ganzen reichen Steinzeit dieser Länder niemals irgendwelchen Pfahlbau nachweisen können, während solche sonst recht häufig überall in Europa vorkommen, selbst in steinzeitlich armen Ländern, fast bis an das Gestade der Ostsee?

Um diese Frage beantworten zu können, ordnen wir die steinzeitlichen Funde aus Mooren oder verwachsenen Seen in zwei Gruppen, je nachdem sie Pfahlbauten angehören oder nicht. Bei näherer Untersuchung und Vergleichung zeigt es sich dann, dass alle diese Pfahlbaufunde von Südeuropa bis zur Ostsee in den Schlus d e r S teinzeit gehören, während ent-

1) K. Gayer: Die Forstbenutzung, 6. Auflage, Berlin 1883. S. 377. - Auf drei wohlerhaltenen Einbäumen (ausgehöhlten Eichenstämmen) aus der Eisenzeit im Nationalmuseum beträgt der senkrechte Abstand zwischen der Reeling und der Unterseite des Bodens nach meiner Messung 25, bzw. 35 und $40 \mathrm{~cm}$. Der Tiefgang ist also ein geringerer als diese Zahlen gewesen, wenn sich das Boot nicht mit Wasser füllen sollte. Ein klinkerweise gebautes Boot aus unserer Zeit von $12^{\prime}$ bis $20^{\prime}$ Lănge, liegt $1^{\prime}$ bis $2^{\prime}(30$ bis $60 \mathrm{~cm})$ tief im Wasser.

2) Vgl. Hochstetter in Sitzber. d. math.-naturw. Classe, Bd. 51, Abth. 1, Wien 1865, S. 275. - F. Troyon: Habitations lacustres. Lausanne 1860, S. 412, Pl. I, Fig. 2, Pl. II, Fig. 4. 
sprechende Wohnstätten ohne Pfähle alle, oder doch zum grössten Teil, äl ter sind. Der Zeitunterschied ist das Entscheidende. Von Beltz ist hervorgehoben worden, dass die Pfahlbauten in Mecklenburg nicht gleichzeitig mit den grossen Steingräbern sind, sondern mit den Steinkisten, also der jüngsten Grabform der Steinzeit. ${ }^{1}$ )

Dass die Pfahlbauten auch sonst jedenfalls nicht älter sind wie die Errichtung der megalithischen Ganggräber, dürfte, nach dem zu urteilen, was bis jetzt bekannt geworden ist, für ga nz E u ropa gelten. ${ }^{2}$ ) Der Pfahlbau wurde, scheint es, erst gegen Ende der Steinzeit oder doch in deren späterem Abschnitt erfunden, um sich von da an als Wasserbautenform durch die ganze Vorzeit zu erhalten. in gewissen Gegenden sogar bis tief hinein in das Mittelalter oder gar durch dasselbe hindurch.

Aus der älteren, der frühneolithischen und paläolithischen Steinzeit hingegen hat sich bisher noch $\mathrm{n}$ irge $\mathrm{nds}$ in der Welt eine Spur von Pfahlbauten gefunden.

Dass bisher in Dänemark keine derartigen Bauten nachgewiesen sind, kann darauf beruhen, dass die hier sonst in grosser Zahl angetroffenen steinzeitlichen Wohnplätze zumeist aus einer älteren Zeit stammen, während bisher überhaupt nur sehr wenig Wohnstätten aus dem Ende der Steinzeit oder aus der Bronzezeit Dänemarks bekannt sind. Dieser mehr wie 1500 jährige Zeitraum war im übrigen Europa die Blütezeit der Pfahlbauten. Es ist denn vielleicht der Zukunft vorbehalten, auch bei uns im Moor erhaltene Pfahlbauten aufzufinden.

Ein Fingerzeig in dieser Richtung ist der wichtige Fund eines steinzeitlichen Pfahlbaues, den man neuerdings im mittleren Schweden, und zwar bei Alvastra in einem Moor unweit des östlichen Ufers des Wettersees gemacht hat. Die nördlich von $58^{\circ}$ nördl. Breite gelegene Pfahlbaustelle wurde 1909 von $\mathrm{O}$. Frödin untersucht, und die reiche Ausbeute ergab, dass diese auf einer von Quellwässern überrieselten Kalkmuddefläche errichtete Ansiedlung in die Zeit der megalithischen Ganggräber fällt. ${ }^{3}$ )

So weit war also schon in der späteren Steinzeit die Pfahlbautenwohnung gegen Norden vorgedrungen, fast ebenso weit wie die megalithischen Gräber reichten.

Wir wollen nun einige der steinzeitlichen Funde, die auf $W$ oh $n$ plä tz en o h n e Pfahlbauten in ehemaligen Seen gemacht sind, herausheben und kurz besprechen.

Zunächst eine der ältesten Wohnstätten Deutschlands, den aus der letzten Interglazialzeit stammenden Fund aus Taubach bei Weimar. Artefakte, Tierknochen und Holzkohlen liegen hier in einer Schicht von Tuff-

1) Jahrb. d. Vereins f. meklenb. Geschichte, Jg. 64, 1899, S. 158. Vgl. Lisch, ebenda, Jg. 30, 1865, S. 97. Beltz: Die Vorgeschichte von Mecklenburg, 1899, S. 16.

2) Vgl. V. Gross: Les tombes lacustres in Keller: Pfahlbauten, 7. Ber., 1876, S. 36 und A. Morel-Fatio in Matériaux etc., vol. 17, 1882, S. 64. A. Naef in L'Anthropologie, t. 12, 1901, S. 269 (Schweiz).

3) O. Frödin: En svensk pảlbyggnad frân stenảldern. Fornvännen 1910, Stockholm S. 29, 74. Vgl. Mannus, Bd. 2. 1910, S. 109-152. 
sand eingeschlossen. Weil dieser Kalktuffsand Characeen-Sand ist, muss er unbedingt am Bode $\mathrm{n}$ e in es Sees sich gebildet haben. Man hat zwar angenommen, dass die alten Lagerplätze der damaligen Menschen auf den Uferwiesen der Ilm sich befunden hätten, dass die Ansiedler vielleicht nur den Sommer über in der Ilmaue gesessen, während sie im Frühjahr und

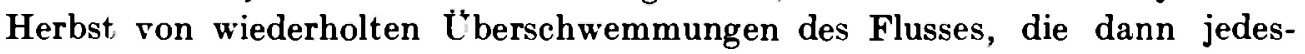
mal die Lagerstätten mit feinem Kalkschlamm bedeckt haben sollten, vertrieben wurden. Diese Annahme dürfte aber mit der natürlichen Beschaffenheit der Ablagerung unvereinbar sein. Dem Geologen v. Fritsch muss beigestimmt werden, wenn er sagt: „Es ist keine Rede von der Fortbildung dieses Lagers, wenn es auch nur kurze Zeit trocken gelegen hätte. Alle darauf gerichteten Vermutungen sind von der Hand zu weisen." Andererseits sind Artefakte, Knochen und Kohle gewiss nicht, wie von ihm angenommen, in die Kalksandschicht "hineingeschwemmt"; sie sind ganz einfach an Ort und Stelle zu Boden gesunken in dem kleinen Wasserbecken, wo die Characeen wuchsen, die den Sand gebildet haben. Alles erklärt sich ungezwungen, wenn wir uns die Menschen auf einem Holzfloss im See wohnend denken, etwa $100 \mathrm{~m}$ vom Ufer entfernt. ${ }^{1}$ )

Gleiche Erklärung liesse sich vielleicht geben für die zahlreichen Fundorte innerhalb des norddeutschen Flachlandes, wo Schalen von Süsswasserkonchylien mit Spuren von Menschen und Resten der diluvialen Säugetiere zusammen vorkommen. ${ }^{2}$ )

Die bekannte Ansiedlung aus dem Ende der Rentierzeit bei Schussenquelle in Württemberg dürfte ebenfalls eine auf der Oberfläche des Wassers schwimmende Behausung des Jägervolkes voraussetzen. Die in einem Wasserbecken gebildete, von Tuff und Torf bedeckte Kulturschicht enthielt keine Pfähle ${ }^{3}$ )

Eine Schicht zusammengeflochtener oder doch ineinander verwickelter Baumstämme mit Spuren von Verkohlung, aber keine Pfähle, wahrscheinlich Reste eines Holzunterbaues, traf man mitten in einem Niedermoor beim Flusse Gave d'Oloron in Béarn (Basses-Pyrénées). Bèi der allerdings nur vorläufigen Untersuchung fand man behauene Flintgeräte von den Typen der Rentierzeit und einige Zähne des Rentieres. ${ }^{4}$ )

1) Aus der umfangreichen Literatur sei hier nur erwähnt: A. Götze in Zeitschrift für Ethnologie, Bd. 24, 1892. Verhandl. S. (366). Lissauer, ebenda 1902, S. (279). Hoernes: Der diluviale Mensch. 1903, S. 23. v. Fritsch im Correspondenz-Blatt der B. Ges. f. Anthropol., Ethnol. und Urg., Jg, 31, 1900, S. 99, 101 bis 103. Hugo Möller in Zeitschrift für Naturwissenschaften, Bd. 74, 1901, S. 237. Hahne und Wüst im Zentralblatt für Mineralogie, Jg. 1908, S. 197. H. Hahne: Das vorgeschichtliche Europa, 1910, S. 12.

2) Wahnschaffe: Die Ursachen der Oberflächengestaltung des norddeutschen Flachlandes, 2. Aufl., 1901, S. 219.

3) O. Fraas im Congres international d'Anthropologie de Copenhague 1869, S. 286 bis 314. Archiv für Anthropologie, Bd. 2, 1867, S. 29 bis 50. F. A. Forel im Bulletin de la Sociéte :vaudoise des / sciences naturelles, Vol. 9, 1867, Nr. 57. Diese Forscher nehmen trockene Bildung der Kulturschicht an.

4) Chaplain Duparc: Sur l'âge des pretendues cites lacustres du Bearn. Matériaux pour l'histoire primitive et naturelle de l'homme. 2e Série. Vol. 8, 1873, S. 456 mit Lageplan und Profil. - Einen Fund von Flintwerkzeugen von Magdalenien-Typen aus dem Moore von Goincourt (Oise) erwähnt Mortillet: Le Prehistorique. 3e edit., 1900, S. 637. 
Aus frühneolithischer Zeit, der Stufe der älteren dänischen Kökkenmöddinger entsprechend, stammt ein beinah vergessener Fund aus Abbeville in Nordfrankreich unweit dem Ausfluss der Somme in den Kanal. Auf dem Grunde des Niedermoores am Ufer des Flusses traf man hier eine steinzeitliche Wohnstätte mit Schichten von Stangen oder Balken, aber ohne Pfähle. Bei der Untersuchung, die viele Jahre zurückliegt, fasste man, allerdings unrichtigerweise, den Wohnplatz als ,keltische Grabstätte“ auf, und die Scherben von irdenen Gefässen als Bruchstücke von ,Aschenurnen“, ${ }^{1)}$ aber unsere jetzige Kenntnis der vorzeitlichen Denkmäler zeigt uns leicht, dass die Stelle eine Wohnstätte gewesen ist.

Bis vor kurzem die einzige aus Skandinavien bekannte grössere steinzeitliche Wohnstätte in einem Moore ohne Holm war die am Ausfluss des Ringsjön in Schonen gelegene, die die Grafen C. und F. Reventlow entdeckt und untersucht haben. Eine grosse Zahl von Altertümern fand sich hier, zusammen mit Knochen und anderem Abfall zu unterst in einer Torfschicht oder zu oberst in dem darunter liegenden Sand, der sich, ebenso wie der Torf, als im Wasser auf dem Seegrund abgelagert erwies. ${ }^{2}$ ) Der Fund gehört hauptsächlich in die ältere Kökkenmöddingerzeit und in den früheren Teil der jüngeren Steinzeit. Die Fundstelle der ältesten Sachen, etwa der Maglemosestufe angehörend, liegt im alten, verlassenen Flusslauf nahe der Eisenbahnbrücke. Geräte aus dem Schluss der Steinzeit, der Zeit der Steinkisten, fehlen überhaupt, was auch von C. D. Reventlow schon hervorgehoben ist. ${ }^{3}$ )

Die Entfernung des Wohnplatzes von dem damaligen nächsten Seeufer betrug ungefähr $900 \mathrm{~m}$; aber weder im Torf noch im Seegrund zeigten sich eingerammte Pfähle, die aus der Steinzeit stammen könnten, und ebensowenig liessen sich andere Reste einer Unterlage für Wohnungen nachweisen. Genau wie in Maglemose bestand das ganze Holzwerk aus einigen kurzen, wagerecht liegenden Stöcken oder Zweigen, von denen mehrere im Feuer gewesen waren. C. D. Reventlow hat als der erste diese Vermutung ausgesprochen, dass die Menschen hier vielleicht auf einem Holzfloss lebten.

In einem andern Moore Schonens, Bare Mosse, fanden sich Steingeräte der Kökkenmöddingerzeit und andere Kulturreste, sowie grosse Streifen von Kiefernrinde, die nach R. Sernander, der die geologischen Verhältnisse

1) Boucher de Perthes: Antiquités celtiques. Tome 1. Paris 1847. S. $182 \mathrm{ff} ., 187$ bis 188, 205, 210, 215. Einige Altertümer von diesem Ort finden sich in der vergleichenden Sammlung des Nationalmuseums. zu Kopenhagen, andere sind mir aus der Sammlung Perthes in Abbeville bekannt. VRl. Picard in Memoires de la societe royale d'emulation d'Abbeville. 1834-1835, S. 94; 1836-1837. S. 221. J. Lubbock: Pre-historic Times. London 1865, S. 307,311 .

2) C. D. Reventlow: Fynden vid Ringsjön. Kongl. Vitterh., Historie och Antiqv. Akad. Månadsblad. Jg. 15, 1886, S. 189; Jg. 18, 1889, S. 86 bis 87 . Vgl. H. Hildebrand ebenda 1886, S. 144, 185. Die geologischen Verhältnisse sind untersucht und beschrieben von Bernhard Lundgren; ebenda 1889, S. 110. Ferner Reventlow in Ymer, Jg. 25, 1905, S. 156 bis 172. Vgl. ausserdem L. Zinck: Nordisk Arch*ologi. Stenalderstudier II. Köbenhavn 1893, S. 38 bis 57 .

3) A. a. O. 1889, S. 88 , vgl. S. 160 . Es fanden sizh keine Knochen von Haustieren. S. 95 . 
untersucht hat, von dem Flosse stammen dürften, auf dem man hier im See gewohnt hat. Die Altertümer waren auf dem ehemaligen Seeboden abgelagert. ${ }^{1}$ )

Aus den Föhrden der kimbrischen Halbinsel sind mehrere grosse, frühneolithische Funde bekannt. die der Verfasser als analog hinstellen möchte.

So der Fund aus dem Brabrander See, dem inneren Teil der ehemaligen Aarhuser Föhrde. Die vielen Stangen, meist aus Haselholz, die mit Spänen von der an Ort und Stelle geschehenen Behauung unter den Altertümern im Schlamm am Seeboden lagen, rühren meiner Meinung nach von einem beweglichen Floss her. ${ }^{2}$ ) Pfähle waren nicht vorhanden.

Ferner sind zu nennen der Fund aus der Koldinger Föhrde, ${ }^{3}$ ) wo die Verhältnisse jedoch nur durch Baggern und deshalb weniger sicher bekannt geworden sind, und der etwa gleichzeitige Fund aus der Kieler Föhrde vor Ellerbek. $Z u$ einer Zeit, da ein am Grund dieser Föbrde vorhandener Binnensee zum Teil in Sümpfe verwandelt worden war, lagen vielleicht die Wohnstätten der Menschen auf dem Wasser jener Sümpfe, vielleicht doch auch auf einem im See hervorragenden Landrücken, dem Ellerbeker Haken. Erst nachdem die Wohnstätten verlassen waren, drang das Salzwasser des Meeres in die Föhrde ein. ${ }^{4}$ )

Das Verhältnis zur Hebung und Senkung des Landes spielt bei diesen Wohnplatzfunden aus den Föhrden eine wichtige Rolle, besonders auch für deren Zeitstellung.

Wagerecht liegende, zum Teil angekohlte Zweige in lockerer Schicht ohne Spur von Pfählen wurden auch auf einer steinzeitlichen Wohnstätte im Kownatken-See, nahe der südwestlichen Ecke von Ostpreussen, gefunden..$^{5}$ ) Dieser „Pfahlbau“ ohne Pfähle wird als der älteste bisher aus dem Lande bekannte angesehen; er gehört zwar der jüngeren Steinzeit an, aber wohl einem nicht ganz späten Teil derselben. Die Lage ist ja eine östliche im südbaltischen Gebiet. Die Bestimmung der hier gefundenen Knochen, die infolge der Wichtigkeit des Fundes auf Arten und Zusammengehörigkeit hin revidiert werden sollte, hat folgende Arten ergeben: Ren (Cervus tarandus), eine Ochsenart, vermutlich Urstier (Bos taurus fossilis), Hirsch (Cervus elaphus), Reh (Cervus capreolus) und Schwein (Sus scropha, Wildschwein?). Unter dem Abfall fanden sich kaum Reste von Haustieren; von einem einzigen zugespitzten Knochengerät (,Lanzenspitze“, Glätter?) wird jedoch

1) R. Sernander in Geologiska Föreningens i Stockbolm Förhandlingar. Bd. 30. Stoockholm 1908. S. 391.

2) Th. Thomsen et A. Jessen: La trouvaille de Brabrand. Memoires des Antiquaires du Nord. 1904, Copenhague, S. 162 bis 232. Die Verfasser neigen sich dieser Auffassung nicht zu. S. 227. Vgl. oben.

3) K. Bahnson in Aarböger for nordisk Oldkyndighed, 1892, Köbenhavn, S. 169.

4) C. A. Weber und J. Mestorf: Wohnstätten der älteren neolithischen Periode in der Kieler Föhrde. 43. Bericht des Museums vaterländ. Altertümer bei der Universität Kiel. Kiel 1904. C. A. Weber in Englers Botanischen Jahrbüchern. Bd. 35, 1904, S. 34.

5) Sitzungsberichte der Alterthumsgesellschaft Prussia. Heft 13, Jg. 43, 1886 bis 1887, S. 73. Taf. I und II. Heft 14, 1887 bis 1888 , S. 268 bis 269 . Katalog des Prussiamuseums. Teil I. Königsberg 1893, S. 48; 1906, S. 71, Abb. 100. 
angegeben, dass es aus dem Mittelfussknochen des Pferdes gearbeitet ist, dies ist aber möglicherweise nur ein später hinzugekommenes Knochengerät aus jüngerer Zeit, das von anderen als Knochenschlittschuh aufgefasst wird. ${ }^{1}$ ) Wirkliche Pfahlbauten, dann aber aus späterer Zeit, kommen hingegen sehr häufig sowohl in der zuletzt erwähnten Gegend als auch in Pommern, Posen, Polen, Galizien und Livland vor. ${ }^{2}$ )

Zum Schluss soll noch unter diesen verstreuten Beispielen, ${ }^{3}$ ) zu denen viele der unten erwähnten kleineren Funde hinzugefügt werden könnten, von denen, nach dem, was vorliegt, nicht bestimmt gesagt werden kann, dass sie aus Wohnstätten stammen, ein grosser Fund erwähnt werden, der viele Vergleichungspunkte mit dem unsrigen aufweist und der in die Steinzeit des nordbaltischen Gebiets gehört. Dies ist der Wohnplatz im ,,MergelMoor" bei Kunda in Estland, in der Mitte des südlichen Ufers des Finnischen Meerbusens, etwa $3 \mathrm{~km}$ vom Meere entfernt. Das Moor ist ein ausgedehntes Niedermoor, der "Mergel" ist eine mächtige Schicht von Schneckenmudde, in deren oberem Teil eine Menge Altertümer aus Knochen, namentlich Harpunen, gefunden wurden. Zu den Geräten waren Knochen vom Urrind, Elch und Wildschwein verwendet. Zwei Geweihstangen vom Rentier fanden sich zwar auch, aber in dem u n t e re $n$ Teil der Mergelschicht und im blauen Ton unterhalb dieser. Zugehörige Knochen von Haustieren ${ }^{4}$ ) und irdene Gefässscherben fehlen vollständig. Der Wohnplatz liegt ungefähr $250 \mathrm{~m}$ von der nächsten Randstelle des Moores entfernt, nicht weit vom Ufer des das Moor durchströmenden Baches, bei $59^{\circ} 29^{\prime} \mathrm{n}$. Br. Nicht die geringste Spur von Pfählen oder irgend einem andern Unterbau für Wohnungen liess sich in dem ehemaligen See nachweisen. Deshalb hat auch Grewingk zunächst auf die Erklärung hingewiesen, die einen Winteraufenthalt auf dem Eise voraussetzt, ${ }^{5}$ ) später hat er aber, worauf ich erst jetzt aufmerksam wurde, seine Ansicht dahin geändert, dass er nunmehr erklärte, das Fischen im ehemaligen Kundasee sei sow ohl im Som mer

1) Munro: Lake Dwellings of Europe. 1890, S. 328. Fig. 99, Nr. 14. Munro: Prehistoric Problems. Edinburgh 1897, S. 291.

2) Munro a. a. O. 1890, S. 312 bis 331. Kohn und Mehlis: Materialien zur Vorgeschichte des Menschen im östlichen Europa. Bd. 1, Jena 1879, S. $66 \mathrm{ff}$. Heydeck in Sitzungsberichte der „Prussia“. Heft 22, 1909, S. 194.

3) Der Fund aus dem altalluvialen Niedermoor bei Endingen in Pommern, westlich von Stralsund, wo unter anderm bearbeitete Knochen und eine Geweihstange des ausgestorbenen Riesenhirsches (Megaceros eurycerus) etwa $2 \mathrm{~m}$ tief gefunden wurden, dürfte ebenfalls $\mathrm{zu}$ den ältesten Wohnstätten in Seen gehören. W. Deecke in Globus. Bd. 78, 1900, S. 13. Deecke: Geologie von Pommern. Berlin 1907, S. 220. Fig. 24.

4) C. Grewingk: Geologie und Archäologie des Mergellagers von Kunda in Estland. Dorpat 1882, S. 22, 29, 64 . (Sonderabdr. aus Archiv für Naturkunde Liv-, Est- und Kurlands. 1. Serie, Bd. 9, Lief. 1, 1882) und Grewingk in Verhandlungen der gelehrten estn. Ges. zu Dorpat. Bd. 12, 1884, S. 13, 73.

5) C. Grewingk a. a. O. 1882 , S. 37, 63. Vgl. wegen geologischer Verhältnisse S. Nikitin in Congres internat. d'Archeologie prehist. à Moscou 1892, Tome 1, S. 17. Utber die Lagerungsverhältnisse und deren Analogie mit entsprechenden in Schonen siehe im übrigen A. G. Nathorst in Bihang till K. Svenska Vetenskaps-Akad. Handlingar. Bd. 17, Afd. III, Nr. 5 (1891), Stockh. 1892, S. 15. 
von einer schwimmenden Vorrichtung, als im Winter rom Eise aus erfolgt. $\left.{ }^{1}\right)$

Auf die Arbeiten des Geologen und Archäologen Constantin Grewingk über die Kundaer Wohnstätte und ihre steinzeitliche Kultur haben wir um so mehr Veranlassung hinzuweisen, als sie die einzigen waren, die vor uns in grösserem Umfange ähnliche Naturverhältnisse und eine verwandte Fundgruppe behandelt haben.

Die Wassertiefe im Mergelsee zur Zeit, als die Harpunen im Mergel stecken blieben, wird von Grewingk auf 3 bis 4 Fuss, etwas über $1 \mathrm{~m}$, geschätzt. ${ }^{2}$ )

Die Wohnstätte ist noch nicht erschöpft, der 1870 begonnene Abbau des Mergellagers aber seit 1904 eingestellt. ${ }^{3}$ ) Dem Kopenhagener Nationalmuseum ist eine Sammlung Altertümer von hier von Ingenieur Emil Riisager geschenkt worden, der sich längere Zeit an Ort und Stelle aufgehalten hat und angab, dass die Altertümer ,oben auf dem Mergel unter dem Torf“" lagen, oder ",hauptsächlich gerade auf der Grenze zwischen Kalk und Torf “..4)

Nach dem, was die Betrachtung der Seeansiedlungen uns gelehrt hat, nehmen wir also an, dass die Leute der älteren Steinzeit und, im Randgebiet, zugleich jene der späteren neolithischen Stufe, wenn sie sich draussen auf dem Wasser in Seen aufhielten, stets auf Holzflössen wohnten, mit denen sie im See umherfuhren, und die sie durch längere Zeiten an einer Stelle verankerten, wo das Wasser flacher war. Diese Annahme wird um so wahrscheinlicher, wenn man bedenkt, dass das Holzfloss die Ausgangsform, das Vorbild ist sowohl für die Pfahlbauten der späteren Zeit als auch für die künstlichen Inseln.

Der berühmte Pfahlbauforscher Keller hat die treffende Bemerkung gemacht, dass ein jeder Pfahlbau das Vorhandensein eines Flosses voraussetzt, auf dem man stehen konnte, während die Pfähle eingerammt wurden. ${ }^{5}$ ) Dass dies richtig ist, wird ein jeder einräumen, der die Erbauung von Brücken und Bollwerken in unserer Zeit gesehen hat. Der Boden, der über die Pfähle gelegt wurde, ähnelte dem Holzfloss, war zwar künstlicher als dieses, jedoch so undicht, dass mannigfache Geräte durch die ơffnungen auf den Grund des Sees fielen.

Eine besondere Form der Pfahlbauten, „Packwerkbau“ genannt, ist aus mehreren übereinander gelegten Holzböden gebildet. Es ist bezeichnend,

1) C. Grewingk: Die neolithischen Bewohner von Kunda in Estland und deren Nachbarn. Verhandlungen der gelehrten estnischen Gesellschaft zu Dorpat. Bd. 12, Dorpat 1884, S. 6,33 bis 35,95 .

2) C. Grewingk a. a. 0. 1884 , S. 10.

3) Rich. Hausmann: Utbersicht über die archäol. Forschungen in den Ostseeprovinzen im letzten Jahrzehnt. Riga 1908 (Historikertag), S. 4.

4) Es dürfte kaum richtig sein, wenn es zeitweilig heisst, dass Altertümer und Knochen sowohl im Kalk (Schneckenmudde), als auch im darunterliegenden Ton gefunden seien; siehe F. Schmidt: Exkursion durch Estland. Congres géologique internat. à Saint-Pétersbourg en 1897, Nr. 12, S. 14.

5) Keller: Pfahlbauten, 2. Ber., 1858, S. 134-135. Ebenfalls Troyon: Habitations lacustres, Lausanne 1860, S. 258. 
dass man bei der ersten Untersuchung derselben bei Wauwyl im Kanton Luzern keine Gegengründe gegen die Auffassung fand, dass die Böden gesunkene, je eine Zeitlang benutzte Holzflösse gewesen seien, die ursprünglich auf dem Wasser schwammen, und bei denen die Pfähle nur zum Anspikern an den Boden gedient hätten. Auf Grund von Beobachtungen an anderen Orten kam man jedoch schliesslich zu dem Ergebnis, dass das Bauwerk am ehesten auf einmal in mehreren Lagen aufgeführt worden war, deren unterste unmittelbar auf dem Seegrund ruhte. ${ }^{1}$ ) Der Packwerkbau gehört ausschliesslich einer f $\mathbf{r}$ ühe n Stufe hochneolithischer Zeit an, und die Theorie von dem ursprünglich schwimmenden Floss wird noch hier von Heierli aufrechterhalten. ${ }^{2}$ )

Hierdurch bildet sich der Utbergang zu der ,,künstlichen Insel“, die uns in ihrer vollkommensten Gestalt in dem irischen und schottischen crannog entgegentritt. „Bei der Aufführung eines solchen scheint man zuerst ein Floss gebaut zu haben aus Baumstämmen, Reisern, Farren und Haidekraut u. a. m., vermischt mit Steinen und Erde, bis die Masse den Grund erreichte. Darauf wurde die ganze Masse zusammengepflöckt und mit Kreisen von Pfählen umgeben, die durch wagerechte Balken verbunden waren usw." 3 )

Alle diese Formen von Wasserbauten weisen also auf das Floss als einfache Grundform zurück, aus der sie sich entwickelt haben.

Endlich dürfte es jetzt auch möglich sein, den Grund dafür anzugeben, warum die Entwicklung die erwähnte Richtung einschlug. Sicher ist die Einführung der Haustierzucht, bezw. der Viehzucht, die Ursachə gewesen, indem das Einstallen der Haustiere feste Wohnungen verlangte. Solange der Mensch nur vom Hund begleitet war, konnten diese beiden allein sich vortrefflich auf dem Floss einrichten; aber Kühen, Schafen und Schweinen war damit nur schlecht geholfen.

\section{Verfahren bei der Untersuchung der Wohnstätte}

Beim Torfstechen war, wie erwähnt, der nördliche Teil des Wohnplatzes zerstört worden; der Torf war jedoch nicht überall ganz bis auf den Grund abgegraben, eine dünne Torfschicht blieb hier über der Schneckenmudde zurück, und beim Durchgraben derselben fand man nun noch mehrere Altertümer. Vom Grenzgraben des Kirchspiels aus gegen Süden hatte dieser Streifen eine Breite von ungefähr $14 \mathrm{~m}$. Bei dem unzerstörten Teil des Wohnplatzes wurde das Untersuchungsverfahren angewandt, das bei den in späteren Jahren ausgeführten grösseren Untersuchungen dänischer Abfallhaufen beobachtet wurde. Hierüber liegt ein ausführlicher Bericht vor. ${ }^{4}$ )

1) Suter in Kellers Pfahlbauten, 3. Ber., 1860, S. 75. J. Lubbock: Pre-historic Times, London 1865 , S. 131 ; 2. edit. 1869 , S. 181.

2) J. Heierli: Urgeschichte der Schweiz, Zürich 1901, S. 99.

3) Rob. Munro: Prehistoric Scotland, S. 430 . Munro: Lake Dwellings, S. 426.

4) A. P. Madsen, Sophus Müller u. a.: Affaldsdynger fra Stenalderen i Danmark, undersögte for Nationalmuseet, Köbenhavn 1900. $4^{\circ}$. 
Nur waren die angewandten Geräte in Übereinstimmung mit der von den Abfallhaufen abweichenden Beschaffenheit des Torfs hier nicht Handrechen. sondern kleine Grabekellen in der Form von Maurerkellen u. dgl.

Zunächst wurde ein quadratisches Feld von $10 m$ Seiten. länge abgesteckt, und da ein rund um das Feld ausgehobener Graben gezeigt hatte, dass sich die Altertümerschicht über den ganzen Platz erstreckie, so wurde dieser in 100 einzelne Räume von je $1 \mathrm{qm}$ Oberfläche geteilt, von denen jeder einzeln untersucht wurde. Jeder Raum wurde wieder nach der Tiefe in mehrere Schichten geteilt: Die Rasenschicht von ungefähr $10 \mathrm{~cm}$ Dicke und darunter $1-6$ Torfschichten von je $20 \mathrm{~cm}$ Dicke, bisman in die Schneckenmudde hinabgelangt war. Diese wurde hierauf mit Spatendurchgegraben. Die gefundenen Altertümer wurden jedes einzelne für sich mit einer Nummer versehen und in bezug auf Platz und Tiefe innerhalb des Raumes in eine Karte eingezeichnet. Die Räume wurden bezeichnet durch die Buchstaben $A, B, C$, D, E. F, G, H, J, K in der Reihenfolge von Westen nach Osten, und zugleich mit den

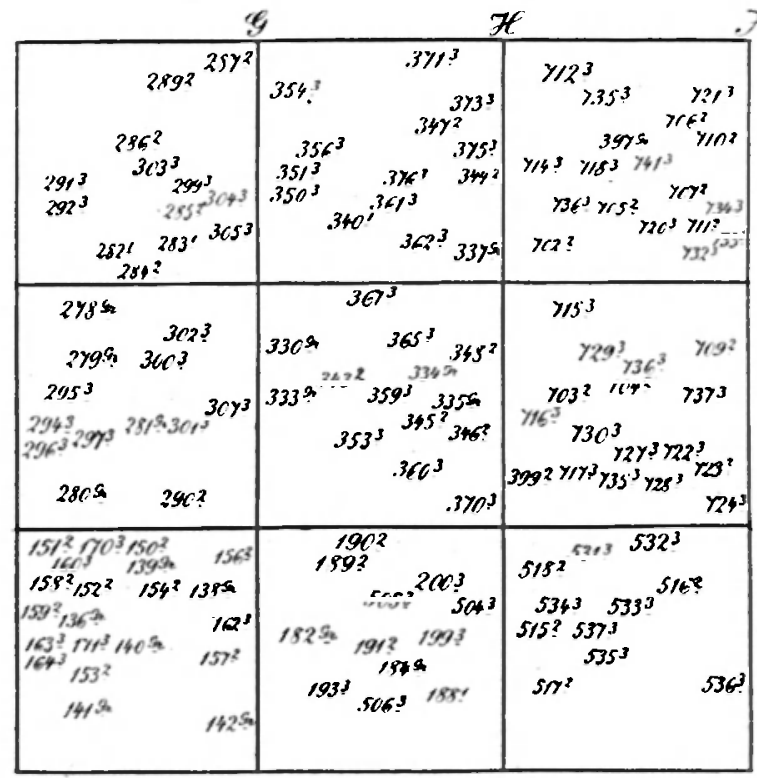

Abb. 11. Plan.

Probe des aufgenommenen Planes über Lage und Tiefe der Altertüm er auf der Anhöhe im Feld $I$. Die Räume $G, H$ und $J 1$ bis 3 (1 obere, 2 mittlere, 3 untere Reihe). Gr. heisst Grasnarbe (Rasen). Die kleinen unterstrichenen Tiefenzahlen rechts oben bei den Nummern der Altertümer bezeichnen 1., 2. und 3. Schicht des Torfes (jede zu $20 \mathrm{~cm}$ ) unterhalb der $10 \mathrm{~cm}$ dicken Rasenschicht. $1 / 40$ nat. Gr. von Norden nach Süden; sie waren an den vier Ecken durch kleine Pfähle begrenzt; der Pfahl in der südöstlichen Ecke trug denselben Buchstaben und dieselbe Zahl wie dieser Raum, bzw. der Raum wurde nach diesem Pfahl benannt. Siehe Abb. 11.

Alle 100 Räume in diesem Feld I wurden vollständig untersucht. Von den anderen unmittelbar gegen Westen, Osten und Süden anstossenden, auf gleiche Weise eingeteilten Feldern II, III, IV, VII und VIII wurden die zunächst gelegenen Partien so weit hinaus untersucht, als eine Ausbeute gewonnen wurde, alles in allem $200 \mathrm{qm}$ (Abb. 12).

Die Bilder Abb. 10, 13 und 14 zeigen Proben der Einteilung und Arbeits we ise. Die regelrechte Untersuchung umfasste demnach einen Platz von $300 \mathrm{qm}$ $\mathrm{Grösse.} \mathrm{Von} \mathrm{dem} \mathrm{nördlichen,} \mathrm{zerstörten}$ Teil dieser Wohnstätte (Feld V und VI) wurde ausserdem eine Strecke von

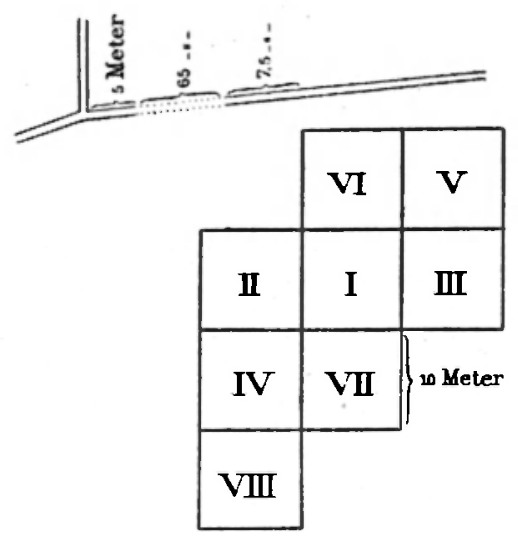

Abb. 12. Lage und Einteilung. t'bersichtsplan über die Lage des Wohnplatzes am Hauptgraben (oben), dem die Kirchspielgrenze folgt, sowie über dessen Einteilung in acht Felder, jedes von $100 \mathrm{gm}$ Grösse. 
$108 \mathrm{qm}$ durchsucht. und die darin gefundenen Sachen wurden getrennt in einer besonderen Abteilung aufgenommen (Abb. 2 und 12).

Von der 75 bis $125 \mathrm{~m}$ nördlicher liegenden Wohnstätte wurden im Jahre 1904 in regelrechter Weise $238 q m$ untersucht. Der ganze in den Jahren 1902 bis 1904 untersuchte Platz war etwa $50 \mathrm{~m}$ lang in nordsüdlicher Richtung, $33 \mathrm{~m}$ breit, wobei die Grenzen jedoch nicht erreicht wurden, zum Teil der älteren Torfstiche wegen.

Die in 1900 gefundenen Knochen, Holzstücke und Holzkohlen wurden nach Raum und Schicht gesammelt; von Knochen wurde alles mitgenommen, von Holz, Holzkohle und Haselnussschalen, die sich in bedeutender Menge fanden, wurden reichlich Proben gesammelt. Abb. 11 zeigt das Lagerungsverhältnis der Altertümer innerhalb derjenigen Räume, wo sie am

dichtesten lagen.

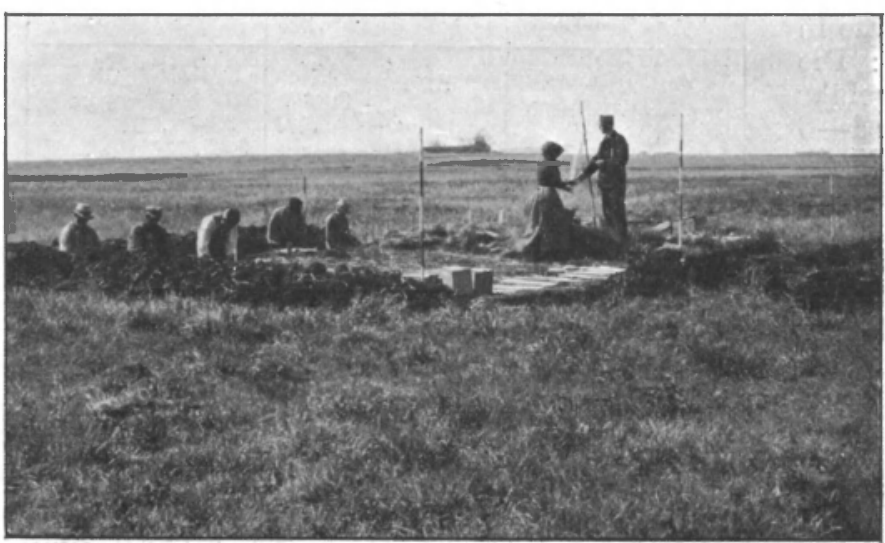

Abb. 13. Die A r beit.

Feld I, Bank E 5 bis 10 wird untersucht. Die gefundenen Sachen werden im Vordergrund gewaschen, auf Brettern getrocknet, mit Nummer etikettiert und eingepackt. Gleichzeitig werden Art und Lage der Altertümer gebucht.

Im Anfang wurden die Flintabfälle fortgeworfen, nachdem sie gleich den Knochenstücken auf die gewöhnliche Weise innerhalb eines jeden Raumes Schicht für Schicht aufgezählt waren; im Verlauf der Arbeit wurde jedoch bestimmt, dass der Flintabfall gleich den übrigen Fundstücken mitgenommen und aufbewahrtwerden sollte.

Es muss noch hervorgehoben werden, dass das Grundwasser auf dem Wohnplatz während der Untersuchung sehr tief stand, etwas tiefer als in den nächstgelegenen Torfstichen und im Hauptgraben, wo es 3,1 bis $3,2 m$ über dem Meeresspiegel stand. Das Wasser legte der Arbeit also keine nennenswerten Hindernisse in den Weg, was sonst oft unter gleichen Verhältnissen der Fall ist. Die Untersuchung wurde hierdurch in hohem Masse erleichtert.

\section{Der Fund}

Die Hauptbestandteile des Fundes waren, wie schon erwähnt, Holz, Knochen und Altertümer.

\section{Holz}

Von Holz wurden hauptsächlich verkohlte, oder vom Feuer angeschwelte Stücke gesammelt, da diese sich am besten erhalten lassen, indem sie nicht durch Eintrocknen einschrumpfen, rissig werden, oder die Struktur 
verändern, und weil die Holzart leichter an Holzkohle als an subfossilem Holz zu bestimmen ist. Bei der Bestimmung einiger Laubholzarten hat mir Professor Dr. phil. E. Rostrup eine ausserordentlich wertvolle Hilfe geleistet; einzelne Holzproben habe ich unter dem Mikroskop untersucht, den weit überwiegenden Teil des Holzes und der Kohle nur mit Hilfe der Lupe.

1033 ausgeführte Bestimmungen von $\mathrm{Holz}$ oder Rinde verteilen sich nach den Holzarten folgendermassen:

Kiefer (Pinus silvestris L.) 835, Hasel (Corylus Avellana L.) 120, Ulme (Ulmus montana Sm.) 45, Espe (Populus tremula L.) 27, Birke (Betula cfr. odorata Bechst.) 6 Proben; vom Faulbaum (Rhamnus Frangula L.) liegen

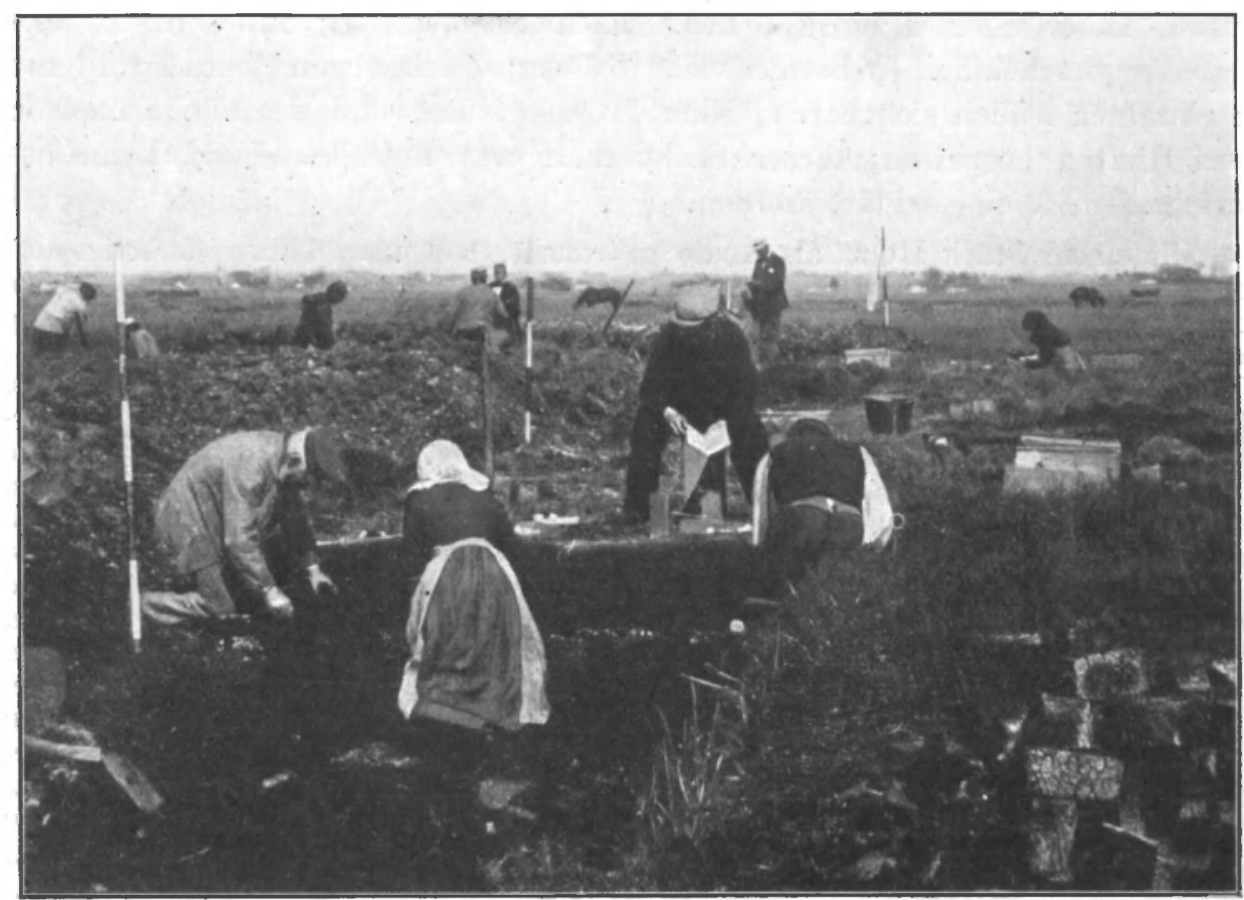

Abb. 14. Die Arbeit.

M. J. Mathiassen phot.

Die Arbeiter im Vordergrunde untersuchen den Torf mit Grabekellen und zerbröckeln den Torf mit der Hand.

einige Kohlenproben aus III C 2, 4. Schicht, von der Buche (Fagus silvatica L.) ein einziges kleines Kohlenstück aus IV K 5, 1. Schicht vor. Ein Teil des gesammelten Holzes ist nicht untersucht worden, aber die Bestimmung grösserer Mengen würde wahrscheinlich den oben erwähnten Tatbestand nicht sonderlich ändern.

Es zeigt sich, dass die $\mathrm{K}$ i e f e $\mathbf{r}$ bei weitem überwiegt (750 Proben Holz, 85 Proben Rinde); besonders die mikroskopische Untersuchung des Holzes, die Form der Zweige und die Rinde erweisen mit Sicherheit, dass die Holzart Kiefer ist, nicht irgend ein anderes Nadelholz. Dagegen ist auf der ganzen Wohnstätte nicht ein einziger Kiefernzapfen gefunden worden. 
Solche hätten der Beachtung nicht entgehen können, ihr Nichtvorhandensein dürfte einen weiteren Anhalt für die Annahme abgeben, dass der Kiefernwald nicht an der Stelle gewachsen, sondern dass das Holz durch Menschen aus dem Walde am Seeufer dahin gebracht worden ist.

Der $\mathrm{H}$ a selst ra $\mathrm{ch}$ hingegen war nicht nur durch Holz und Rinde vertreten, sondern auch durch seine Früchte. In den untersuchten Proben wurden 24 ganze (meist kleine) Nüsse und 370 grössere Bruchstücke von Nussschalen gezählt. Sowohl die runde Form (f. sılvestris) als auch die länglichen Formen ( $f$. orata und $f$. oblonga) kamen vor; die runde war bei weitem die häufigere. ${ }^{1}$ ) Die Schale war nicht selten gerippt.

Irgend welche sichere Spuren, dass die Nüsse von Menschen geknackt waren, haben sich allerdings nicht nachweisen lassen; indessen ist dies höchst wahrscheinlich in betreff vieler Stücke; Zeichen von Zähnen sind nur in einzelnen Fällen sichtbar. ${ }^{2}$ ) Nicht wenige Nüsse sind der Länge nach in zwei Hälften gespalten; dieser Sachverhalt war auffallend und kann auf verschiedene Weise erklärt werden.

Mit einem Stück Holz, als Keule gebraucht, soll man Nüsse derartig aufschlagen können, und auf diese Art könnte denn auch dort vorgegangen worden sein. Doch muss bemerkt werden, dass die Natur selbst die gleiche Spaltung hervorbringen kann, indem die Nüsse springen, wenn die Schale austrocknet; diese öffnet sich dann wie eine Fruchtkapsel in zwei Klappen von der Spitze aus. Eine Reihe von Proben verschiedener Stufen zeigt diesen Zusammenhang. Derartige Nüsse sind dann nicht von Menschen geöffnet, worauf auch Virchow die Aufmerksamkeit gelenkt hat. ${ }^{3}$ ) Das Austrocknen des Moores kann die Schalen dazu veranlasst haben, sich zu öffnen, während sie sonst in Mooren gewöhnlich ganz bleiben. Im übrigen könnte jedoch hier noch eine dritte Ursache in Betracht kommen. H. Winge hat mich darüber aufgeklärt, dass Eichhörnchen die Nüsse genau in der Art aufknacken können, dass die Schale mit geraden Bruchflächen in zwei Hälften ohne Zahnmerkmale gespalten wird. Unter den Knochen im Funde kommt auch ein einzelner von einem Eichhörnchen vor. Da nun aber bei der Wohnstätte kein Wald gewesen ist, so dürfte das Eichhörnchen gefangen oder getötet auf den See hinausgebracht worden sein. Der Gedanke ist früher ausgesprochen worden, dass das Steinzeitvolk Eichhörnchen in der Gefangenschaft auf seinen Pfahlbauten ${ }^{4}$ ) gehalten hat, aber irgend ein Beweis dafür, dass dies der Fall gewesen ist, kann doch ebensowenig hier für Maglemose erbracht werden, als man dies anderwärts vermocht hat.

Nagespuren von Mäusen finden sich nicht an den Nüssen oder vielleicht nur an einer einzigen Nuss, ${ }^{5}$ ) während dieselben ausserordentlich häufig an

1) Vgl. Gunnar Andersson: Svenska växtvärldens historia. Stockholm 1896, S. 80 .

2) Merkmale von der Zerdrückung durch Zähne entstehen lange nicht immer beim Knacken der Nüsse. - Geknackte Nüsse und steinerne Mörser fanden sich im Pfahlbau zu Alvastra. Frödin in Fornvännen 1910, S. 50, Fig. 31.

3) Rud. Virchow: Die Pfahlbauten im nördlichen Deutschland. Zeitschr. f. Ethnologie. Bd. 1, 1869, S. 413. Virchow sagt zwar, dass die Nüsse leicht springen, wenn sie im Wasser liegen; allein die darauf folgende Austrocknung dürfte wohl doch eher die Ursache sein. Siehe Gunnar Andersson: Hasseln i Sverige. Sweriges geologiska Undersökning. Ser. Ca. Nr. 3. Stockholm 1902, 4 , S. 156, Fig. 1, 2, 20. Hier findet man auch Abbildungen der verschiedenen Nussformen mit eingehender Beschreibung derselben.

4) Pfahlbau im Mondsee in Ober-Österreich. M. Much in Mittheilungen der Anthropolog. Gesellsch. in Wien, Bd. 4, 1874, S. 306.

5) Vgl. Gunnar Andersson a. a. O. (1896), S. 80, Fig. 51 a. 
Hornsachen in dem Funde vorkommen, ${ }^{1}$ ) ebenso wie einzelne Knochen von Mäusen benagt sind.

Mehrere Nussschalen sind geschwärzt, angeschwelt oder durch das Feuer aus den Herdstellen teilweise verkohlt.

Die Rinde ron $\mathrm{Has}$ el und $\mathrm{B}$ ir ke kam des öfteren in kurzen, ringförmigen Rollen vor. Die meisten sind gewiss auf natürliche Weise gebildet, abgelöst; aber eine der kleineren, $2 \mathrm{~cm}$ weit und $0,8 \mathrm{~cm}$ breit, ist sichtlich zugeschnitten, und es ist nicht ganz ausgeschlossen, dass solche Rindenrollen beim Fischfang oder für andere $Z$ wecke verwendet worden sind. Anzeichen von einem Gebrauch sind jedoch nicht zu sehen. Kleine Rollen von Birkenrinde finden noch in unserer Zeit Anwendung als Flot t oder $\mathrm{Schwimmer}$ für die Fischnetze, und diese Bedeutung hat man auch solchen Rindenrollen beigelegt, die sich auf einem steinzeitlichen Wohnplatze auf Gotland fanden. ${ }^{2}$ ) Auf einem Wohnplatze aus der Steinzeit bei Schussenried (Federsee) in Württemberg fand, man eine Schüssel, gefüllt mit derartigen kleinen Rollen von Birkenrinde; ${ }^{3}$ ) diese mögen für ähnliche Zwecke bestimmt gewesen sein, oder sie dienten bei der Zubereitung von Birkenteer zu Kitt, für den man auch hier in unserem Funde Verwendung gehabt hat.

Das Vorkommen der Ulme auf dem Wohnplatz in Maglemose ist interessant, unter anderem, weil es das erstemal ist, dass diese Holzart in dänischen Mooren nachgewiesen ist. In unseren ältesten Muschelhaufen aus der Steinzeit kommt dagegen Ulmenkohle häufig vor.4)

Von der Eiche fand man bei der Untersuchung in Maglemose keine Spur. Auch Sernander und seinen Begleitern gelang es nicht bei dreimaligem Besuche irgendwelche Blätter der Eiche im Moore zu finden. ${ }^{5}$ ) Blätter sind hier überhaupt selten, weil die Wohnstätte so weit vom Ufer des Sees entfernt lag.

Dagegen konnte Lagerheim in einer Torfprobe, die auf Veranlassung von Holst durch M. J. Mathiassen in unmittelbarer Nähe der Wohnstätte entnommen war, Pollenkörner von mehreren Gewächsen, darunter auch der Eiche, nachweisen. Es fanden sich Staubkörner von Eiche, Ulme, Birke, Hasel, Kiefer, von einer Ericacee, Gras, Seerose, Aspidium filix mas und Polystichum thelypteris. Noch bis ein paar Millimeter über der Grenze gegen die Schneckenmudde wurden im Wassertorf (Lebertorf) Staubkörner der Eiche

1) Dieselbe Beobachtung von Nagespuren von Mäusen an Hirschhorn wurde in Pfahlbauten der Schweiz gemacht (Keller: Pfahlbauten, 8. Bericht, 1879, S. 13, 28; auch in den sogenannten „Steinbergen“ von F. A. Forel: Les tenevieres des lacs suisses. Archives des sciences physiques et naturelles. 3e Pèr., Tome 1, 1879, Geneve, p. 438, note 2), wie solche auch von Japetus Steenstrup an Hirschhorn aus dem Kökkenmödding von Mejlgaard (Mus. Nr. 11 423) bemerkt wurden.

2) Hansson in Svenska Fornminnesföreningens Tidskrift, Bd. 10, Stockholm 1900, S. 11.

3) Rob. Munro: Lake-Dwellings of Europe, 1890, S. 151.

4) E. Rostrup in Affaldsdynger fra Stenalderen i Danmark. Kjöbenhava 1900, $4^{\circ}$, S. 191. S. 434.

5) R. Sernander in Geologiska Föreningens i Stockholm Förhandlingar, Bd. 31, 1909, 
durch die mikroskopische Untersuchung Lagerheims nachgewiesen. Gewiss ist dies ein schönes Untersuchungsergebnis, aber daraus zu schliessen, dass die Eiche während der Bildung der ganzen Lebertorfschicht in nächster oder weiterer Umgebung des Sees wuchs. ${ }^{1}$ ) erscheint nicht ganz gerechtfertigt, und zwar aus zwei Gründen. Einmal ist es bekannt, dass Pollenkörner (und Pilzsporen), durch die Luftströmungen getragen, über w e it e Strecken, vielleicht Hunderte von Kilometern, fortgeführt werden, und zweitens mögen diese ganz winzigen Gebilde, wenn abgelagert, sicher von den Tierchen des Seebodens häufig genug in tiefere Schichten mitgeschleppt werden. ${ }^{2}$ ) Die Pollenkörner sind somit für sich allein keine massgebenden Fossilien; wäre ein Eichenwald in der Umgebung des Sees vorhanden gewesen, so würden auch Blätter und Zweige aufzufinden sein.

Endlich mag erwähnt werden, dass an zwei Bruchstücken von Kiefernzweigen (Pinus silvestris), zu äusserst im Holz, Larvengänge von Borkenkäfern (Hylesinini und Tomicini) sichtbar sind; eines der Stücke ist an dem einen Ende angesengt und durch das Feuer verkohlt, ist also zweifellos in menschlichen Händen gewesen. Die Gänge sind von zwei Arten Borkenkäfer genagt, einer grösseren und einer kleineren.

\section{Herdfeuer}

haben auf dem Wohnplatz hier draussen im See geflammt. Daher rühren die vielen Brände und die Holzkohle, die sich überall im Torf verbreitet fanden. Ausserdem ist die Einwirkung des Feuers an dem Vorkommen mehrerer vom Feuer zersprengter Flintstücke sowie angebrannter und angeschwelter Knochenstücke erkennbar, unter denen sich Knochen vom Elch, Hirsch und Wildschwein finden. Eigentliche Feuerplätze und Herdstellen mit Steinpflaster, wie solche von anderen Wohnstätten bekannt sind, liessen sich jedoch $\mathrm{n} i \mathrm{ch}$ nachweisen, was auch ganz damit übereinstimmt, dass die Ablagerung im Wasser vor sich gegangen ist, indem die Kohle vom Floss herausgeworfen worden oder von der auf demselben befindlichen Feuerstelle heruntergefallen ist.

\section{Das Feuer}

könnte wohl hier auf verschiedene Weise entzündet worden sein. ${ }^{3}$ ) Irgendein Beweis dafür, dass in dieser Absicht ein Reiben oder Bohren Anwendung gefunden hat, liegt jedoch nicht vor; hingegen ist es aus gewissen Gründen wahrscheinlich, dass man es verstanden hat, sich Feuer zu verschaffen, indem man mit Flint, der ja in grösseren Mengen vorkam, Funken schlug. Es fand sich nämlich nicht nur ein einzelnes, $5,4 \mathrm{~cm}$ grosses Stück

1) N. O. Holst: Postglaciala Tidsbestämningar. Sveriges geologiska Undersökning, Ser. C. Ársbok 2 (1908), Nr. 8, Stockholm 1909, S. 35 bis 36 mit Anmerkung.

2) C. Wesenberg-Lund in Geologiska Föreningens i Stockholm Förhandlingar, Bd. 31, 1909, S. 468.

3) Georg F. L. Sarauw: Le feu et son emploi dans le Nord de l'Europe aux temps prehistoriques et protohistoriques. Annales du XXe Congres archeologique et historique de Belgique, Gand 1907, Tome 1, S. 196 bis 226. 
S ch we f e lkies, das oben in der Schneckenmudde lag (in Raum VII D 3, 2. Schicht zusammen mit einer Axt aus Urstierknochen), wohin es nicht leicht zufällig gekommen sein kann, ${ }^{1}$ ) sondern auch ein anderer von den zum Feuerschlagen gebrauchten Gegenständen, der Fangstoff war vorhanden, der $\mathrm{Z}$ u n der, mit dem man die durch das Schlagen des Flintes gegen den Schwefelkies erzeugten Funken auffängt.

Man fand auf der Wohnstätte ein grösseres Bruchstück eines Röhrenschwammes, den Prof. Dr. E. Rostrup die Güte hatte, als Feuer $\mathrm{s} \mathrm{chwa} \mathrm{m} \mathrm{m} \mathrm{(Polyporus} \mathrm{igniarius} \mathrm{Fr.)} \mathrm{zu} \mathrm{bestimmen.} \mathrm{Auch} \mathrm{auf} \mathrm{der} \mathrm{nörd-}$ lichen Wohnstätte in Maglemose fand Mathiassen in 1903 ein Stück desselben Pilzes. Dieser, der als Schmarotzerpilz an Eichen, Birken, Zitterpappeln, Haseln und anderen Holzarten wächst, hat sogar bis in die neuere Zeit, auch hier im Norden zum Feuerfangen Verwendung gefunden, und namentlich um ein glimmendes Feuer auf dem Herde während der Nacht zu erhalten. Rostrup hat bei uns häufiger den Feuerschwamm subfossil im Torf gefunden. ${ }^{2}$ ) Da dieser „Schwamm", wie erwähnt, auf Bäumen schmarotzt, kann er doch nicht ohne menschliches Hinzutun an Orte kommen, wo keine Bäume wachsen, also nicht an einen Ort, wie die Wohnstätte in Maglemose. Ich schliesse hieraus, dass der Schwamm in diesem Falle vom Steinzeitvolk eingesammelt ist. Dass er weiters nicht zufällig mit dem Leseholz für die Feuerstätte mitgekommen ist, stütze ich auf den Umstand, dass der Feuerschwamm oder seine nahen Verwandten, die in der gleichen Weise Verwendung finden, aus nicht wenig stein- und bronzezeitlichen Wohnstätten in verschiedenen Gegenden Europas bekannt sind, welche Regelmässigkeit sicher nicht dem Zufall zugeschrieben werden kann.

So hat man in Dänemark einen Fruchtkörper des Feuerschwammes auf einer unterseeischen, steinzeitlichen Wohnstätte in Nysted Nor gefunden. ${ }^{3}$ ) Aus dem Ausland können Pfahlbauten in Bosnien (Ripac) erwähnt werden, ferner in Österreich (Mondsee, Laibacher Moor), Norditalien (bei Verona und an verschiedenen Orten bei Parma; hier nicht selten). Schweiz (Moosseedorfsee, Meilen, Robenhausen) und Deutschland (Wangen, Wismar, Gressow und Lüptow-See), ausserdem ein Fund aus der älteren neolithischen Zeit tief im Torf bei Husum in Schleswig, wie endlich Bare Mosse und der Pfahlbau bei Alvastra in Schweden. Hier und im Pfahlbau von Mondsee fand sich auch Schwefelkies. ${ }^{4}$ )

1) Auf der oben genannten steinzeitlichen Wohnstätte auf Gotland wurden ebenfalls ein paar kleine Stücke Schwefelkies gehoben (Hansson a. a. O., S. 11), und im neolithischen Pfahlbau bei Alvastra fand Frödin Schwefelkies, Feuerpinksteine aus Quarzit und Feuerschwamm. Fornrännen 1910 , S. 58 bis 62 , Fig. 56 bis 59 .

2) Ebenfalls in Torfmooren Norwegens, Schwedens und Finnlands wurde dieser Pilz an. getroffen. J. Holmboe a. a. O., 1903, S. 112.

3) Mus. Nr. A 17196 bis 17220 . Bestimmt von E. Rostrup als Polyporus igniarius.

4) Radimsky in Wissenschaftl. Mitth. aus Bosnien und der Herzegovina, Bd. 5, 1897, S. 71. "Feuerschwamm". - M. Much: Die Kupferzeit in Europa. 2. Aufl., Jena 1893, S. 11. Much in Mitth. d. Anthropolog. Gesellsch. in Wien, Bd. 6. 1876, S. 188. "Buchenschwämme“, „Holzschwämme“. Aus dem neolithischen Pfahlbau im Laibacher Moor besitzt das k. k. naturhistor. Hofmuseum in Wien einen „Baumschwamm" (Polyporus). - Strobel e Pigorini: Le terremare e le palafitte del Parmense, 2 a relazione, Milano 1864, S. 28, 125. Fund aus Loffia, Torfmoor unweit Verona. Nuoro giornale botanico italiano, Vol. 22, Firenze 1890, S. 28. Polyp. ign. - Keller: Pfahlbauten, 2. Bericht, S. 147; 3. Ber., S. 99. Osw. Heer: Die Pflanzen 
Schliesslich hat sich der Feuerschwamm auf einem vorgeschichtlichen Wohnplatz gefunden, wo er unter allen Umständen von Menschen hingebracht sein muss; in der Karhofhöhle in Westfalen lagen Reste des Schwammes in der aus der Vorzeit stammenden Kulturschicht. ${ }^{1}$ )

Abgesehen von den Haselnüssen, haben sich auf dem Wohnplatz in Maglemose keine t'berreste von Pflanzen gefunden, von denen man annehmen könnte, dass sie den Bewohnern als Nahrung gedient haben. Man hat hier wohl fast ausschliesslich von Fle is ch gelebt, das das Jägerund Fischervolk sich von einer grösseren Reihe verschiedener Tiere zu verschaffen gewusst hat, deren zerschlagene und zum Zweck der Markgewinnung aufgespaltene Knochen sich in Menge über dem Wohnplatz verstreut fanden.

\section{Die Knochen,}

von denen ein Teil an das Zoologische Museum zu Kopenhagen abgegeben wurde, sind vom Zoologen $\mathrm{Herluf} W$ inge untersucht worden, der mit grossem Entgegenkommen untenstehende ('bersicht über seine Bestimmungen ${ }^{2}$ ) mitgeteilt hat:

Esox lucius, Hecht. Mehrere Knochen, darunter mindestens 9 rechte Unterkiefer.

Einzelne Knochen anderer Fische, wohl unbestimmbar.

Emys orbicularis (E. europaea), Sumpfschildkröte. Eine Platte einer Bauchschale.

Anas acuta, Spitzente. 5 Rabenschnabelknochen, 3 Oberarme, 2 Speichen, 3 Stücke des Ellbogenbeines, 1 Mittelhand. Der Unterschied von Anas penelops, Pfeifente, ist nur gering.

Anas boscas, Stockente. 3 Rabenschnabelknochen, 1 Schlüsselbein, 11 Oberarme mit dem oberen Ende, davon 5 rechte, 6 linke, ausserdem 4 andere Stücke von Oberarmen; 1 Ellbogenbein, 1 Mittelhand, 1 Schienbein. Mehrere Knochen von jungen Enten, ungewiss von welcher Art.

Cygnus olor, Höckerschwan. Es finden sich keine besonders charakteristischen Stücke, die deutlich den Unterschied von dem C. musicus, Singschwan, beweisen könnten; aber die Knochen scheinen am besten mit dem C. olor übereinzustimmen. Stück eines Unterkiefers, Beckenwirbel, Schulterblatt, 8 Stücke von Oberarmen, 7 Stücke von Ellbogenbeinen, 7 Stücke von Speichen, 1 Mittelhand, 1 Fingerglied, 1 Stück von einem Becken, 1 ganzer

der Pfahlbauten, Zürich 1865, S. 42. Polyp. ign. - Lisch: Pfahlbauten in Meklenburg, 2. Ber., 1867, S. 26, 46. Polyp. igniarius. Virchow in Z. f. Ethnol., Bd. 4, 1872, Verhandl. S. (173). „Baumschwamm (Polyporus)“. - J. Mestorf in Mitth. d. anthropolog. Ver. Schl.Holst., H. 15, Kiel 1902, S. 19. „Baumschwämme“. - Sernander in Geol. Foren. i Stock. holm Förh., Bd. 30, 1908, S. 391. Polyp. cfr. igniarius. Frödin in Fornvännen 1910, S. 61, Fig. 59. Polyporus fomentarius Fr.

1) Nachrichten über deutsche Alterthumsfunde, Jg. 5, 1894, S. 71. Polyporus. Der Fund aus der Karhof-Höhle befindet sich jetzt im Museum in Dortmund.

2) Die Funde aus Maglemose an Vogel- und Säugetierknochen sind mit aufgezählt in H. Winge: Om jordfundne Fugle fra Danmark. Videnskabelige Meddelelser fra den naturhistoriske Forening i Kjöbenhavn, 1903, S. 61 bis 109, und H. Winge: Om jordfundne Pattedyr fra Danmark. Ebenda 1904, S. 193 bis 304. 
Mittelfussknochen und Stücke von 4 anderen, 1 Zehenglied. - Einige Knochen von ganz jungen Vögeln, 1 Rabenschnabelbein, 1 Schenkelknochen, 3 Schienbeine und anderes sind wahrscheinlich auch von Schwänen.

Pagonetta glacialis, Eisente. 2 linke Oberarme.

Podicipes cristatus, Grosser Lappentaucher. Beckenwirbel, 2 Brustbeine, 3 Oberarme, 1 Speiche, 2 Schenkelknochen, 3 Schienbeine.

Colymbus arcticus, Polar-Seetaucher. Stück eines Unterkiefers, Mittelfuss.

Grus cinerea, Kranich. Mittelstück vom Oberarm, Mittelstück vom Schienbein.

Larus ridibundus, Lachmöve. 1 Oberarm.

Ardea cinerea, Fischreiher. Mittelstück vom Oberarm.

Botaurus stellaris, Rohrdommel. Mittelstücke von 2 ungleichen Ellbogenbeinen, Mittelstück vom Schenkelknochen.

Phalacrocorax carbo, Scharbe. Stück von Becken, Stück vom Oberarm eines jungen Vogels, 3 Stücke von Ellbogenbeinen, Stück der Mittelhand, Stück vom Schienbein. Mittelfuss.

Milvus ictinus, Gabelweihe. Das obere Ende eines Ellbogenbeins, eine Mittelhand, beides Knochen von einem jungen Vogel.

Haliaetus albicilla, Seeadler. Das obere Ende einer Speiche, Mittelstücke von 2 ungleichen Ellbogenbeinen, Mittelstücke von 2 Schenkelknochen, 1 Zehenglied.

Picus martius, Schwarzspecht. Eine Mittelhand, ganz.

Garrulus glandarius, Eichel-Häher. Schienbein ohne das untere Ende, genau übereinstimmend mit dem des Eichel-Hähers. Der Knochen ist von einem jungen Vogel, doch etwas stärker als beim Tannen-Häher. Elster und Dohle kommen nicht in Frage, die Ähnlichkeit mit dem Tannen-Häher ist hingegen gross.

Lepus europaeus, Hase. Ein zweiter Mittelhandknochen.

Castor fiber, Biber. Stück eines Vorderzahns, 1 Backenzahn, 1 Schlüsselbein, 3 ungleiche Oberarme, 1 Speiche, 3 ungleiche Ellbogenknochen, 1 Beckenhälfte, 2 Schenkelknochen, 3 ungleiche Schienbeine, 1 Fersenbein.

Sciurus vulgaris, Eichhörnchen. Das obere Ende eines Schienbeines.

Felis catus fera, Wildkatze. Ein Schulterblatt, oberes Ende vom Oberarm, Hüftknochen, unteres Ende vom Schenkelknochen.

Canis vulpes, Fuchs. 1 Schulterblatt, das untere Ende eines Oberarmes, 1 Speiche ohne das untere Ende, 2 ungleiche Schienbeine, 1 dritter Mittelfussknochen.

Canis familiaris, Hund. Ein Unterkieferast eines jungen Hundes, mit dem Raubzahn noch in dem Kiefer verborgen, Schläfen- und Scheitelknochen ebenfalls von Jungen, Hinterhaupts- und Trommelbein von ausgewachsenem, Stück eines Ringwirbels, ein dritter Halswirbel.

Ursus arctus, Bär. 1 oberer vorderster Mahlzahn, jung; 1 Stirnbein, das untere Ende eines Oberarmes und 1 Ellbogenbein von Jungen, 1 Unterkieferast, 2 obere Enden von Ellbogenbein, das obere Ende eines zweiten Mittelhandknochens, 2 Klauenglieder von Ausgewachsenen.

Martes sylvatica, Edelmarder. 1 Oberkiefer, 2 rechte Unterkiefer, Stück 
von einer Hirnschale, 1 Ringwirbel, 2 ungleiche Oberarme, 3 ungleiche Ellbogenbeine, 2 ungleiche Beckenhälften, 5 rechte und 5 linke Schienbeine.

Meles taxus, Dachs. 1 Gesicht, Stück eines Oberkiefers. Stück der Hirnschale, 4 ungleiche Unterkiefer, 1 Oberarm, 2 Speichen, 1 Ellbogenbein.

Sus scrofa ferus, Wildschwein. Eine Menge Knochen von männlichen und weiblichen, jungen und alten Tieren; unter anderen : 6 Oberkieferstücke mit der Eckzahngrube von alten weiblichen Tieren, 2 von alten männlichen; 10 Oberkiefer mit dem letzten Backenzahn, alle ungleich, 2 rechte Oberkiefer, mit Milchzähnen und mit $m 1$ in der Grube: 1 Unterkiefer von einem ausgewachsenen, weiblichen Tiere mit Eckzahn, 2 von ausgewachsenen. männlichen; 4 Unterkiefer mit dem letzten Backenzahn. 14 Unterkiefer mit Milchzähnen, うे rechte, 9 linke, die jüngsten mit $m 1$ im Kiefer verborgen, einige mit $m 1$ im Durchbruch, einer mit $m 2$ im Durchbruch; viele lose untere Eckzähne von Ebern, wenigstens 25 ziemlich gut erhalten, davon 15 rechte, und viele Bruchstücke; 2 obere Eckzähne von Ebern; einige wenige obere und untere Eckzähne von weiblichen Tieren; 15 rechte, 19 linke Schulterblätter; 17 obere Enden von Speichen: 22 obere Enden vom Ellbogenbein; 21 untere Enden vom Schienbein ausgewachsener Tiere; 20 Beckenhälften von ausgewachsenen; 15 Sprungbeine, 18 Fersenbeine usw.

Cervus capreolus, Reh. Viele Knochen von männlichen und weiblichen Tieren, alten und jungen. darunter: 5 ganze Stirnen mit Gehörn und 9 lose Stirnknochen mit Gehörn (einer davon ron einem jungen Tier mit hautbekleidetem Gehörn), wohl alle von verschiedenen Tieren. Ein abgeworfenes Gehörn und mehrere Bruchstücke; verschiedene Stücke von Unterkiefern, davon 8 linke mit dem letzten Backenzahn oder dessen Grube und ein Unterkiefer mit Milchzähnen und mit $m 1$ im Durchbruch; 8 rechte, 13 linke Schulterblätter; 7 rechte, 6 linke untere Enden von Oberarmen; 7 rechte, 4 linke Beckenknochen usw.

Cervus elaphus, Edelhirsch, Rothirsch. Eine Menge Knochen, darunter: 3 Unterkiefer von ausgewachsenen (die zwei wohl zusammengehörig aus I F 6, 2. Schicht und III A 2, 3. Schicht); 1 Unterkiefer von einem jungen mit Milchzähnen im Durchbruch. Viele Geweihe, mehr oder weniger bearbeitet, verschiedene davon natürlich abgeworfen; mehrere Wirbel; 6 ungleiche Schulterblätter, 6 untere Enden von Oberarmen, wohl ungleich; 3 ungleiche untere Enden von Speichen usw.; 25 ganze untere Enden von Mittelhand- oder Mittelfussknochen und 13 lose Gelenkrollen (fast alle abgeschnitten).

Alces machlis, Elch. Viele Knochen; darunter: 2 obere, vollständige Zahnreihen und 1 untere von erwachsenem, wohl alle zusammengehörig (aus I K 2, 3. Schicht, III A 2, 2. Schicht, III B 1, 4. Schicht), einige lose obere und untere Backenzähne von anderen erwachsenen Tieren, obere und untere Kieferstücke von wenigsten 3 Jungen mit Milchzähnen (der jüngste mit nicht vollständig durchgebrochenen Zähnen, der älteste mit stark abgenutzten Milchzähnen und mit den Ersatzzähnen bereit zum Durchbruch); viele andere Stücke von Gesichtern und Hirnschalen, davon eine Stirne von einem männlichen mit abgeschnittenem Geweih, eine Stirne von einem weiblichen und 
eine Stirne von wenigstens einem Jungen; viele Stücke von Geweihen; mehrere Wirbel, Stücke von wenigstens 4 Schulterblättern; untere Enden von 3 linken Oberarmen; 2 obere, 2 untere Enden von Speichen (das eine mit dem dazu gehörigen Stück Ellbogenbein: aus I J 4, 3. Schicht und I J 3, 2. Schicht); das obere Ende vom Ellbogenbein (zu einem Dolch verarbeitet, jung); Handwurzelknochen zum Teil zusammengehörig, von mindestens 6 ungleichen Händen (eine davon jung); Stücke von 3 ungleichen Becken, verschiedene Stücke von Schenkelknochen und Schienbeinen; 2 Kniescheiben; 5 rechte, 3 linke Sprungbeine, 2 rechte, 3 linke Fersenknochen; 3 navic.-cub.; 1 cuneif. III; 18 ganze untere Enden von Mittelhand- und Mittelfussknochen (alle abgeschlagen) und 8 lose Gelenkrollen (ebenfalls abgeschlagen), verschiedene andere Stücke von Mittelhand und Mittelfuss, auch ein Stück von einer Nebenzehe; 26 obere Enden von ersten Finger- oder Zehengliedern; 19 obere Enden von zweiten Fingeroder Zehengliedern (nur 2 ganze Glieder); 18 ganze Hufglieder und anderes.

Bos taurus urus, Ur. Viele Knochen: Das meiste von der einen Seite eines Gesichtes, verschiedene andere Stücke von Hirnschalen, ein Hornzapfen; mehrere Wirbel, darunter 2 letzte Lendenwirbel, zusammengehörig, mit „,künstlichen“ Gelenkflächen auf den Gelenkfortsätzen (beide aus I H 2 , 2. Schicht, ein dazu gehöriges Stück gefunden in I G 3, 3. Schicht); verschiedene Rippen; Stücke von mindestens 5 Schulterblättern, das untere Ende einer Speiche, Handwurzelknochen von wenigstens 5 ungleichen Händen; 1 ganzer Mittelhandknochen und untere Enden von 3 weiteren (alle auf die eine oder andere Weise künstlich bearbeitet); Stücke von 5 linken Becken und einem rechten; 2 Schenkelknochenköpfe; 2 Stücke von Schienbeinen, 4 Kniescheiben, 2 Sprungbeine; 4 Fersenknochen, wohl alle ungleich; 3 rechte, 3 linke navic.-cub.; 13 obere Enden von ersten Fingeroder Zehengliedern; 11 zweite Finger- oder Zehenglieder; 10 Hufglieder.

Die allermeisten der erwähnten Knochen stimmen genau mit denen des Urrindes überein; nur in betreff einzelner könnte es fraglich sein, ob sie von ungewöhnlich kleinen Urrindern (einer Zwergform) oder von grossem, zahmem Rind sind; dies gilt besonders von zwei unteren Enden von Mittelhandknochen, beide bearbeitet (aus I K 6, 2. Schicht und aus dem Ringgraben um Feld I herum oder aus einem Teil der Grasnarbenschicht über Feld I).

Homo sapiens, Mensch. Ein Schenkelknochen und ein Fingerglied von Erwachsenen, ein Unterkiefer von einem Kind.

\section{Herluf Winge.}

I enschenknochen finden sich, wie bekannt, ziemlich häufig auf steinzeitlichen Wohnstätten, meist jedoch nur in geringer Anzahl und verstreut ohne Ordnung und Zusammenhang, anscheinend ganz wie die Tierknochen behandelt; so war es auch hier der Fall. Wenigstens zwei Personen, einem Erwachsenen und einem Kinde, haben in diesem Falle die Knochen gehört. Der gefundene Schenkelknochen von einem Erwachsenen zeigt Schnitte und Schabespuren; da er jedoch in der obersten Torfschicht unter der Grasnarbe lag, bei deren Entfernung der Spaten verwendet werden musste, kann die Schabespur auch vom Spaten herrühren; es bleiben jedoch 
noch verschiedene Schnittmarken zurück, von denen einige sich auf der entgegengesetzten Seite befinden und aus dem Altertum zu stammen scheinen. Die beiden Enden des Knochens sind ausserdem abgebrochen. Hieraus den Schluss zu ziehen, dass man das Fleisch von den Menschenknochen heruntergeschnitten habe, vielleicht sogar, um es zu essen, würde jedoch unberechtigt sein. Dafür ist der Beweis viel zu schwach. ${ }^{1}$ ) Aber die Sache verdient erwähnt zu werden, weil andere steinzeitliche Funde, sowohl aus Dänemark als aus Schweden, anscheinend in dieselbe Richtung weisen. In dem Abfallhaufen bei Örumaa fand man z. B. das abgehauene untere Ende von Speiche und damit zusammengehörendem Ellbogenbein vom Menschen, ${ }^{2}$ ) und die in der Steinzeit bewohnte Höhle „Stora Förvar““ auf Stora Karlsö bei Gotland enthielt in der Kulturschicht Menschenknochen, die auf eine Art und Weise behandelt waren, die den Gedanken an Menschenfresserei nahelegt. ${ }^{3}$ ) Dasselbe gilt von neolithischen Wohnplätzen in Uppland.4) Dementsprechender Sachverhalt wird auch aus anderen Ländern erwähnt. ${ }^{5}$ ) Jedoch muss man diese Mitteilungen gewiss noch mit grosser Vorsicht aufnehmen, da verschiedene Quellen für einen Irrtum nicht ausgeschlossen sind.

Der $\mathrm{H}$ u n $\mathrm{d}$ ist das einzige zahme Tier, dessen Knochen mit Sicherheit unter den Tieren aus der Steinzeit in Maglemose nachgewiesen sind, eine Tatsache, der man die grösste Bedeutung beilegen muss. Nagespuren von Hunden finden sich ausserdem an vielen Knochen anderer Tiere.

Nicht die geringsten Reste fanden sich vom zahmen Schwein oder Schaf, diesen für die jüngere Steinzeit so wichtigen Haustieren, während von Rindern nur einige ganz wenige Knochen vorhanden waren, die zwar auf das zahme Rind zurückgeführt werden könnten, aber auch von der Zwergform herstammen können, in der das Urrind auftrat.

In der obersten Torfschicht wurden einige, zum Teil zusammengehörige Knochen von Kälbern des zahmen Rindes (Bos taurus domesticus) aufgefunden .

1) Beschädigung durch früheren Torfstich ist z. B. nicht ausgeschlossen. - Uber Irrtümer, durch natürliches Zerspalten der Knochen, bzw. Menschenknochen, veranlasst, siehe Japetus Steenstrup: Mammuthjæger-Stationen ved Predmost. Oversigt over Vidensk, Selskabs Forhandlinger, 1888, Kjöbenhavn. S. 179 bis 182 .

2) A. P. Madsen u. a.: Affaldsdynger fra Stenalderen i Danmark, 1900, S. 144; vgl. S. 80, 110. - Auch der Fund aus der Wohnstätte im Brabrander See enthielt einige wenige Menschenknochen. Mémoires des Antiq. du Nord, 1904, S. 209.

3) G. Retzius in Ymer 1890. Stockholm 1891, S. 285 bis 287. O. Montelius: Kulturgeschichte Schwedens. 1906, S. 17. Untersuchungen der Höhle von Hj. Stolpe ausgeführt.

4) O. Almgren in Fornvännen, 1906, S. 113 bis 115. - Vgl. Almgren: „Kung Björns Hög“. Stockholm 1905, $4^{\circ}$, S. 45; 36, 44, Fig. 28.

5) Uber Kannibalismus in der Vorzeit Europas siehe Rich. Andree: Die Anthropophagie, 1887. H. Matiegka in Mitth. d. Anthropol. Ges. Wien, Bd. 26, 1896, S. 129. M. Hoernes: Natur- und Urgeschichte des Menschen. Bd. 1, Wien 1909, S. 491. Zu der hier angeführten Literatur sei noch hinzugefügt: Uber Knochen aus dem Packwerkbau bei Schussenried Fraas in Correspondenz-Blatt, Jg. 1877, S. 161; Knochen mit Feuerstein geschabt und dann begraben in der Höhle von Mas d'Azil Piette in l'Anthropologie, Tóme 6, 1895, S. 280, Tome 7, 1896, S. 386; dann Salomon Reinach: Antiquites nationales, I, Paris 1889, S. 155 mit Anm. 4 (ausführliche Literaturangabe) und Mortillet: Le Préhistorique, 3e edition, Paris 1900, S. 336. 
Diese können aber mit grosser Wahrscheinlichkeit als von Tieren stammend bezeichnet werden, die in neuerer Zeit im Moor umgekommen sind. Auf jeden Fall können sie nicht als Beweis dafür gebraucht werden, dass das Steinzeitrolk hier zahmes Vieh gehalten hat. Auf dem Wohnplatze fand sich ja auch, sogar etwas tiefer ( $40 \mathrm{~cm}$ unter der Oberfläche des Moores), ein Tüderpfahl aus Buchenholz und von ganz moderner Form, der einen deutlichen Wink in diesem Sinne gibt. ${ }^{1}$ )

Die Knochen von wilde n, nicht gezähmten Tieren gehörten 30 verschiedenen Arten an, ${ }^{2}$ ) die zum grössten Teil schon aus den steinzeitlichen Wohnstätten in Dänemark bekannt sind. ${ }^{3}$ ) Von den 78 Arten wilder Wirbeltiere aus den Kökkenmöddingern waren 22 Arten in Maglemose vorhanden, während 8 davon allein dort gefur,den sind, nämlich: Sumpfschildkröte, Spitzente, Höckerschwan. Lachmöve, Rohrdommel, Gabelweihe, Schwarzspecht und Eichel-Häher.

Der Unterschied beruht ganz entschieden darauf, dass die Wohnstätte in einem Binnensee, nicht am Meere wie die Kökkenmöddinger, lag. Von den 56 Arten, die fehlen, sind ungefähr 42 ausgeschlossen, weil sie im Meere leben oder im wesentlichen an dasselbe gebunden sind. Die 14 übrigen sind: Auerhahn, Kleiner und Graukehliger (Rothalsiger) Lappentaucher, Wespenfalke, Waldkauz, Ringeltaube, Grosser Buntspecht, Krähe, Igel, Waldwühlmaus, Luchs, Wolf, Iltis und Otter. Nur die letztere, die später auf der nördlichen Wohnstätte mit dem Iltis gefunden wurde, und der Auerhahn kommen ziemlich häufig in den Muschelhaufen vor; dass der Auerhahn in Maglemose fehlt, beruht gewiss nur auf einem Zufall; die 12 anderen sind selten.

Obgleich das Meer nur $3 \mathrm{~km}$ von der Wohnstätte entfernt ist, hat man vom Strand keinen Fang und keine Beute mit heimgebracht, weder von Schaltieren, noch von höheren Tieren. Man hat hier nur von den Tieren gelebt, die sich in der nächsten Umgebung der Wohnstätte fanden, im See, im Wald und Feld. Diese Tatsache dürfte Beachtung verdienen; eine Erklärung für sie soll später gegeben werden.

Fischknochen kamen recht häufig vor, aber nicht in grösserer Menge was eigentlich zu verwundern ist. Doch können diese kleinen Knochen in dem zähen Torf leicht der Beachtung entgehen und nicht alle gesammelt und mitgenommen worden sein.

Der Rest, den man von der Sumpfschildkröte fand, eine Platte einer Bauchschale, trug keine Schnittspuren, weshalb es nicht ausgemacht ist, dass das Tier von Menschen getötet ist. In welcher Schicht die Platte lag, ist nicht ermittelt. Die Schildkröte konnte ja in dieser Umgebung ein freiwilliges Dasein geführt, einen natürlichen Tod gefunden und die Platte sich nachher losgelöst haben. Man hätte, wie schon gesagt, unter dem

1) An dieser Stelle wurden irgend welche Altertümer erst in 70 bis $90 \mathrm{~cm}$ Tiefe unter der Torfoberfläche gefunden, höher keine. Vgl. oben S. 56, 64.

2) Die nördlicher in IIaglemose liegende Wohnstätte, die 1904 untersucht wurde, ergab ausser Knochen derselben Arten, darunter zahlreiche Elchknochen, zugleich solche vom Iltis (Mustela putorius), Fischotter (Lutra vulgaris) und der Gambette (Totanus calidris).

3) Siehe H. Winge in Affaldsdynger fra Stenalderen i Danmark, 1900. S. 178 bis 180. 
Abfall Knochen vom Auerhahn erwarten können, da die Naturverhältnisse anscheinend vorzüglich mit seinen Ansprüchen übereingestimmt haben. Eine Art Ersatz haben wir im Schwarzspecht (Picus martius), der, worauf H. Winge aufmerksam macht, ähnliche Ansprüche an einen Standort mit vorhandenem Nadelholz stellt wie der Auerhahn, weshalb er jetzt, und zwar nur als zufälliger Gast, in Dänemark zu den grössten Seltenheiten gehört, während er noch sowohl südlich als nördlich vom Lande lebt. ${ }^{1}$ ) Von den anderen Tieren bietet der Elch das grösste Interesse, da er sonst nur aus einem einzigen dänischen Muschelhaufen. demjenigen bei Ertebölle am Limfjord, und zwar hier nur sparsam auftretend, dann aus der steinzeitlichen Wohnstätte im Brabrander See und bei Skottemarke auf Laaland bekannt ist. Auffallend ist daher die grosse Menge Knochen in unserem Fund, die beweist, dass das Tier auf Seeland noch gleichzeitig mit dem Steinzeitvolk gelebt hat und ihm von diesem stark nachgestellt worden ist, einem Volke, das ihn wohl namentlich des Fleisches halber gejagt, aber auch verstanden hat, seine Knochen, Geweihe und Zähne zu Geräten und Schmuck zu verw erten.

Im übrigen kamen die Knochen vom Edelhirsch, Reh, Ur und Wildschwein in grösster Menge vor, wodurch die Nähe des Waldes angedeutet ist; der Hase, der am ehesten ein Feldtier ist, fehlte jedoch auch nicht. Der Biber hat wahrscheinlich in demselben See gelebt, in dem die Wohnstätte lag. Biberstöcke fanden sich jedoch nicht.

Die ganze Zahl der gesammelten Stücke von Knochen und Horn, die nicht zu Geräten verarbeitet waren, belief sich auf 3667 , ziemlich regelmässig über den Platz verteilt, stellenweise, und namentlich in einem Gürtel quer über die Erhebung durch Feld I dichter und, wie auch die Altertümer, in allen Schichten auftretend, von der Oberfläche des höchsten Teiles bis zum Grund, am zahlreichsten, oder an Zahl sogar weit überwiegend, jedoch nach unten zu, im Wassertorf, gegen die Schneckenmudde hin, in deren oberstem Teil einzelne Knochen eingebettet sein können. Abb. 5 und 10 (Seite 60 und 77 ) geben hierüber Aufschluss. Auch die verschiedenen Tierarten, deren Knochen nur in hinreichend grosser Anzahl vorlagen, kamen von der obersten bis zur untersten Schicht vor; dieses gilt sowohl vom Urrind als auch vom Wildschwein, Elch, Hirsch und Reh.

Eine sehr grosse Menge von den Geweihen und Knochen, über 400 Stück oder $11 \%$, trägt deutliche Schnittspuren.

An mehreren Rippen von grossen Säugetieren ist die Innenseite geschabt, was auch sonst auf späteren neolithischen Wohnstätten vorkommt.

Das abgeworfene Geweih vom Edelhirsch hat man gesammelt, oder man hat die Stangen vom Stirnbein losgeschlagen und dann durch viele Schnitte sie in kleinere Stücke zerlegt. In einer ähnlichen Weise wurde bei den Geweihschaufeln des Elches vorgegangen.

Utber Geräte und Vorarbeiten zu solchen aus Knochen und Horn soll in dem folgenden Abschnitt, der die Altertümer behandelt, gesprochen werden.

1) H. Winge: Om jordfundne Fugle fra Danmark. Videnskab. Meddelelser fra den naturhist. Forening i Kjöbenhavn, 1903, S. 103. 